Florida International University FIU Digital Commons

6-26-2018

\title{
The Effects of Video Prompting on Teaching Daily Living Tasks to Individuals with Autism Spectrum Disorder
}

Mashal Salman Aljehany

Florida International University, malje004@fiu.edu

DOI: $10.25148 /$ etd.FIDC006855

Follow this and additional works at: https:// digitalcommons.fiu.edu/etd

Part of the Educational Methods Commons, Special Education and Teaching Commons, and the Vocational Education Commons

\section{Recommended Citation}

Aljehany, Mashal Salman, "The Effects of Video Prompting on Teaching Daily Living Tasks to Individuals with Autism Spectrum Disorder" (2018). FIU Electronic Theses and Dissertations. 3778.

https://digitalcommons.fiu.edu/etd/3778 


\section{FLORIDA INTERNATIONAL UNIVERSITY}

Miami, Florida

\section{THE EFFECTS OF VIDEO PROMPTING ON TEACHING DAILY LIVING TASKS \\ TO INDIVIDUALS WITH AUTISM SPECTRUM DISORDER}

A dissertation submitted in partial fulfillment of the

requirements for the degree of

DOCTOR OF EDUCATION

in

EXCEPTIONAL STUDENT EDUCATION

by

Mashal Salman Aljehany 
To: Dean Michael R. Heithaus

College of Arts, Sciences and Education

This dissertation, written by Mashal Salman Aljehany, and entitled The Effects of Video Prompting on Teaching Daily Living Tasks to Individuals with Autism Spectrum Disorder, having been approved in respect to style and intellectual content, is referred to you for judgment.

We have read this dissertation and recommend that it be approved.

Elizabeth Cramer

Patricia Barbetta

Haiying Long

Kyle Bennett, Major Professor

Date of Defense: June 26, 2018

The dissertation of Mashal Salman Aljehany is approved.

Dean Michael R. Heithaus

College of Arts, Sciences and Education

Andrés G. Gil

Vice President for Research and Economic Development and Dean of the University Graduate School

Florida International University, 2018 
(C) Copyright 2018 by Mashal Salman Aljehany

All rights reserved. 


\section{DEDICATION}

I dedicate this dissertation to children with disabilities and my family. 


\section{ACKNOWLEDGMENTS}

I cannot express enough thanks to my major professor, Dr. Kyle Bennett for his teaching, advice, patience, encouragement, and believing in me. Dr. Kyle is a role model who inspires me professionally and personally. Without his guidance and unlimited support this dissertation would not have been possible.

I would like to thank all my committee members, Dr. Elizabeth Cramer, Dr. Patricia Barbetta, and Dr. Haiying Long for their valuable feedback and unlimited support throughout the past four years.

I would like to thank University of Jeddah, Saudi Arabia and the Saudi Arabian Cultural Mission to the United States for giving me a doctoral scholarship and supporting me financially.

I would like to express my appreciation to the government and people of the United States for the great hospitality and allowing me to achieve my educational dream.

Faith in God reduces my homesick feelings and gives me strength and peace when I am far away from home; thanks to God.

Finally, I would like to express my love and thanks to my wife, Mona, my children, Shadi and Enas, as well as my parents, sisters, and brothers for their love, wishes, inspirations, and support. 


\title{
ABSTRACT OF THE DISSERTATION \\ THE EFFECTS OF VIDEO PROMPTING ON TEACHING DAILY LIVING TASKS \\ TO INDIVIDUALS WITH AUTISM SPECTRUM DISORDER
}

\author{
by \\ Mashal Salman Aljehany \\ Florida International University, 2018 \\ Miami, Florida \\ Professor Kyle Bennett, Major Professor
}

Individuals with autism spectrum disorder (ASD) experience difficulties with learning age-appropriate daily living skills (DLS) at their homes, schools, and in the community. Such skills are significant for independent life, post-school education, employment, and overall quality of life. Video prompting (VP) is a teaching practice that has demonstrated positive outcomes in teaching a variety of DLS to individuals with ASD.

The overarching purpose of this collected papers dissertation was to investigate the effects of VP interventions on improving DLS of individuals with ASD. My dissertation includes two separate papers. The first paper is a meta-analysis that examined the overall effect of VP when teaching DLS to individuals with ASD across single-case research design (SCRD) studies. An analysis of potential moderators was also examined: VP intervention types, participants' ages, and participants' disabilities. There were 54 participants across 17 studies meeting the study's inclusion criteria. The results demonstrated a high-moderate effect size (ES) for VP on the acquisition of DLS across 17 studies including 54 participants. The analysis of potential moderators showed no 
significant differences across all moderator variables. Limitations and implications for research and practices are provided in Chapter II.

The second paper is a SCRD study comparing the effects of VP alone to least-tomost prompting alone on improving three office-related tasks to secondary-aged children with developmental disabilities. An adapted alternating treatment design (AATD), including baseline, comparison, best treatment, and final treatment phases was used to examine the interventions. Data related to the effects, efficiency, and social validity of both interventions were collected to address the research questions. Video prompting was effective for all participants, while least-to-most promoting was effective for two participants. Also, VP was more efficient than least-to-most prompting in terms of sessions-to-criterion and percent of errors for all participants. Least-to-most prompting was more efficient than VP in terms of the total duration of teaching time for all participants. Finally, all participants and their teachers reported positive perspectives regarding the study's procedures and outcomes. Limitations, future research, and implications for practices are discussed in Chapter III. Lastly, the summary of the entire dissertation and extended discussions of both papers are presented in Chapter IV. 


\section{TABLE OF CONTENTS}

\section{CHAPTER}

PAGE

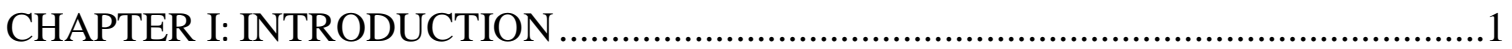

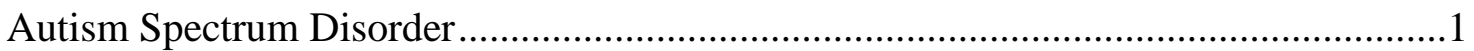

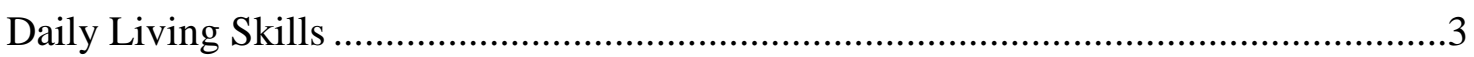

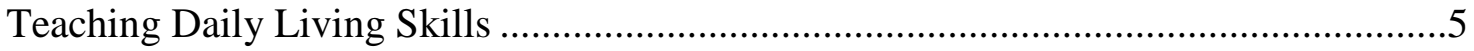

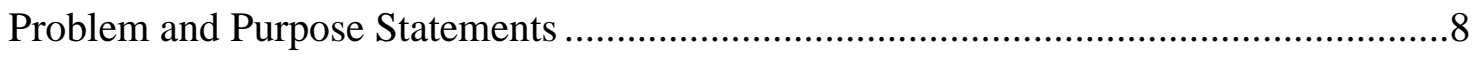

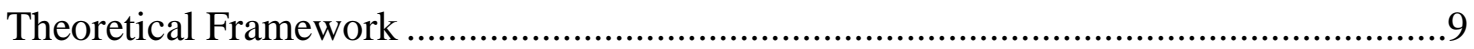

Description of Collected Papers .............................................................................

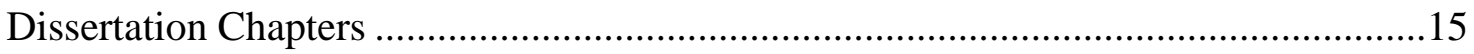

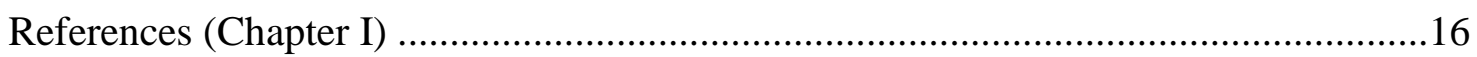

CHAPTER II: PAPER ONE, META-ANALYSIS OF VIDEO PROMPTING TO TEACH DAILY LIVING SKILLS TO INDIVIDUALS WITH AUTISM SPECTRUM

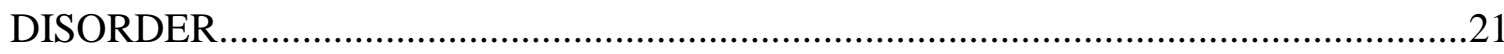

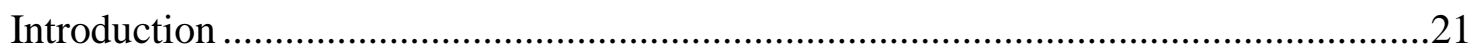

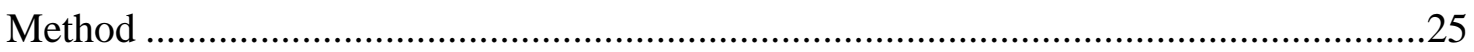

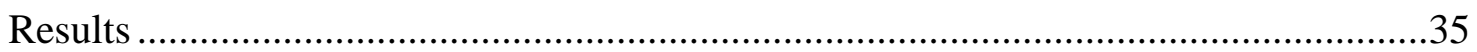

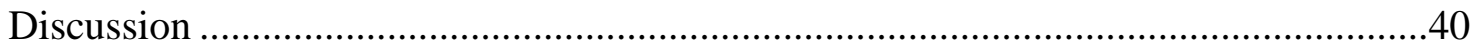

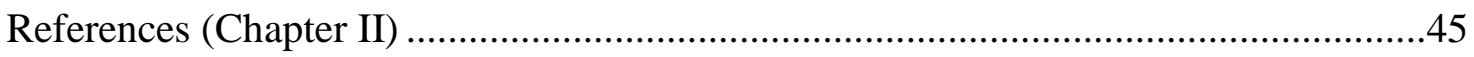

CHAPTER III: PAPER TWO, A COMPARISON OF VIDEO PROMPTING AND

LEAST-TO-MOST PROMPTING FOR TEACHING OFFICE-RELATED TASKS TO CHILDREN WITH AUTISM AND INTELLECTUAL DISABILITY ...........................50

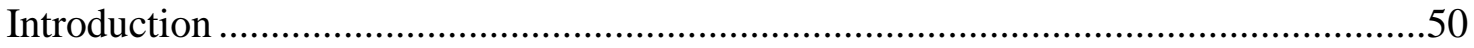

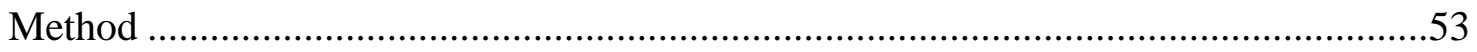

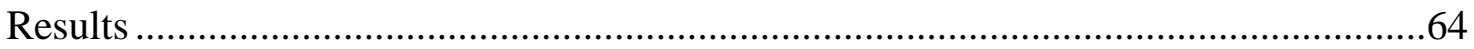

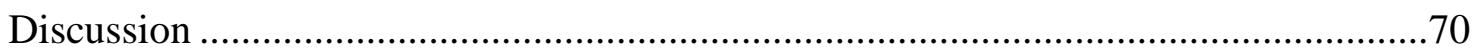

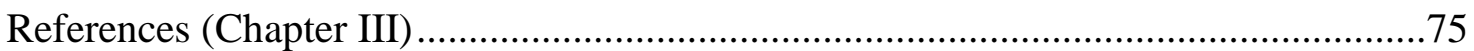

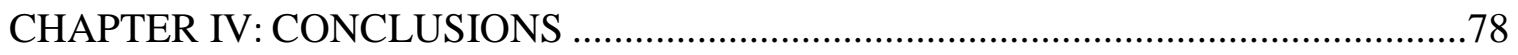

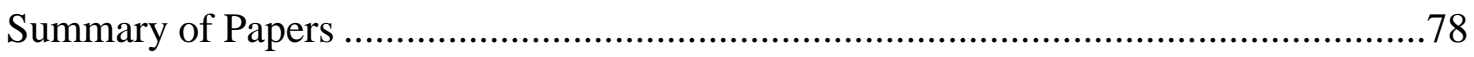

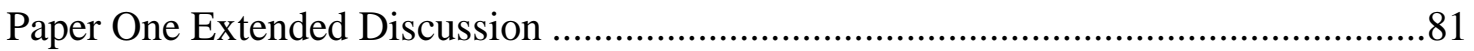

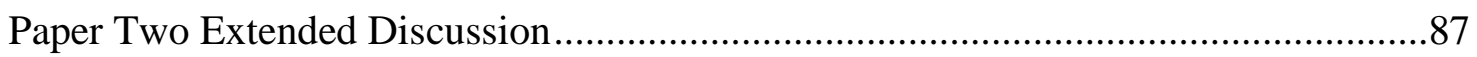

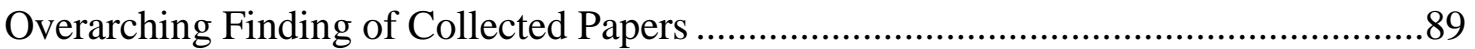

Overall Practical Implications of Collected Papers................................................90

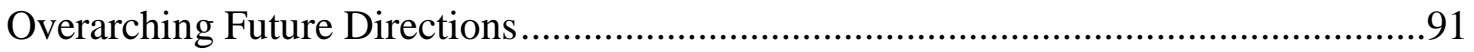

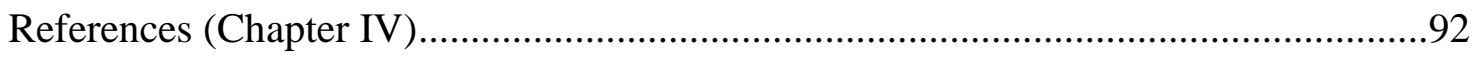




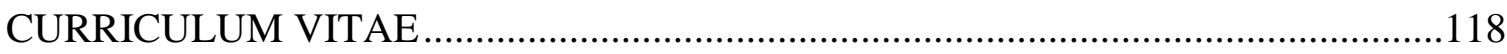




\section{LIST OF TABLES}

TABLE

PAGE

Table 1. Participant Characteristics of Paper One. .................................................... 36

Table 2. Features of the Studies Included in Paper One............................................ 37

Table 3. Task Analyses of Target Tasks and Video Clip Duration. ............................... 55

Table 4. Counterbalance of Tasks and Interventions Across Participants....................... 58

Table 5. Efficiency Data of Video Prompting and Least-to-Most Prompting................. 69

Table 6. Video Prompting as an Evidence-based Practice. .......................................... 86 


\begin{tabular}{|c|c|}
\hline \multicolumn{2}{|c|}{ ABBREVIATIONS } \\
\hline Autism Spectrum Disorder & ASD \\
\hline Adapted Alternating Treatments Design & AATD \\
\hline Centers for Disease Control and Prevention & $\mathrm{CDC}$ \\
\hline Childhood Autism Rating Scale-Second Edition & CARS-2 \\
\hline Confidence Interval & $\mathrm{CI}$ \\
\hline Daily Living Skills & DLS \\
\hline Developmental Disabilities & $\mathrm{DD}$ \\
\hline Florida International University & FIU \\
\hline Institute of Education Sciences & IES \\
\hline Intellectual Disability & ID \\
\hline Interobserver Agreement & IOA \\
\hline Multiple Probe Design & MPD \\
\hline Percentage of Non-Overlapping Data & PND \\
\hline Single-Case Research Design & SCRD \\
\hline Treatment Fidelity & $\mathrm{TF}$ \\
\hline Video-Based Instruction & VBI \\
\hline Video Modeling & VM \\
\hline Video Prompting & VP \\
\hline What Works Clearinghouse & WWC \\
\hline
\end{tabular}




\section{CHAPTER I}

\section{INTRODUCTION}

This collected papers dissertation statistically examined the effectiveness of video prompting (VP) interventions within the single-case research design (SCRD) literature and compared the effects of VP to least-to-most prompting in teaching daily living skills (DLS) for individuals with autism spectrum disorder (ASD). Chapter I includes a literature review relevant to the dissertation's variables, brief problem and purpose statements, theoretical framework, and description of the collected papers, and dissertation chapters.

Many families of individuals with ASD want their children to live independent lives as possible. They do not want their children to depend on them and caregivers to engage in typical daily living activities (Heiman, 2002). To meet such goals, these individuals should learn basic daily living, functional, and vocational skills to enhance their independence (Ayres, Lowery, Douglas, \& Sievers, 2011). For instance, if an adult with ASD wants to live in his or her own home independently, he or she must be taught how to prepare food, clean furniture, wash dishes, do laundry, and take care of his or her hygiene. To be employed, he or she needs to learn necessary job skills that maximize his or her chances to be hired. Indeed, independent life has a significant impact on overall quality of life for individuals with developmental disabilities (DD) and ASD.

\section{Autism Spectrum Disorder}

The rate of individuals who have been diagnosed with ASD has noticeably increased since the beginning of the 21st century in the United States. The Centers for Disease Control and Prevention (CDC) has monitored the prevalence of ASD among 
children aged 8 years in 11 different states since 2000. In the reports of 2000 and 2002, they indicated that one in 150 children had ASD. In the report of 2012, they stated that one in 68 children had ASD (CDC, 2016). In the latest report of 2014, they indicated that one in 59 children had ASD (CDC, 2018). The prevalence of ASD occurred across all groups regardless of their racial, ethnic, or socioeconomic status.

Consequently, the growing number of individuals with ASD has economic consequences nationally and personally in the United States. For instance, the cost of direct and indirect medical, educational, and other related services for individuals with ASD are approximately 11.5 to 60.9 billion dollars every year (CDC, 2016). Because of the growth in the population of individuals with ASD and the high cost of their education and treatments, providing effective intervention practices to this population becomes a significant challenge in schools (CDC, 2016).

Autism spectrum disorder is a developmental disability identified by three major symptoms, including difficulties in social skills, challenges in verbal and nonverbal communication skills, and stereotyped behaviors that can be repeated and restricted to specific activities and interests (American Psychiatric Association, 2013). Children with ASD have difficulties in establishing normal conversations, have challenges with developing successful peer relationships, and have sensory issues. They often engage in repetitive body movements, as well (American Psychiatric Association, 2013).

Deficits in social, communication, and behavioral development usually lead to diminished school performance, poor adaptive behaviors, and difficulties with independent living (Gillham, Carter, Volkmar, \& Sparrow, 2000). Howlin, Goode, Hutton, and Rutter (2004) conducted a study to measure adult outcomes for 68 
individuals with ASD who had an IQ of 50 or higher. They found that most of these individuals were very dependent on their caregivers and families. The majority were scored as having poor and very poor outcomes regarding independent functional living skills, rate of employment, social relationships, communication skills, and academic skills (e.g., reading and spelling). In recent studies, researchers have reported similar findings related to poor post-secondary outcomes (Shattuck et al., 2012) and deficits with independent life skills (Taylor et al., 2012) among individuals with ASD.

\section{Daily Living Skills}

Daily living skills are also known as functional living skills, self-care skills, and independent living skills, which are described as the skills that a person exhibits during his or her daily routine. Specifically, these skills are the person's ability to perform normal activities and basic daily skills that are needed in the school, home, work, and community environments (Ayres et al., 2011). As a major component of adaptive behavior, DLS are categorized into different domains including personal skills, domestic activities, community-related skills, and job-related skills. Some examples of DLS are laundering, dressing, washing dishes, setting a table, money-related skills, and jobspecific skills (Maenner et al., 2013).

Teaching DLS to individuals with ASD is essential for improving the quality of their lives. Teaching daily living and vocational skills enhance independent skills and self-determination among individuals with ASD (Cannella-Malone et al., 2011; Mechling, 2007). Poor basic daily routines (e.g., food preparation \& laundry) among individuals with ASD may lead them to depend on parents, siblings, and teachers (Domire \& Wolfe, 2014). Families also hope to minimize their concerns about the future 
of their children with ASD to be more independent and productive individuals in the society (Heiman, 2002).

Furthermore, having appropriate independent DLS supports successful inclusion at school, in the community, and in workplace settings (Carnahan, Hume, Clark, \& Borders, 2009). When individuals with ASD can perform daily living activities at school, home, and the workplace independently, they may develop a high sense of empowerment, self-control, and self-esteem, which reflects positively on their life satisfaction (Pierce \& Schreibman, 1994).

Additionally, developing job-related skills of adults with ASD may lead to increased job opportunities. The limited career opportunities for individuals with ASD is documented in the literature (Hendricks, 2010). Indeed, these individuals need to meet the expectations of job providers who are looking for trained, independent, and socialized employees. In sum, appropriate DLS help individuals with ASD to engage effectively in their community, to be independent as possible, and to increase their career opportunities.

Daily living skills are developed in the child's natural environment through social learning and observation. Thus, gaining these skills is an outcome of the interactions between the child and his or her family, peers, community, and society. However, learners with DD, including those with ASD, show significant deficits in developing DLS through social learning observation (Jacobson \& Ackerman, 1990). Thus, developing these important skills using the most effective intervention practices should be a priority at homes and schools (Gardner \& Wolfe, 2013). Fortunately, the widespread use of technology, such as videos via handheld devices, has made a substantial contribution in teaching these needed skills to individuals with ASD. In fact, improving daily living and 
vocational skills through instruction-based technology can enhance the independence of individuals with DD, including those with ASD, in the future (Boser, Goodwin, \& Wayland, 2014).

\section{Teaching Daily Living Skills}

The Individuals with Disabilities Education Improvement Act of 2004 requires school professionals to provide evidence-based practices and transition planning to individuals with disabilities to be prepared for productive and independent lives after leaving public school (Ayres et al., 2011). Many intervention practices have been used to teach daily living and vocational tasks to children with ASD in the literature. For example, Ninci et al. (2015) reviewed 52 studies and their ESs in teaching functional living tasks to persons with ASD. Strong treatment effects were found across (a) audio cueing interventions, (b) behavioral interventions, such as response prompting, and (c) visual cueing interventions, such as picture schedules. Moderate treatment effects were found across video-based instruction (VBI). Moreover, Bennett and Dukes (2014) conducted a systematic review and examined 14 studies on teaching DLS to secondary individuals with ID and ASD. They found that the majority of interventions used applied behavioral analysis, such as differential reinforcement, prompting, and self-monitoring.

One of the growing evidence-based practices in the last 20 years for teaching DLS to children with ASD is VBI (Wong et al., 2015). Video-based instruction is a broad term for a variety of strategies that use technology (e.g., tablets, smartphones, computers, \& televisions) as the main elements of instruction whereby a skill is displayed on a video clip and subsequently imitated by the learner (Bellini \& Akullian 2007). The theoretical roots of VBI come from the principles of social learning theory and observational 
learning, that characterize learning as a cognitive process that occurs through observation and modeling (Schunk, 2012). The use of VBI applications have shown positive outcomes in teaching a variety of daily living and vocational skills, such as self-feeding, money management, and job-related skills to individuals with DD (Bellini \& Akullian 2007). Also with VBI, these learners maintained these skills over time and generalized them to different settings and behaviors (Wong et al., 2015).

Video modeling (VM) and VP are two primary applications of VBI (CannellaMalone, O'Reilly, Edrisinha, Sigafoos, \& Lancioni, 2006). With VM instruction, the practitioner plays a video clip of a model performing a desired skill in its entirety. Then, the learner is given an opportunity to watch the entire video clip before imitating the observed skill (Rayner, Denholm, \& Sigafoos, 2009). Video modeling has been shown to be effective in improving several DLS for individuals with DD and ASD, such as first aid skills (Ozkan, 2013), cooking skills (Mechling \& Collins, 2012), and putting away groceries (Ayres \& Langone, 2007).

With VP instruction, the instructor plays a video clip of one step in a task analysis, asks the learner to imitate what he or she observed, and repeats the same procedures until completing all the task steps that comprise the skill (Sigafoos et al., 2007). The use of VP has demonstrated effectiveness in teaching DLS to individuals with ASD, such as tying shoes (e.g., Rayner, 2011), washing dishes (e.g., Sigafoos et al., 2007), and preparing food (e.g., Johnson, Blood, Freeman, \& Simmons, 2013).

Video prompting has been used as an intervention package, that includes additional intervention components. One of the common intervention components that has been used within VP intervention packages is response prompting systems, and 
specifically, least-to-most prompting (Banda, Dogoe, \& Matuszny, 2011). Prompts are specific antecedent stimuli that increase the occurrences of correct responses at identified times and circumstances (Wolery, Ault, \& Dyle, 1992). The aim of prompting is to increase independent responding in the presence of the desired antecedent stimuli (Wolery et al., 1992). Prompting is associated with a discriminative stimulus (i.e., target stimulus or natural cue) and provided before or during the occurrence of the desired skill to reduce incorrect responses and increase the chances of correct responses in upcoming learning sessions (Collins, 2007). Ultimately, provided prompts are faded until the correct independent response is established (Wolery et al., 1992).

When using least-to-most prompting, the instructor provides a hierarchy of prompts starting from the least intrusive prompt to the most intrusive prompt. Verbal, gestural, model, and then physical prompts are gradually delivered to the learner as needed until he or she performs the task independently (Zirpoli, 2005). Least-to-most prompting as a response prompting system is an evidence-based practice (Wong et al., 2015). It has been shown to be effective in teaching social, behavioral, daily living, and vocational skills to individuals with ASD (Schuster et al., 1998).

Least-to-most prompting as an intervention component is used either during VP instruction or as a supportive intervention when VP has not been effective in improving skill acquisition. Some individuals with severe and profound DD need additional verbal, gestural, model, and physical prompts to learn the tasks during VP instruction (CannellaMalone et al., 2011; Goodson, Sigafoos, O'Reilly, Cannella, \& Lancioni, 2007). Indeed, researchers have demonstrated successful use of least-to-most prompting within VM and VP intervention packages in teaching leisure activities (e.g., Cannella-Malone et al., 
2016), job-related tasks (e.g., Van Laarhoven, Johnson, Van Laarhoven-Myers, Grider, \& Grider, 2009), and food preparation skills (e.g., Johnson et al., 2013) to individuals with DD. However, the inclusion of this, and other prompting systems, makes it difficult to determine the intervention components responsible for the skill acquisition among students; consequently, the lack of clarity makes it challenging for researchers to inform practitioners of the most efficient manner in which to teach students with disabilities.

\section{Problem and Purpose Statements}

Some reviews of the literature on VP have been conducted (Banda et al., 2011; Domire \& Wolfe, 2014; Gardner \& Wolfe, 2013; Hong et al., 2016). Collectively, these reviews have supported the effectiveness of VP interventions in teaching a variety of DLS and other behaviors to individuals with DD, including ASD. However, Banda et al. (2011), Domire and Wolfe (2014), and Gardner and Wolfe's (2013) reviews used narrative approaches to examine the effects of VP interventions. They did not statistically measure the magnitude of change in participants' performances in response to the use of VP. Hong et al. (2016) statistically analyzed the effects of VP and VM together, which limited the ES determination of VP in isolation. A major gap in the current VP literature is the lack of statistical analysis that identifies the ES of VP interventions on DLS for individuals with ASD within the SCRD literature, and this is the purpose of Paper One in this collected papers series.

With respect to Paper Two, providing the most effective intervention practices for teaching students with disabilities is mandatory in schools (Horner et al., 2005). Given that VP has been compared to different teaching strategies, such as picture prompts, to identify its effectiveness and efficiency for students with DD. Two recent research 
studies compared the effects of VM or VP to least-to-most prompting. In one study, Ulke-Kurkcuoglu (2015) examined the effects of VM and least-to-most prompting to teach play skills among three young children with ASD. Later, Cannella-Malone, Chan, and Jimenez (2017) compared the effects of VP with error correction to live modeling followed by least-to-most prompting to improve job-related skills among adults with DD. Both studies supported the effectiveness of VM or VP and least-to-most prompting for improving target skills. However, there is a need to extend the results of these studies by comparing the effects of VP alone to least-to-most prompting alone without providing any additional procedures when teaching DLS to adolescents with ASD and ID. Such comparisons allow researchers to determine the effectiveness and efficiency of both interventions without intervening with additional variables on the skill acquisition, as well as help educators to develop and use the most effective teaching strategies in classrooms. Thus, the aim of Paper Two is to identify the differences between VP alone and least-to-most prompting alone for improving DLS of secondary-aged children with ASD and ID.

The overarching aim of this dissertation is to explore the overall effectiveness of VP statistically and to compare the effects of VP to least-to-most prompting across DLS individuals with ASD to provide further instructional options for teachers when developing DLS among students with ASD.

\section{Theoretical Framework}

My dissertation was conceptualized using two theoretical frameworks, and each theory is explained in this section. The first theory is observational learning theory, which is the theoretical framework of using VBI, including VP interventions. The second theory 
is that of stimulus control and transfer of stimulus control, which is the theoretical framework of using response prompting systems, including least-to-most prompting.

\section{Observational Learning Theory}

The use of VBI applications is driven from the observational learning, which is an essential component of social learning theory (Bandura, 1977). Bandura supported the conditioning theories of learning, but investigated additional aspects of learning and the environment to provide explanations in how human behaviors develop (Schunk, 2012). Bandura's work on social learning theory included the role of the learner's cognitive processes in relation to the social environment (Bandura, 1977; Schunk, 2012).

There are four factors that are essential for modeling to occur. The first factor is attention, whereby the individual attends to the model. Focusing and noting the behavior is essential for imitation to occur. The second factor is retention, which is the individual's ability to remember the model for later imitation (i.e., immediate or delayed imitation). The third factor is reproduction; that is, the learner has the ability to emit the behavior that was observed. The fourth factor is motivation, which is defined as the desire to exhibit the model on the basis of internal or external contingencies (Bandura, 1977; Schunk, 2012). With respect to the use of VBI, including VP, the learner should view the model throughout a video clip with enough attention, remember what he or she observed, be capable to perform the model, and be motivated by the model along with covert or overt contingencies of reinforcement.

\section{Stimulus Control and Transfer Stimulus Control}

The concept of prompting is driven from the principles of stimulus control and transfer of stimulus control. Behavior is occasioned and maintained by an antecedent and 
a consequence, respectively (Schunk, 2012). The antecedent becomes a discriminative stimulus when it works as the cue for responding. Stimulus control occurs when the learner repeatedly provides a response during the presence of a discriminative stimulus and when reinforcement follows (Wolery et al., 1992). As a result, learning is occurring, and the learner will be able to respond to the discriminative stimulus independently in the future.

In the early stages of learning, the learner has an equal probability to provide correct or incorrect responses when experiencing the intended discriminative stimulus. If the learner does not respond to the intended discriminative stimulus, or respond incorrectly, the intended discriminative stimulus can be paired with an additional stimulus, known as a prompt (e.g., physical prompt). The prompt, when applied and faded, increases the probability that the discriminative stimulus will occasion the correct response. During the instruction, these additional prompts are faded gradually so that the learner will respond when only the discriminative stimulus is presented (Wolery et al., 1992). Matching the discriminative stimulus with additional prompts, and then fading these additional prompts, is referred to as transfer stimulus control (Wolery et al., 1992). Establishing stimulus control is required for any teaching practice to be considered successful.

\section{Description of Collected Papers}

The collected papers dissertation includes two papers investigating the effects of VP interventions to improve DLS for individuals with ASD. Paper One is a meta-analytic literature review within the SCRD literature. Paper Two is a comparison study that evaluated the effects of VP and least-to-most prompting. In the following sections, the 
running title, authorship, writing format, purpose, method, and publication outlet of each paper are introduced.

\section{Paper One}

The running title. The running title of Paper One is "Meta-Analysis of Video Prompting to Teach Daily Living Skills to Individuals with Autism Spectrum Disorder."

Authorship. The authors of Paper One were the doctoral candidate as the lead author and Dr. Kyle Bennett as the second author.

Writing format. Paper One follows the collected papers dissertation format guidelines of the College of Arts, Sciences and Education and University Graduate School of Florida International University (FIU); the Publication Manual of the American Psychological Association, Sixth Edition (American Psychological Association, 2010); and the Journal of Special Education Technology, which is the peer-reviewed journal where the paper was accepted for publication.

Purpose. The purpose of Paper One was to conduct a statistical analysis of the ES of VP on teaching DLS to individuals with ASD across SCRD studies. Additionally, it investigated the ESs of VP on teaching DLS across three potential moderators, including (a) VP used alone versus VP with additional response prompting or error correction procedures, (b) participants' age range, and (c) participants with ASD versus those with ASD plus ID.

Method. Paper One applied SCRD meta-analytic review procedures using the non-parametric measure of Tau- $U$ (Parker, Vannest, Davis, \& Sauber, 2011). Figure 1 represents the procedures applied in Paper One. 
Publication outlet. Paper One was submitted to the Journal of Special Education Technology (JSET) in January 26, 2018. The paper was reviewed, and the journal's reviewers recommended publication with revisions. The paper was revised and resubmitted in April 6, 2018. The paper was fully accepted in April 29, 2018.

1. Evaluation of Research Designs: What Works Clearinghouse (WWC) standards were used to evaluate the SCRD of studies.

2. Systematic Literature Search: Four systematic searches of the literature were conducted: (a) an examination of databases, (b) conducting journal hand searches, (c) reviewing previous systematic reviews, and (d) hand searches for studies meeting the inclusion criteria.

3. Extractions of Qualitative Data: Six qualitative data variables were extracted from each included study, including the three potental moderators.

4. Extraction of Quantitative Data: Data from adjacent A-B phase contrasts were extracted from each included study.

5. Tau- $\boldsymbol{U}$ Effect Size Calculation and Analysis: The web-based Tau- $U$ calculator and the WinPEPI meta-analysis software were used to calculate and analyze the Tau- $U$, standard error, and confidence intervals.

Figure 1. The meta-analytic review procedures that were conducted in Paper One

\section{Paper Two}

The running title. The running title of Paper Two is "A Comparison of Video Prompting and Least-to-Most Prompting for Teaching Office-Related Tasks to Children with Autism and Intellectual Disability." 
Authorship. The authors of Paper One were the doctoral candidate as the lead author and Dr. Kyle Bennett as the second author.

Writing format. Paper Two follows the collected papers dissertation format guidelines of the College of Arts, Sciences and Education and University Graduate School of FIU, and the Publication Manual of the American Psychological Association, Sixth Edition (American Psychological Association, 2010).

Purpose. The purpose of Paper Two was to compare the effectiveness, efficiency, and social validity of VP alone to least-to-most prompting alone when teaching three office-related tasks to three secondary-aged children with ASD and ID.

Method. Three children (12 - 15 years old) with ASD and moderate ID participated in the experiment. The study was conducted in a special education learning center for students with DD. The dependent variables were three office-related tasks: (a) making a photocopy, (b) making a label tag for a file folder, and (c) sending a fax. The independent variables were VP alone and least-to-most prompting alone. To determine the effectiveness, the dependent measure was the percent of steps in the task analyses completed correctly and independently by the participants. Additionally, three types of efficiency data were collected and analyzed including sessions-to-criterion, percent of errors, and the total amount of instructional time. Preference assessment, accuracy of measurement, treatment fidelity (TF), and social validity data were also collected.

The study's experimental design was an adapted alternating treatment design (AATD). The design consisted of four phases that included a continuous baseline, a comparison phase with control probes, a best treatment phase, and a final treatment phase. During the baseline, participants' responses on completing all target tasks were 
continuously assessed before introducing both interventions. In the comparison, VP and least-to-most prompting were applied to teach two independent tasks in an alternating fashion. Throughout this phase, a third task was used as control probes (no intervention was applied) to detect possible multi-treatment interference and to serve as a baseline phase for the next condition (Wolery, Gast, \& Ledford, 2014). During the best treatment, each participant was taught to complete a target task using the most effective intervention. During the final treatment, one participant used VP to complete the target task that she could not complete using least-to-most prompting during the comparison phase.

Publication outlet. Paper Two will be submitted to a special education peerreviewed journal.

\section{Dissertation Chapters}

This dissertation applied the FIU School of Education and Human Development guidelines and formats for the collected papers dissertation option. It includes this introductory chapter and a conclusion chapter, as well as the two papers previously described. The chapters of this collected papers dissertation are as follows: Chapter I: Introduction, related literature review, research rationale; Chapter II: Meta-analysis of VP to teach DLS to individuals with ASD;

Chapter III: A comparison of VP and least-to-most prompting for teaching office-related tasks to children with ASD and ID; and

Chapter IV: Conclusions, contributions, implications. 


\section{References (Chapter I)}

American Psychiatric Association. (2013). Diagnostic and statistical manual of mental disorders (5th ed.). Arlington, VA: Author.

American Psychological Association. (2010). Publication manual of the American Psychological Association (6th ed.). Washington, DC: Author.

Ayres, K. M., \& Langone, J. (2007). A comparison of video modeling perspectives for students with autism. Journal of Special Education Technology, 22(3), 15-30.

Ayres, K. M., Lowery, K. A., Douglas, K. H., \& Sievers, C. (2011). I can identify Saturn but I can't brush my teeth: What happens when the curricular focus for students with severe disabilities shifts. Education and Training in Autism and Developmental Disabilities, 46(1), 11-21.

Banda, D. R., Dogoe, M. S., \& Matuszny, R. (2011). Review of video prompting studies with persons with developmental disabilities. Education and Training in Autism and Developmental Disabilities, 46, 514-527.

Bandura, A. (1977). Social learning theory. Englewood Cliffs, NJ: Prentice Hall.

Bellini, S., \& Akullian, J. (2007). A meta-analysis of video modeling and video selfmodeling interventions for children and adolescents with autism spectrum disorders. Exceptional children, 73(3), 264-287.

Bennett, K. D., \& Dukes, C. (2014). A systematic review of teaching daily living skills to adolescents and adults with autism spectrum disorder. Review Journal of Autism and Developmental Disorders, 1(1), 2-10. doi: 10.1007/s40489-016-0075-z.

Boser, K. I., Goodwin, M. S., \& Wayland, S. C. (Eds.). (2014). Technology tools for students with autism: Innovations that enhance independence and learning. Baltimore, Maryland: Paul H. Brookes Publishing Co.

Cannella-Malone, H. I., Chan, J. M., \& Jimenez, E. D. (2017). Comparing self-directed video prompting to least-to-most prompting in post-secondary students with moderate intellectual disabilities. International Journal of Developmental Disabilities, 63(4), 211-220.

Cannella-Malone, H. I., Fleming, C., Chung, Y., Wheeler, G. M., Basbagill, A. R., \& Singh, A. H. (2011). Teaching daily living skills to seven individuals with severe 
intellectual disabilities: A comparison of video prompting to video modeling. Journal of Positive Behavior Interventions, 13, 144-153.

Cannella-Malone, H. I., Miller, O., Schaefer, J. M., Jimenez, E. D., Page, E. J., \& Sabielny, L. M. (2016). Using video prompting to teach leisure skills to students with significant disabilities. Exceptional Children, 82(4), 463-478.

Cannella-Malone, H. I., O’Reilly, M., Edrisinha, C., Sigafoos, J., \& Lancioni, G. E. (2006). Comparing video prompting to video modeling for teaching daily living skills to six adults with developmental disabilities. Education and Training in Developmental Disabilities, 41, 344-356.

Carnahan, C. R., Hume, K., Clarke, L., \& Borders, C. (2009). Using structured work systems to promote independence and engagement for students with autism spectrum disorders. Teaching Exceptional Children, 41(4), 6-14.

Centers for Disease Control and Prevention. (2016, July 11). Autism Spectrum Disorder: Data \& Statistics. Retrieved from https://www.cdc.gov/ncbddd/autism/data.html.

Centers for Disease Control and Prevention. (2018, May 17). Prevalence of autism spectrum disorder among children aged 8 years - Autism and Developmental Disabilities Monitoring Network, 11 Sites, United States. Retrieved from https://www.cdc.gov/mmwr/volumes/67/ss/ss6706a1.htm?s_cid=ss6706a1_w\#sug gestedcitation.

Collins, B. C. (2007). Moderate and severe disabilities: A foundational approach. Upper Saddle River, NJ: Pearson Education, Inc.

Domire, S. C., \& Wolfe, P. (2014). Effects of video prompting techniques on teaching daily living skills to children with autism spectrum disorders: A review. Research and Practice for Persons with Severe Disabilities, 39(3), 211-226. doi: $10.1177 / 1540796914555578$.

Gardner, S., \& Wolfe, P. (2013). Use of video modeling and video prompting interventions for teaching daily living skills to individuals with autism spectrum disorders: A review. Research and Practice for Persons with Severe Disabilities, $38(2), 73-87$.

Gillham, J. E., Carter, A. S., Volkmar, F. R., \& Sparrow, S. S. (2000). Toward a developmental operational definition of autism. Journal of autism and developmental disorders, 30(4), 269-278. 
Goodson, J., Sigafoos, J., O’Reilly, M., Cannella, H., \& Lancioni, G. E. (2007). Evaluation of a video-based error correction procedure for teaching a domestic skill to individuals with developmental disabilities. Research in Developmental Disabilities, 28(5), 458-467.

Heiman, T. (2002). Parents of children with disabilities: Resilience, coping, and future expectations. Journal of Developmental and Physical Disabilities, 14, 159-171.

Hendricks, D. (2010). Employment and adults with autism spectrum disorders: challenges and strategies for success. Journal of Vocational Rehabilitation, 32, $125-134$.

Hong, E. R., Ganz, J. B., Mason, R., Morin, K., Davis, J. L., Ninci, J., ... \& Gilliland, W. D. (2016). The effects of video modeling in teaching functional living skills to persons with ASD: A meta-analysis of single-case studies. Research in Developmental Disabilities, 57, 158-169. doi: 10.1016/j.ridd.2016.07.001.

Horner, R. H., Carr, E. G., Halle, J., McGee, G., Odom, S., \& Wolery, M. (2005). The use of single-subject research to identify evidence-based practice in special education. Exceptional children, 71(2), 165-179.

Howlin, P., Goode, S., Hutton, J., \& Rutter, M. (2004). Adult outcome for children with autism. Journal of Child Psychology and Psychiatry, 45, 212-229.

Jacobson, J. W., \& Ackerman, L. J. (1990). Differences in adaptive functioning among people with autism or mental retardation. Journal of Autism and Developmental Disorders, 20, 205-219.

Johnson, J. W., Blood, E., Freeman, A., \& Simmons, K. (2013). Evaluating the effectiveness of teacher implemented video prompting on an iPod touch to teach food preparation skills to high school students with autism spectrum disorders. Focus on Autism \& Other Developmental Disabilities, 28(3), 147-158.

Maenner, M. J., Smith, L. E., Hong, J., Makuch, R., Greenberg, J. S., \& Mailick, M. R. (2013). Evaluation of an activities of daily living scale for adolescents and adults with developmental disabilities. Disability and Health Journal, 6(1), 8-17.

Mechling, L. C. (2007). Assistive technology as a self-management tool for prompting students with intellectual disabilities to initiate and complete daily tasks: A literature review. Education and Training in Developmental Disabilities, 42, 252 269. 
Mechling, L. C., \& Collins, T. S. (2012). Comparison of the effects of video models with and without verbal cueing on task completion by young adults with moderate intellectual disability. Education and Training in Autism and Developmental Disabilities, 47, 223-235.

Ninci, J., Neely, L. C., Hong, E. R., Boles, M. B., Gilliland, W. D., Ganz, J. B., ... \& Vannest, K. J. (2015). Meta-analysis of single-case research on teaching functional living skills to individuals with ASD. Review Journal of Autism and Developmental Disorders, 2(2), 184-198. doi: 10.1007/s40489-014-0046-1.

Ozkan, S. Y. (2013). Comparison of peer and self-video modeling in teaching first aid skills to children with intellectual disability. Education and Training in Autism and Developmental Disabilities, 48, 88-102.

Parker, R. I., Vannest, K. J., Davis, J. L., \& Sauber, S. B. (2011). Combining nonoverlap and trend for single-case research: Tau-U. Behavior Therapy, 42(2), 284-299. doi: 10.1016/j.beth.2010.08.006.

Pierce, K., \& Schreibman, L. (1994). Teaching daily living skills to children with autism in unsupervised settings through pictorial self-management. Journal of Applied Behavior Analysis, 27, 471-481.

Rayner, C. (2011). Teaching students with autism to tie a shoelace knot using video prompting and backward chaining. Developmental Neurorehabilitation, 14(6), 339-347.

Rayner, C., Denholm, C., \& Sigafoos, J. (2009). Video-based intervention for individuals with autism: Key questions that remain unanswered. Research in Autism Spectrum Disorders, 3(2), 291-303.

Schunk, D. H. (2012). Learning theories: An educational perspective (6th Ed.). Boston, MA: Pearson.

Schuster, J. W., Morse, T. E., Ault, M. J., Doyle, P. M., Crawford, M. R., \& Wolery, M. (1998). Constant time delay with chained tasks: A review of the literature.

Education and Treatment of Children, 21, 74-106.

Shattuck, P. T., Narendorf, S. C., Cooper, B., Sterzing, P. R., Wagner, M., \& Taylor, J. L. (2012). Postsecondary education and employment among youth with an autism spectrum disorder. Pediatrics, 129, 1042-1049. 
Sigafoos, J., O'Reilly, M., Cannella, H., Edrisinha, C., de la Cruz, B., Upadhyaya, M....Young, D. (2007). Evaluation of a video prompting and fading procedure for teaching dish washing skills to adults with developmental disabilities. Journal of Behavioral Education, 16(2), 93-109. doi: 10.1007/S10864-006-9004-z.

Taylor, J. L., McPheeters, M. L., Sathe, N. A., Dove, D., Veenstra-Vander Weele, J., \& Warren, Z. (2012). A systematic review of vocational interventions for young adults with autism spectrum disorders. Pediatrics, 130, 531-538.

Ulke-Kurkcuoglu, B. (2015). A comparison of least-to-most prompting and video modeling for teaching pretend play skills to children with autism spectrum disorder. Educational Sciences: Theory \& Practice, 15(2), 499-517.

Van Laarhoven, T., Johnson, J., Van Laarhoven-Myers, T., Grider, K., \& Grider, K. (2009). The effectiveness of using a video iPod as a prompting device in employment settings. Journal of Behavioral Education, 18(2), 119-141.

Wolery, M., Ault, M. J., \& Dyle, P. M. (1992). Teaching students with moderate and severe disabilities: Use of response prompting strategies. White Plains, NY: Longman.

Wolery, M., Gast, D. L., \& Ledford, J. R. (2014). Comparison designs. In D. L. Gast \& J. R. Ledford (Eds.), Single case research methodology: Applications in special education and behavioral sciences ( $2^{\text {nd }}$ ed., pp. 377-396). New York, NY: Routledge.

Wong, C., Odom, S. L., Hume, K. A., Cox, A. W., Fettig, A., Kucharczy k, S., . . \& \& Schultz, T. R. (2015). Evidence-based practices for children, youth, and young adults with autism spectrum disorder: a comprehensive review. Journal of Autism and Developmental Disorders, 45, 1951-1966.

Zirpoli, T. (2005) Behavior management. Upper Saddle River, New Jersey: Pearson. 


\title{
CHAPTER II
}

\section{PAPER ONE: META-ANALYSIS OF VIDEO PROMPTING TO TEACH DAILY LIVING SKILLS TO INDIVIDUALS WITH AUTISM SPECTRUM DISORDER}

\author{
Mashal S. Aljehany and Kyle D. Bennett \\ Introduction
}

Individuals with autism spectrum disorder (ASD) experience significant deficits in the domains of social-communication and repetitive and restricted behaviors and interests (American Psychiatric Association, 2013). Features of the disorder such as difficulty with attending behaviors; deficits in imitation skills; issues with expressive, receptive, and pragmatic language; and the presence of stimulus over-selectivity can result in complications that individuals with ASD experience while learning skills (Gonzalez, Cassel, Durocher, \& Lee, 2017). Among the skills that seem to be affected are those related to functional living and vocational, and a lack of such skills can negatively impact independence and quality of life (Carothers \& Taylor, 2008).

Daily living skills (DLS) refer to behaviors that allow individuals to function as independently as possible in everyday activities such as hygiene, domestic, community, employment, and leisure (Bennett \& Dukes, 2014). Indeed, Domire and Wolfe (2014) contended that such skills are prerequisites needed to enhance job opportunities and independent living for individuals with ASD. Fortunately, there has been a recent increase in research activity to identify evidence-based practices for teaching DLS to individuals with ASD (Bennett \& Dukes, 2014).

One evidence-based practice that has gained attention in recent years for teaching DLS is video-based instruction (VBI; Banda, Dogoe, \& Matuszny, 2011). This 
methodology includes several variations, with the most prominent being video modeling (VM) and video prompting (VP). During VM, a practitioner plays a video clip of an entire task being performed from beginning to end before the student has an opportunity to perform the skill. When using VP, however, the practitioner plays a video clip of one task step being completed before the student attempts that skill, and this sequence repeats until all task steps have been attempted or completed (Sigafoos et al., 2007).

Researchers have demonstrated the effectiveness of VP when teaching DLS to individuals with ASD. To date, three systematic reviews on VP have been conducted (Banda et al., 2011; Domire \& Wolfe, 2014; Gardner \& Wolfe, 2013). Banda, Dogoe, and Matuszny (2011) were among the first researchers to examine the literature on the effects of VP with individuals with ASD learning skills. Their review of the literature assessed the effects of VP across 18 studies that were inclusive of 68 participants with developmental disabilities (DD). The majority of participants in the studies were adolescents or adults, and many individuals had a dual diagnosis of ASD and intellectual disability (ID). A significant finding from the Banda et al. study was that VP has frequently been included with different intervention components, such as antecedentbased response prompting and consequence-based error correction procedures. These strategies were used as adjunct interventions when VP, by itself, was not effective in improving participants'skills. Nevertheless, Banda et al. reported that VP with and without response prompting or error correction improved the DLS of the majority of the participants reviewed. In 12 studies, Banda et al. reported that VP led to participants' maintaining and generalizing the skills, two issues known to be problematic among learners with ASD (Gonzalez et al., 2017). 
Following the review by Banda et al. (2011), Gardner and Wolfe (2013), and Domire and Wolfe (2014) conducted their systematic reviews of the VP literature and focused on participants with ASD learning DLS. Gardner and Wolfe examined the effects of VP among 38 participants with ASD across 13 studies, while Domire and Wolfe evaluated the effects of VP among 38 participants with ASD in 12 studies. These research teams also reported the inclusion of participants with comorbid diagnoses of ASD and ID. Additionally, Gardner and Wolfe and Domire and Wolfe reported that response prompting or error correction was part of the VP intervention package in some studies. Notwithstanding the inclusion of additional strategies, both research teams reported that VP demonstrated positive outcomes when teaching DLS to individuals with ASD. Moreover, both research teams indicated that VP helped participants maintain the skills over time as well as generalize the skills to other environments, and this finding is similar to Banda et al.

One feature of the Domire and Wolfe (2014) study, which differed from the other reviews, was their use of percentage of non-overlapping data (PND) to summarize the effects observed in each participant's graph among the included studies. They found that seven studies had 100\% PND for each participant indicating strong intervention effects. The remainder of the studies reported varying levels of PND that ranged from low to high overlap among the participants.

In a fourth study, Hong et al. (2016) conducted a meta-analysis of VM (that included VP studies) on teaching DLS to individuals with ASD, the majority of whom had a secondary diagnosis of ID. There were 66 participants with ASD across 23 studies meeting Hong et al. inclusion criteria. By using the Tau- $U$ effect size (ES) non-overlap 
index and the Kruskal-Wallis test to analyze 119 A-B phase contrasts statistically, Hong et al. found that the overall ES of VM (inclusive of VP) interventions was $0.83 \mathrm{CI}_{95}$ $[0.79,0.87]$. This finding represents a moderate ES (Parker, Vannest, \& Davis, 2011; Parker, Vannest, Davis, \& Sauber, 2011). Additionally, Hong et al. did not find significant differences between potential moderators that included age, diagnosis, independent variables (i.e., formats of VM inclusive of VP), and dependent variables (i.e., various DLS).

These published reviews provided valuable insight regarding the effects of VP interventions but with some limitations. First, the reviews of Banda et al. (2011) and Gardner and Wolfe (2013) did not use quantitative techniques to examine the magnitude of change in DLS in response to VP intervention packages. Second, although Domire and Wolfe (2014) used PND to measure non-overlap, they did not measure the overall ES of VP across all included studies. Moreover, some researchers have questioned the utility of using PND as an ES measure when analyzing studies (Parker et al., 2011). Third, upon close inspection of the Hong et al. (2016) data, VM and VP studies were combined in the analysis. Indeed, there were nine such studies whereby VP was used rather than VM. Although VM and VP are both VBI strategies that share commonalities, there are essential differences in their application (Banda et al., 2011). Unlike using VM to teach individuals behavior chains, VP requires a short time period for attention and retention given that one step is viewed and completed before advancing to additional steps in the behavior chain. This feature seems to be appropriate for learners with ASD who could have attention difficulties (Travers, Klinger, \& Klinger, 2011). Furthermore, Banda et al. indicated that VP could be more effective than VM for individuals with moderate to 
severe disabilities, and they also suggested that VP seemed to be more effective than VM when teaching lengthy behavior chains. Thus, there appear to be essential distinctions between VP and VM that researchers and practitioners should consider when deciding on specific VBI tactics when the goal is to teach skills comprised of behavior chains to individuals with ASD.

Given the distinction between VM and VP, the purpose of this meta-analysis was to use the Tau- $U$ ES index to determine the magnitude of change of DLS in response to VP among individuals with ASD. Moreover, Banda et al. (2011), Gardner and Wolfe (2013), and Domire and Wolfe (2014) reported that VP had been implemented in isolation and in combination with other interventions. The data from these reviews also demonstrated that VP has frequently been used with adolescents and adults; younger participants have been less commonly included in VP studies. Finally, Banda et al. suggested that VP might be more appropriate for individuals with moderate to severe learning needs. Therefore, an additional purpose of this study was to compare the magnitude of change of DLS across potential moderators including VP with and without additional response prompting and error correction strategies, participants' ages, and participants' disabilities.

\section{Method}

\section{Definitions}

As part of this study, we compared the effects of VP alone to VP with additional response prompting or error correction procedures. VP alone was defined as VP where voice-over narration was either included or not included as part of the intervention package. This decision was made due to two reasons: (a) Researchers frequently include 
voice-over narration as part of VBI interventions (Mechling \& Collins, 2012) and (b) recent studies that demonstrated VP with or without voice-over narration resulted in marginal differences on participants' ability to learn and perform the skills being taught (e.g., Bennett, Gutierrez, \& Honsberger, 2013; Gutierrez, Bennett, McDowell, Cramer, \& Crocco, 2016). Moreover, VP alone could include reinforcement as part of the intervention package since reinforcement is needed for learning to occur (Cooper, Heron, \& Heward, 2007).

VP with additional responses prompting or error correction included those studies whereby researchers added response prompts to increase the likelihood of participants responding correctly. These tactics included prompting and fading systems (e.g., least-to-most prompting, most-to-least prompting, graduated guidance, time delay progressions) and isolated prompting strategies (e.g., physical, live modeling, gestural, and additional verbal prompts beyond any initial voice-over narration provided on the video recording) combined with the VP procedure. The prompts could be delivered as an antecedent condition or a consequence condition.

$D L S$ were defined as domestic and personal care skills (e.g., laundry skills), shopping skills (e.g., purchasing items), money skills (e.g., using an ATM), community skills (e.g., using public transportation), vocational skills (e.g., cleaning tables), functional academic skills (e.g., filling in job applications), and leisure/play skills where the focus was learning to engage in the activity (e.g., playing card games) and unrelated to communication or social skills. 


\section{Inclusion and Exclusion Criteria}

The inclusion criteria of this meta-analysis included the following: (a) The study was published in a peer-previewed journal in English between 1991-2017; (b) the study included at least one participant diagnosed with ASD; (c) the study used VP alone or VP plus response prompting or error correction as independent variables; (d) the study targeted DLS as dependent variables; (e) the study used a single case research design (SCRD); and (f) studies had to meet the Institute of Education Sciences (IES), What Works Clearinghouse (WWC), SCRD standards with or without reservations (see Appendix A). Literature reviews and qualitative case studies were excluded from the current study. Moreover, group designs were excluded from the present study as ESs of SCRD should not be combined with those from group design research for analysis (Beretvas \& Chung, 2008).

\section{Literature Search}

We conducted four systematic searches of the literature that included an examination of databases, conducting journal hand searches, reviewing previous systematic reviews on the topic, and conducting an ancestral search of articles meeting our inclusion criteria. The database search included (a) Education Resources Information Center, (b) EPSCOhost, (c) PsychINFO, and (d) PsycARTICLES. The following search terms were entered into each database: video prompt* or video model* or video instruction or video intervention or video based instruction and autis* or ASD or autism spectrum disorder or developmental disability. Next, we conducted a journal hand search for articles published between August 2016 and August 2017 to identify possible studies not yet prorogated on the databases. The journals searched included (a) Journal of Autism 
and Developmental Disorders, (b) Education and Training in Autism and Developmental Disabilities, (c) Focus on Autism and Other Developmental Disabilities, (d) Journal of Special Education Technology, and (e) Research in Autism Spectrum Disorder. Then, we examined the reference lists of previous systematic reviews of the literature that were conducted by Banda et al. (2011), Domire and Wolfe (2014), and Gardner and Wolfe (2013) as these were recent reviews on the topic. Finally, the reference sections of each study that met the inclusion criteria were searched for additional studies.

\section{Screening and Reliability of Inclusion Criteria (a)-(e)}

This initial search yielded 955 articles. To screen for potential inclusion in this meta-analysis, both authors independently read the titles and abstracts of the articles from the database and hand searches as well as the titles from the reference sections of the systematic reviews and the articles meeting the inclusion criteria. Studies that indicated the use of any VBI application (e.g., VM, VP, video self-modeling) in either the title or abstract were subjected to a full review. During the full review, both authors independently read 245 articles and applied the inclusion criteria (a)-(e). The full review resulted in 32 articles meeting the initial five inclusion criteria. Point-by-point interobserver agreement (IOA) was calculated on inclusion criteria (a)-(e) across all studies subjected to the full review. The IOA formula used was dividing the number of agreements by the number of agreements plus disagreements and multiplying by 100 (Cooper et al., 2007). Our initial IOA equaled 96.7\% (range $=60-100 \%)$. We reached consensus to include or exclude articles following the initial IOA. 


\section{Evaluation of Research Designs and Reliability of Inclusion Criterion (f)}

The authors independently examined the methodology of the remaining 32 studies, using the WWC SCRD standards (version 3.0), inclusive of the additional criteria recommended for analyzing studies that used the multiple probe design (MPD; IES, 2014). When applying the WWC SCRD standards, studies can either meet the design standards without reservations, meet the design standards with reservations, or not meet the design standards (see Appendix B). Those studies meeting the design standards with or without reservation were included in the study, while those not meeting the standards were excluded from the study. Note that in the current meta-analysis, we did not examine the strength of evidence of intervention effects to include or exclude studies as recommended by the WWC SCRD standards. Using such a standard for a meta-analysis could lead to a sampling bias. That is, excluding studies with no evidence of effects may lead to targeting only positive outcomes while ignoring less effective outcomes of the VP intervention, which may affect the overall ES estimation (Ledford, Wolery, \& Gast, 2014; Mason, Davis, Boles, \& Goodwyn, 2013).

First, we coded whether the appropriate SCRD was selected given the parameters of the study as recommended by the WWC (IES, 2014). Second, we applied the following standards when evaluating each study: (a) The intervention was systematically manipulated by the research team, (b) more than one observer collected data, (c) IOA data were collected for a minimum of $20 \%$ across conditions/phases of the study and equaled at least $80 \%$, (d) there were an appropriate number of demonstrations of effect given the SCRD selected, and (e) there were an appropriate number of data points per condition/phase. Moreover, we applied the additional design standards when evaluating 
the MPD, including that (a) The initial baseline data must overlap across tiers of the design and (b) probes must be conducted immediately before introducing the independent variable (IES, 2014). Finally, we applied a modified standard to studies whereby researchers used the adapted alternating treatments design (AATD). The IES (2014) discusses alternating treatments generically although there are specific comparison designs that have slight differences among the guidelines for implementation (see Wolery, Gast \& Ledford, 2014). According to Wolery et al. (2014), although a baseline condition can enhance the traditional alternating treatments design, it is not required. However, the AATD requires a pre-comparison baseline condition since the design allows researchers to examine differing treatment effects on non-reversible behaviors targeted for acquisition among participants (Wolery et al., 2014). Moreover, Wolery et al. stated that a minimum of three stable baseline data points was needed when researchers used the AATD to evaluate interventions. Thus, we required studies where the AATD was used to have a minimum of three baseline data points.

Point-by-point IOA was calculated for the application of the WWC SCRD standards across all analyzed studies. The IOA was calculated by dividing the number of agreements by the number of agreements plus disagreements and multiplying by 100 (Cooper et al., 2007). The IOA equaled 98.7\% (range $=85.7 \%-100 \%$ ). Moreover, an additional IOA procedure was calculated on the decision to include or exclude an article in the final analysis using the same formula, and that IOA equaled $90.6 \%$. There were three disagreements, and these were reconciled by consensus. After all inclusion criteria (a)-(f) were applied, 17 studies were accepted for analysis into the current investigation. 


\section{Extractions of Qualitative Data and Reliability}

Six qualitative data variables were independently extracted by the two authors from the included studies. These variables included (a) participant demographics (i.e., number of participants with ASD, gender, age, and disability), (b) the setting(s) in which the studies occurred, (c) the VP intervention package details (i.e., use of VP alone or VP plus response prompting or error correction), (d) the DLS targeted, (e) the SCRD used, and (f) the number of extracted A-B phase contrasts. Six of the 17 studies (35.3\%) were coded for IOA. Point-by-point IOA was calculated by dividing agreements by agreements plus disagreements and multiplying by 100 (Cooper et al., 2007). The IOA equaled 100\% for the qualitative data extraction.

\section{Extraction of Quantitative Data and Reliability}

Data from adjacent A-B phase contrasts were extracted and evaluated (Parker \& Vannest, 2012) of those participants with ASD across the included studies. Targeting a specific population, such as individuals with ASD and omitting others in meta-analytic reviews, has been reported in the literature (i.e., Hong et al., 2016; Ninci et al., 2015). Note that a control behavior condition before an intervention condition in a comparative SCRD was considered an adjacent A and B phases contrast (control condition/probes to the best treatment condition), and thus, these data were extracted and analyzed. The extraction of data points was omitted in the following situations: (a) any reversal contrasts (B1 vs. A2; Parker \& Vannest, 2012), (b) phases of participants without ASD, (c) intervention phases that did not implement VP alone or VP plus response prompting or error correction, and (d) generalization and maintenance phases/conditions as these 
data were infrequently reported in our sample. In total, $115 \mathrm{~A}-\mathrm{B}$ phase contrasts were extracted from all studies.

The data points for each A-B phase contrast were extracted by applying the rankorder method (Ninci et al., 2015; Parker et al., 2011). Using this method, the data points in a graph are ranked based on their relative order across adjacent conditions/phases. The lowest data point across two adjacent conditions/phases was ranked number one, the second lowest data point was ranked number two, and so on until the entire data series was ordered in relative rank. When two or more data points were at the same level on the graph, the same ranking was assigned.

Fifty of the 115 A-B phase contrasts (43.5\%) were coded for IOA. Point-by-point IOA was calculated by dividing the number of agreements by the number of agreements plus disagreements and multiplying by 100 (Cooper et al. 2007). For the ranked ordered data extraction, IOA equaled $98.1 \%$ (range $=50-100 \%$ ). Note that the one A-B phase contrast where IOA equaled $50 \%$ was a function of one disagreement early in the data series that resulted in disagreements in all subsequent data points for that A-B phase contrast only. Disagreements were resolved by the authors building consensus.

\section{Potential Moderators}

In addition to examining the overall effect of VP on teaching DLS to individuals with ASD, each extracted A-B phase contrast was classified based on three potential moderators: VP intervention type, participants' ages, and participants' disabilities. The VP intervention type was classified into two groups: (a) VP alone (i.e., using VP without additional intervention practices other than voice-over narration and reinforcement), and

(b) VP plus response prompting or error correction. Participants' ages were classified into 
four groups: (a) early childhood (aged 1-5 years), (b) elementary (aged 6-12 years), (c) secondary (aged 13-17 years), and (d) adult (aged 18 years and older). Participants' disabilities were classified into two groups: (a) ASD and (b) ASD plus ID.

\section{Tau- $U$ Effect Size Calculation and Analysis}

We used the Tau- $U$ non-overlap index to evaluate the omnibus ES of VP to teaching DLS to individuals with ASD and to compare the ESs of the potential moderators of VP intervention type, age, and disability (Parker, Vannest, Davis, et al., 2011). Tau- $U$ is a non-parametric statistical index that measures non-overlap among data points between A and B phases with the possibility to control for baseline phase trends (Parker, Vannest, Davis, et al., 2011). Tau- $U$ with baseline trend control was selected because it demonstrates strong statistical power compared to other non-overlap indexes and provides a conservative analysis by measuring A-B phase non-overlap data with the option of controlling for positive baseline trends in any pattern (Parker, Vannest, Davis, et al., 2011).

Ranked order data points for each adjacent A-B phase contrast $(n=115)$ were entered into the web-based Tau- $U$ calculator resulting in Tau- $U$, SETau, and confidence interval (CI) values for each contrast (Vannest, Parker, Gonen, \& Adiguzel, 2016). When the A phase showed a positive trend (i.e., Tau- $U$ was greater than or equal to 0.1 ), the A-B phase contrast was corrected to control for this trend (Camargo et al., 2016).

Next, we entered the Tau- $U$ and $S E_{T a u}$ values of each phase contrast into the WinPEPI (Version 11.6) meta-analysis software (Abramson, 2011) to obtain an omnibus ES for using VP to teach DLS to individuals with ASD. A fixed-effect model was used to weight all Tau- $U$ and $S E$ Tau values of A-B phase contrasts to estimate the omnibus ES, 
$S E$, and CIs, which was done automatically by the software (Bowman-Perrott, Burke, Zaini, Zhang \& Vannest, 2016; Parker et al., 2011). For analyzing the omnibus ES statistically, we selected a CI of $95 \%$. A value within the range of 1 to 0.93 indicated a large ES, 0.92 to 0.63 indicated a moderate ES, and 0.62 to 0 indicated a small ES (Parker et al., 2011; Parker, Vannest, Davis, et al., 2011).

In addition, we grouped all A-B phase contrasts based on potential moderators and calculated the ES for each group. For example, A-B phases coded as VP alone were grouped together and A-B phases coded as VP plus response prompting or error correction were grouped together. The Tau- $U$ and $S E T a u$ values of each A-B phase in each group were entered into WinPEPI as two independent samples to calculate an ES and SE for each group. This procedure was completed for each potential moderator comparison.

\section{Significance Test of Potential Moderators}

The potential moderators of VP intervention type (i.e., VP alone versus VP plus response prompting or error correction), participants' ages (i.e., aged 1-5 years, 6-12 years, 13-17 years, and 18 years and older), and disability category (i.e., ASD vs. ASD plus ID) were analyzed for statistical significance using CI hypothesis testing (Payton, Greenstone, \& Schenker, 2003). For these potential moderator analyses, a CI of 83.4\% was used as this gives an approximate $\alpha$ value at $p=.05$ (Payton et al., 2003). Payton et al. (2003) argued against using higher CI (e.g., 90\% or 95\%) for such significance tests as these provide restricted analyses that could miss subtle but significant differences among variables being examined. If the lower limit and upper limit of $83.4 \%$ CIs of compared ES indexes in potential moderator groups do not overlap, the groups are significantly different at the level of $p=.05$ (Payton et al., 2003). 
Overlapping CI testing in meta-analytic reviews within SCRD have been documented in the peer-reviewed literature (Bowman-Perrott et al., 2016; Camargo et al., 2016).

In addition to analyzing the overlap of CIs, the Kruskal-Wallis test was used to examine differences among the potential moderators. The Kruskal-Wallis test is a nonparametric statistical procedure that compares at least two independent samples (Kruskal \& Wallis, 1952), which was appropriate for synthesized data based on the nonparametric Tau- $U$ ES. Significance testing between moderator groups was determined at the level of $p=.05$. This statistical procedure has also been used in SCRD metaanalyses to test potential moderator variables (Hong et al., 2016; Ninci et al., 2015).

\section{Results}

We identified 17 studies meeting the inclusion criteria to be evaluated in this meta-analysis. Across these studies, there were 54 participants and $115 \mathrm{~A}-\mathrm{B}$ phase contrasts. First, we provide a qualitative analysis, and this is followed by a quantitative analysis of the data.

\section{Qualitative Data}

We evaluated the qualitative data on participants' demographics including gender, age, and disability (see Table 1). There was an equal number of secondary-aged students and adults, which outnumbered elementary-aged students and students in the early childhood category. Additionally, the majority of the participants had ASD plus ID. 
Table 1

Participant Characteristics of Paper One.

\begin{tabular}{lcc}
\hline Variables & $n$ & $\%$ \\
\hline Gender & 46 & 85.2 \\
Male & 8 & 14.8 \\
Female & & \\
Age/grade & 2 & 3.7 \\
Early childhood & 10 & 18.5 \\
Elementary & 21 & 38.9 \\
Secondary & 21 & 38.9 \\
Adult & & \\
Disability & 21 & 38.9 \\
ASD without ID & 33 & 61.1 \\
ASD plus ID &
\end{tabular}

Note. $\mathrm{ASD}=$ autism spectrum disorder. ID = intellectual disability.

We also examined the features of the studies, and these included the research sites, targeted DLS, VP intervention type, and the SCRD used by researchers (see Table 2). Most of the research was conducted at school sites; this was followed by vocational centers and university settings. Specific areas within these general sites included classrooms, kitchens, simulated living rooms, workrooms, home economic rooms, dining rooms, lobbies, laundry rooms, cafeterias, therapy/vocational rooms, and an indoor swimming pool. Additionally, the DLS of washing and laundry was targeted the most by researchers with the remaining skills receiving nearly equal attention among the accepted studies. Furthermore, the majority of studies focused on VP alone versus VP with response prompting or error correction. Lastly, researchers used a variety of SCRD 
among the included studies; the AATD and the MPD accounted for the majority of the designs.

Table 2

Features of the Studies Included in Paper One.

\begin{tabular}{|c|c|c|}
\hline Variables & $n$ & $\%$ \\
\hline \multicolumn{3}{|l|}{ Research sites } \\
\hline Schools & 11 & 64.7 \\
\hline Vocational centers & 4 & 23.5 \\
\hline University & 2 & 11.8 \\
\hline \multicolumn{3}{|l|}{ Daily living skills targeted } \\
\hline Washing/laundry & 6 & 35.3 \\
\hline Cooking & 3 & 17.6 \\
\hline $\begin{array}{l}\text { Putting away items, cleaning, folding, } \\
\text { setting table }\end{array}$ & 3 & 17.6 \\
\hline Play/leisure & 3 & 17.6 \\
\hline Office/vocational & 2 & 11.8 \\
\hline \multicolumn{3}{|l|}{ Intervention type } \\
\hline Video prompting alone & 12 & 70.6 \\
\hline $\begin{array}{l}\text { Video prompting plus response } \\
\text { prompting/error correction }\end{array}$ & 5 & 29.4 \\
\hline \multicolumn{3}{|l|}{ Research designs } \\
\hline Adapted alternating treatments design & 5 & 29.4 \\
\hline Multiple probe design & 5 & 29.4 \\
\hline Multiple baseline design & 3 & 17.6 \\
\hline Combination designs & 4 & 23.5 \\
\hline
\end{tabular}




\section{Quantitative Data}

We analyzed the omnibus ES of using VP to teach DLS to individuals with ASD. Next, we conducted analyses on the aggregate ESs based on VP intervention type, participants' ages, and participants' disabilities. Figure 2 contains a forest plot with the number of participants per potential moderator, the number of A-B phase contrasts analyzed per potential moderator, Tau- $U$ values, $S E$, CI, and the Kruskal-Wallis test results (see Figure 2).

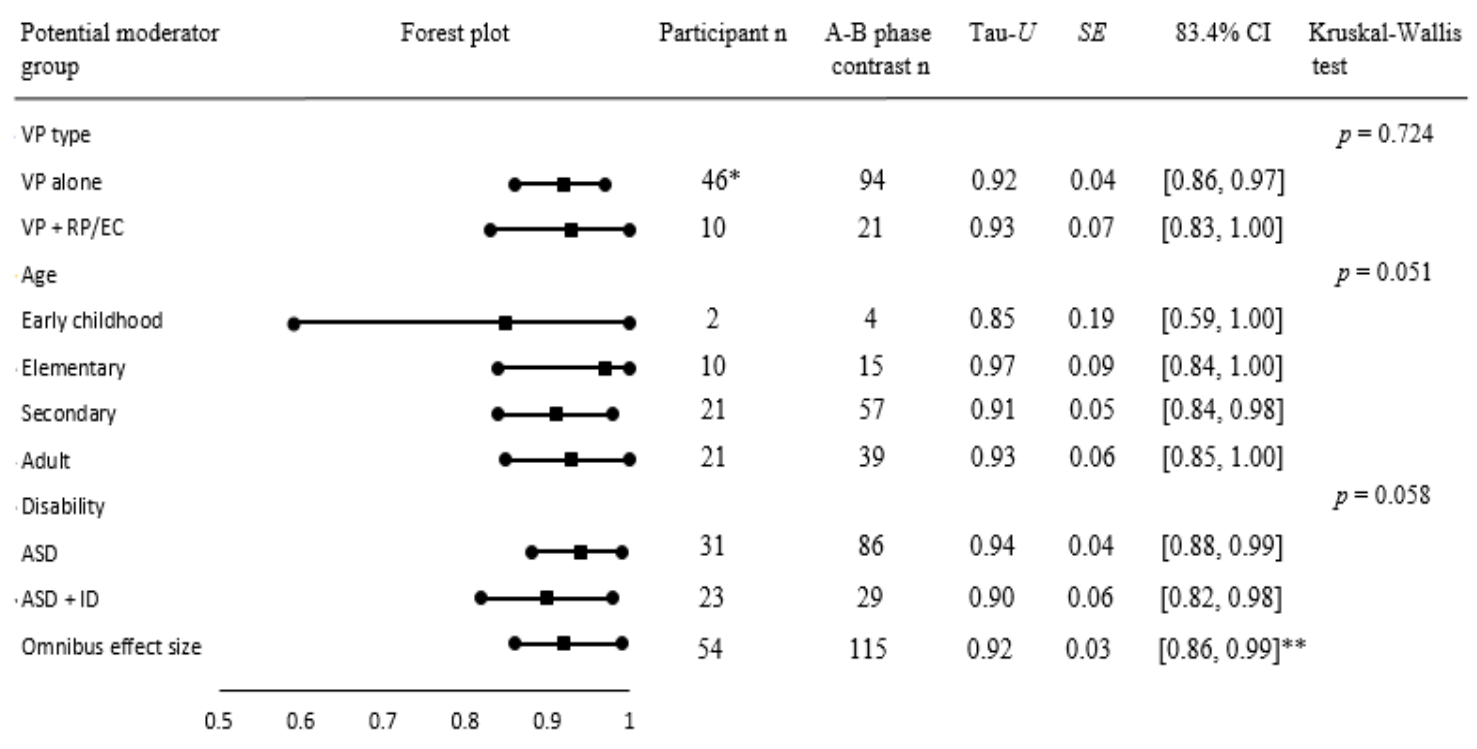

Figure 2. Forest plot of omnibus Tau-U and potential moderator analysis. ASD $=$ autism spectrum disorder; $\mathrm{CI}=$ confidence interval; closed circles = lower limit, upper limit; closed squares = Tau-U value; $\mathrm{EC}=$ error correction; $\mathrm{ID}=$ intellectual disability; $\mathrm{RP}=$ response prompting; $\mathrm{SE}=$ standard error; $\mathrm{VP}=$ video prompting. *Two participants used both VP alone and VP plus response prompting/error correction in different tasks. ${ }^{*}$ The lower limit and upper limit values are based on $95 \%$ CI.

Omnibus ES. The omnibus Tau- $U$ was $0.92\left(S E=.03, \mathrm{CI}_{95}=[0.86,0.99]\right)$. This finding represents a moderate omnibus ES of using VP to teach DLS to individuals with ASD (see Figure 2). A total of $79.1 \%$ of A-B phase contrasts fell within the range of a 
large ES, $14.8 \%$ of A-B phase contrasts were within the range of a moderate ES, and $6.1 \%$ of A-B phase contrasts were in the small ES range.

VP intervention type. The Tau- $U$ value of the VP alone group indicated a moderate $\mathrm{ES}(\mathrm{ES}=.92, S E=.04, \mathrm{CI} 83.4=[0.86,0.97])$, while the Tau- $U$ value of the VP plus response prompting or error correction group showed a large ES $(\mathrm{ES}=.93, S E=.07$, CI83.4 $=[0.83,1])$. Confidence interval testing at $83.4 \%$ showed overlap between these variables; therefore, there were no significant differences between the groups (Payton et al., 2003). Additionally, the Kruskal-Wallis test showed no significant differences across the two groups ( $p=.724$; see Figure 2).

Participants' ages. The Tau- $U$ value of the early childhood group was within the range of a moderate $\mathrm{ES}(\mathrm{ES}=.85, S E=.19, \mathrm{CI} 83.4=[0.59,1])$. For the elementary group, the Tau- $U$ value fell within the range of a large $\mathrm{ES}(\mathrm{ES}=.97, S E=.09, \mathrm{CI} 83.4=[0.84,1])$. When looking at the secondary group, the Tau- $U$ value was in the range of a moderate ES $(\mathrm{ES}=.91, S E=.05, \mathrm{CI} 83.4=[0.84,0.98])$. Finally, the Tau- $U$ value of the adult group was in the range of a large $\mathrm{ES}(\mathrm{ES}=.93, \mathrm{SE}=.06, \mathrm{CI} 83.4=[0.85,1])$. An examination of $\mathrm{CI}$ at 83.4\% for significance testing showed overlap across each age-group, and thus, there were no significant differences among these groups of participant (Payton et al., 2003). Moreover, the Kruskal-Wallis test revealed no significant differences across all age groups ( $p=.051$; see Figure 2).

Participants' disabilities. The Tau- $U$ value of the ASD group was within the range of a large $\mathrm{ES}(\mathrm{ES}=.94, S E=.05, \mathrm{CI} 83.4=[0.87,1])$, and the Tau- $U$ value of the ASD plus ID group was within the range of a moderate $\mathrm{ES}(\mathrm{ES}=.91, S E=0.05, \mathrm{CI} 83.4=$ $[0.84,0.98])$. Confidence interval analysis at $83.4 \%$ revealed an overlap between the two 
groups indicating no significant differences (Payton et al., 2003). Additionally, the Kruskal-Wallis test revealed no significant differences between the groups $(p=.056$; see Figure 2).

\section{Discussion}

The purpose of this study was to conduct a meta-analysis of the SCRD data on using VP to teach DLS to individuals with ASD. An additional objective was to analyze the moderators of VP intervention type, participants' ages, and participants' disabilities. Our findings revealed a moderate omnibus Tau- $U$ score in the upper range of that category, demonstrating that VP is an effective strategy for teaching DLS to students with ASD. This finding is supported by, and extends, the past systematic reviews of the literature conducted by Banda et al. (2011), Gardner and Wolfe (2013), and Domire and Wolfe (2014). An analysis of the potential moderators showed Tau- $U$ values that ranged from a moderate to a large ES, with most scores falling within the large ES range. Moreover, there were no significant differences among the moderators within each category indicating that $\mathrm{VP}$ is an effective intervention across these variables.

The current results differ from those reported in a recent meta-analysis by Hong et al. (2016) on the effects of VM (inclusive of VP) on teaching DLS skills to individuals with ASD. Our overall Tau- $U$ value was higher than that reported by Hong et al., and our moderator Tau- $U$ values were higher within each age group and among participants with ASD with and without a comorbid ID. In two instances, the early childhood and the secondary-aged group of participants, our Tau- $U$ scores nearly doubled those reported in the Hong et al. meta-analysis. These differences suggest the possibility that their findings might have underestimated the effects of VP by combining this 
methodology with VM. Indeed, VM and VP are distinct strategies that should be differentially applied depending on the parameters in which the procedures are used (e.g., participant severity of disability and length of the behavior chain targeted; Banda et al., 2011; Cannella-Malone et al., 2011).

\section{Implications}

The findings from the current study suggest that VP is a viable strategy for teaching DLS to specific individuals with ASD. Our data indicated that VP is an effective intervention when used with secondary-aged and adult students. Thus, teachers and related service providers should use this strategy with confidence when teaching these skills to this population of students.

The data also demonstrated that the strategy was effective for elementary-aged students. However, there were few participants in this age group. Consequently, we recommend that practitioners use caution when using VP to teach DLS to students of this age group until more data are published in the peer-reviewed literature.

Unfortunately, there is not enough evidence at this time to suggest the use of VP to teach DLS to young children with ASD (aged five years and younger). There were only two participants in the studies meeting our inclusion criteria. Although the Tau- $U$ score for this age group was within the moderate ES range, one of these individual's score fell within the small ES category. Clearly, more evidence is needed among the early childhood and elementary-aged populations before researchers can make a stronger recommendation related to the utility of VP when used to teach DLS, and this finding is supported by the systematic reviews conducted by Banda et al. (2011), Gardner and Wolfe (2013), and Domire and Wolfe (2014). 
In addition to the effects of VP on teaching DLS to learners among various age categories, our data also showed that VP was effective when teaching these skills to individuals with ASD with and without a secondary diagnosis of ID. Nonetheless, our findings showed that students with a comorbid diagnosis of ASD and ID might need additional response prompting or error correction. In those studies where supplementary procedures were required, participants tended to be adolescents or adults with the majority of these individuals having ASD with ID (e.g., Cannella-Malone, Wheaton, Wu, Tullis, \& Park, 2012; Gardner \& Wolfe, 2015; Goodson, Sigafoos, O’Reilly, Cannella, \& Lancioni, 2007). Thus, educators and similar professionals should consider the use of additional response prompts or error correction strategies to help the students. However, to achieve independence, practitioners and caregivers must be aware of these added procedures and plan to fade these tactics so that learners can (a) emit the DLS without response prompting or error correction or (b) can access the VP system to support their learning needs without adult support (Banda et al., 2011).

\section{Limitations}

Several limitations should be considered when interpreting the results of this meta-analysis. First, as with any systematic review and meta-analysis, it is possible that additional studies could have been identified but were not given our inclusion criteria. Second, we examined the peer-reviewed SCRD data and excluded theses and dissertations. This exclusion could increase the threat of publication bias in the current study. Third, we excluded some studies from the present analysis due to our modification made to the WWC SCRD standards related to the AATD. Specifically, for those studies where the AATD was used, we required a sufficient number of baseline data points based 
on other WWC SCRD baseline standards given that Wolery et al. (2014) called for baseline data points when researchers use the AATD. This modification required us to exclude some studies using comparative SCRD. Nevertheless, researchers should consider this modification given the differences between the alternating treatments design and AATD parameters used to assess the internal validity of studies. Fourth, there were very few participants in the early childhood category. Thus, conclusions regarding this age-group are limited. Fifth, generalization and maintenance data were infrequently reported among the included studies. Therefore, we excluded these conditions from our analysis, which could limit our understanding of the generalized and long-term effects of VP on DLS acquisition.

\section{Future Research}

The results of this meta-analysis contributed to the literature in several meaningful ways; the findings also highlighted areas in need of additional research. Overall, more research is needed on the effects of VP on DLS instruction considering that some studies did not meet specific WWC SCRD standards. We encourage future researchers to consider these standards when designing and conducting studies on this topic.

In addition to increasing the overall volume of studies meeting research design standards, specific research topics related to VP and DLS instruction are needed. First, we suggest that researchers study the effects of VP on DLS acquisition with younger children. Additional meta-analyses should be conducted once enough data have been generated by these individual studies to examine the omnibus ES and potential moderators among this age-group. Next, researchers should study the degree of 
maintenance and the generalized effects of the VP intervention across age groups and DLS. There was a paucity of data on these effects in the current study. Furthermore, additional research is needed exploring the effects of VP on play/leisure and vocational skills given these behavior sets were less frequently examined when compared to domestic skills. We also recommend that researchers investigate the effects of VP on DLS in authentic environments since most studies that met our inclusion criteria were conducted in contrived settings. Finally, we suggest that researchers examine other potential moderators not studied in this meta-analysis as this information can inform research and practice.

\section{Conclusion}

In this study, we analyzed the SCRD data on using VP to teach DLS to individuals with ASD. Overall, the tactic was moderately to highly effective when applied to teach DLS to this population. There were no significant differences among potential moderators of VP with or without additional response prompting or error correction, participants' ages, or participants' disabilities. Although further research is needed on the effects of VP on DLS acquisition - particularly with younger populations as well as in authentic environments - the quantitative data from this analysis adds to the previous qualitative systematic reviews on the effectiveness of VP for teaching DLS to individuals with ASD. 


\section{References (Chapter II)}

References marked with an asterisk indicates studies included in the meta-analysis.

Abramson, J.H. (2011). WINPEPI updated: Computer programs for epidemiologists, and their teaching potential. Epidemiologic Perspectives \& Innovations. Retrieved from http://www.brixtonhealth.com/pepi4windows.html.

American Psychiatric Association. (2013). Diagnostic and statistical manual of mental disorders (5th ed.). Arlington, VA: Author.

Banda, D. R., Dogoe, M. S., \& Matuszny, R. (2011). Review of video prompting studies with persons with developmental disabilities. Education and Training in Autism and Developmental Disabilities, 46, 514-527.

*Bennett, K. D., Crocco, C., Loughrey, T. O., \& McDowell, L. S. (2017). Effects of video prompting without voice-over narration among students with autism spectrum disorder. Behavioral Development Bulletin, 22(1), 147-158. doi: 10.1037/bdb0000058.

Bennett, K. D., \& Dukes, C. (2014). A systematic review of teaching daily living skills to adolescents and adults with autism spectrum disorder. Review Journal of Autism and Developmental Disorders, 1(1), 2-10. doi: 10.1007/s40489-016-0075-z.

*Bennett, K. D., Gutierrez, A., \& Honsberger, T. (2013). A comparison of video prompting with and without voice-over narration on the clerical skills of adolescents with autism. Research in Autism Spectrum Disorders, 7(10), 12731281. doi: 10.1016/j.rasd.2013.07.013

*Bennett, K. D., Gutierrez, A., \& Loughrey, T. (2016). Comparison of screen sizes when using video prompting to teach adolescents with autism. Education and Training in Autism and Developmental Disabilities, 51(4), 379-390.

Beretvas, S. N., \& Chung, H. (2008). A review of single-subject design meta-analyses: Methodological issues and practice. Evidence-Based Communication Assessment and Intervention, 2, 129-141. doi: 10.1080/17489530802446302.

Bowman-Perrott, L., Burke, M. D., Zaini, S., Zhang, N., \& Vannest, K. (2016). Promoting positive behavior using the Good Behavior Game: A meta-analysis of single case research. Journal of Positive Behavior Interventions, 18(3), 180-190. doi: $10.1177 / 1098300715592355$.

Camargo, S. P. H., Rispoli, M., Ganz, J., Hong, E. R., Davis, H., \& Mason, R. (2016). Behaviorally based interventions for teaching social interaction skills to children 
with ASD in inclusive settings: A meta-analysis. Journal of Behavioral Education, 25(2), 223-248. doi: 10.1007/s 10864-015-9240-1.

*Cannella-Malone, H. I., Fleming, C., Chung, Y., Wheeler, G. M., Basbagill, A. R., \& Singh, A. H. (2011). Teaching daily living skills to seven individuals with severe intellectual disabilities: A comparison of video prompting to video modeling. Journal of Positive Behavior Interventions, 13, 144-153. doi: 10.1177/1098300710366593.

*Cannella-Malone, H. I., Wheaton, J. E., Wu, P., Tullis, C. A., \& Park, J. H. (2012). Comparing the effects of video prompting with and without error correction on skill acquisition for students with intellectual disability. Education and Training in Autism and Developmental Disabilities, 47(3), 332-344.

*Cannella-Malone, H. I., Brooks, D. G., \& Tullis, C. A. (2013). Using self-directed video prompting to teach students with intellectual disabilities. Journal of Behavioral Education, 22(3), 169-189. doi: 10.1007/s10864-013-9175-3

*Cannella-Malone, H., Miller, O., Schaefer, J. M., Jimenez, E. D., Page, E. J., \& Sabielny, L. M. (2016). Using video prompting to teach leisure skills to students with significant disabilities. Exceptional Children, 82(4), 463-478. doi: 10.1177/0014402915598778.

*Cannella-Malone, H., O’Reilly, M., Edrisinha, C., Sigafoos, J., \& Lancioni, G. E. (2006). Comparing video prompting to video modeling for teaching daily living skills to six adults with developmental disabilities. Education and Training in Developmental Disabilities, 41, 344-356.

Carothers, D. E., \& Taylor, R. L. (2008). How teachers and parents can work together to teach daily living skills to children with autism. Focus on Autism and Other Developmental Disabilities, 19(2), 102-104. doi: $10.1177 / 10883576040190020501$.

Cooper, J. O., Heron, T. E., \& Heward, W. L. (2007). Applied behavior analysis (2 ${ }^{\text {nd }}$ ed.). Upper Saddle, NJ: Pearson.

Domire, S. C., \& Wolfe, P. (2014). Effects of video prompting techniques on teaching daily living skills to children with autism spectrum disorders: A review. Research and Practice for Persons with Severe Disabilities, 39(3), 211-226. doi: 10.1177/1540796914555578.

*Gardner, S. J., \& Wolfe, P. S. (2015). Teaching students with developmental disabilities daily living skills using point-of-view modeling plus video prompting with error correction. Focus on Autism and Other Developmental Disabilities, 30(4), 195207. doi:10.1177/1088357614547810. 
Gardner, S., \& Wolfe, P. (2013). Use of video modeling and video prompting interventions for teaching daily living skills to individuals with autism spectrum disorders: A review. Research and Practice for Persons with Severe Disabilities, 38(2), 73-87. doi: 10.2511/027494813807714555.

Gonzalez, K., Cassel, T., Durocher, J. S., \& Lee, A. (2017). Overview of autism spectrum disorders. In E. Amanda Boutot (Ed.), Autism Spectrum Disorders: Foundations, characteristics, and effective strategies ( $2^{\text {nd }}$ ed., pp. 1-20). Boston, MA: Pearson.

*Goodson, J., Sigafoos, J., O’Reilly, M., Cannella, H., \& Lancioni, G. E. (2007). Evaluation of a video-based error correction procedure for teaching a domestic skill to individuals with developmental disabilities. Research in Developmental Disabilities, 28(5), 458-467. doi: 10.1016/j.ridd.2006.06.002.

*Gutierrez, A., Bennett, K. D., McDowell, L. S., Cramer, E. D., \& Crocco, C. (2016). Comparison of video prompting with and without voice-over narration: A replication with young children with autism. Behavioral Interventions, 31(4), 377389. doi: 10.1002/bin.1456.

Hong, E. R., Ganz, J. B., Mason, R., Morin, K., Davis, J. L., Ninci, J., ... \& Gilliland, W. D. (2016). The effects of video modeling in teaching functional living skills to persons with ASD: A meta-analysis of single-case studies. Research in Developmental Disabilities, 57, 158-169. doi: 10.1016/j.ridd.2016.07.001

Institute of Education Sciences, U.S. Department of Education, National Center for Education Evaluation and Regional Assistance (2014). The what works clearinghouse procedures and standards handbook, Version 3.0. Retrieved from https://ies.ed.gov/ncee/wwc/FWW.

Kruskal, W. H., \& Wallis, A. W. (1952). Use of ranks in one-criterion variance analysis. Journal of the American Statistical Association, 47, 583-621. doi: $10.2307 / 2280779$.

Ledford, J. R., Wolery, M., \& Gast, D. L. (2014). Controversial and critical issues in single case research. In D. L. Gast \& J. R. Ledford (Eds.), Single case research methodology: Applications in special education and behavioral sciences $\left(2^{\text {nd }}\right.$ ed., pp. 377-396). New York, NY: Routledge.

Mason, R. A., Davis, H. S., Boles, M. B., \& Goodwyn, F. (2013). Efficacy of point-ofview video modeling: A meta-analysis. Remedial and Special Education, 34(6), 333-345. doi: 10.1177/0741932513486298.

*Mechling, L. C., Ayres, K. M., Bryant, K. J., \& Foster, A. L. (2014). Comparison of the effects of continuous video modeling, video prompting, and video modeling on 
task completion by young adults with moderate intellectual disability. Education and Training in Autism and Developmental Disabilities, 49(4), 491-504.

*Mechling, L. C., Ayres, K. M., Foster, A. L., \& Bryant, K. J. (2013). Comparing the effects of commercially available and custom-made video prompting for teaching cooking skills to high school students with autism. Remedial \& Special Education, 34(6), 371-383. doi: 10.1177/0741932513494856.

Mechling, L. C., \& Collins, T. S. (2012). Comparison of the effects of video models with and without verbal cueing on task completion by young adults with moderate intellectual disability. Education and Training in Autism and Developmental Disabilities, 47(2), 223-235.

*Mechling, L. C., \& Gustafson, M. R. (2008). Comparison of static picture and video prompting on the performance of cooking-related tasks by students with autism. Journal of Special Education Technology, 23(3), 31-45.

Ninci, J., Neely, L. C., Hong, E. R., Boles, M. B., Gilliland, W. D., Ganz, J. B., ... \& Vannest, K. J. (2015). Meta-analysis of single-case research on teaching functional living skills to individuals with ASD. Review Journal of Autism and Developmental Disorders, 2(2), 184-198. doi: 10.1007/s40489-014-0046-1.

Parker, R. I., \& Vannest, K. J. (2012). Bottom-up analysis of single-case research designs. Journal of Behavioral Education, 21(3), 254-265. doi: 10.1007/s10864012-9153-1.

Parker, R. I., Vannest, K. J., \& Davis, J. L. (2011). Effect size in single case research: A review of nine nonoverlap techniques. Behavior Modification, 35, 303-322. doi: $10.1177 / 0145445511399147$.

Parker, R. I., Vannest, K. J., Davis, J. L., \& Sauber, S. B. (2011). Combining nonoverlap and trend for single-case research: Tau-U. Behavior Therapy, 42(2), 284-299. doi: 10.1016/j.beth.2010.08.006.

Payton, M. E., Greenstone, M. H., \& Schenker, N. (2003). Overlapping confidence intervals or standard error intervals: What do they mean in terms of statistical significance? Journal of Insect Science, 3(4), 1-6.

*Sigafoos, J., O’Reilly, M., Cannella, H., Edrisinha, C., de la Cruz, B., Upadhyaya, M., ...Young, D. (2007). Evaluation of a video prompting and fading procedure for teaching dish washing skills to adults with developmental disabilities. Journal of Behavioral Education, 16(2), 93-109. doi: 10.1007/S10864-006-9004-z

*Sigafoos, J., O'Reilly, M., Cannella, H., Upadhyaya, M., Edrisinha, C., Lancioni, G. E., ...Y Young, D. (2005). Computer-presented video prompting for teaching 
microwave oven use to three adults with developmental disabilities. Journal of Behavioral Education, 14, 189-201. doi: 10.1007/s10864-005-6297-2.

Travers, B. G, Klinger, M. R., \& Klinger, L. G. (2011). Attention and working memory in ASD. In D. Fein (Ed.), The neuropsychology of autism (pp. 161-184). New York, NY: Oxford University Press.

Vannest, K. J., Parker, R. I., \& Gonen, O., \& Adiguzel, T. (2016). Single-case research: Web-based calculators for SCR analysis (Version 2.0) [Web-based application]. College Station, TX: Texas A\&M University. Retrieved from http://www.singlecaseresearch.org.

Wolery, M., Gast, D. L., \& Ledford, J. R. (2014). Comparison designs. In D. L. Gast \& J. R. Ledford (Eds.), Single case research methodology: Applications in special education and behavioral sciences ( $2^{\text {nd }}$ ed., pp. 377-396). New York, NY: Routledge.

*Yanardag, M., Akmanoglu, N., \& Yilmaz, I. (2013). The effectiveness of video prompting on teaching aquatic play skills for children with autism. Disability and Rehabilitation, 35(1), 47-56. doi: 10.3109/09638288.2012.687030. 


\title{
CHAPTER III
}

\section{PAPER TWO: A COMPARISON OF VIDEO PROMPTING AND LEAST-TO- MOST PROMPTING FOR TEACHING OFFICE-RELATED TASKS TO CHILDREN WITH AUTISM AND INTELLECTUAL DISABILITY}

\author{
Mashal S. Aljehany and Kyle D. Bennett
}

\section{Introduction}

Children with developmental disabilities (DD), including those with autism spectrum disorder (ASD) and intellectual disability (ID) have experienced difficulty completing complex tasks involving multiple steps (Kraijer, 2000; MacDuff, Krantz, \& McClannahan, 1993). Daily living skills (DLS) are frequently comprised of numerous steps, and the development of these skills are essential. Indeed, poor DLS can result in a lack of independence, decreased quality of life, and lead to employment challenges for individuals with DD (Domire \& Wolfe, 2014; Hayden, 1997; Hendricks 2010).

Recent evidence indicates that video-based instruction (VBI) has been effective with improving a variety of DLS among individuals with DD (Bellini \& Akullian 2007; Wong et al., 2015). There are several variations of VBI including video modeling (VM) and video-self modeling. Broadly, these VBI formats involve showing a video clip of an entire task to a learner before requiring him or her to perform the task (Bellini \& Akullian, 2007). An additional variant of VBI is video prompting (VP), which involves the presentation of a single task step before requesting the student to imitate what he or she has observed until the entire task has been attempted or completed (Banda, Dogoe, \& Matuszny, 2011). 
A frequently used prompting and prompt fading strategy that has been added to VP treatment packages is least-to-most prompting (Banda et al., 2011). Researchers have demonstrated successful use of VP with least-to-most prompting to teach leisure skills (e.g., Cannella-Malone et al., 2016), job-related skills (e.g., Van Laarhoven, Johnson, Van Laarhoven-Myers, Grider, \& Grider, 2009), and washing dishes (Gardner \& Wolfe, 2015 ) to children and adults with DD. Least-to-most prompting involves an instructor providing a hierarchy of prompts starting from the least intrusive to the most intrusive prompt (Wolery, Ault, \& Doyle, 1992; Wong et al., 2015). The purpose of least-to-most prompting is to increase the correct responses of students by providing additional cues before or during the presence of a discriminative stimulus, and then gradually fading these additional cues until the learner responds to the discriminative stimulus alone (Wolery et al., 1992).

Recently, researchers began to compare the effects of VBI to least-to-most prompting when teaching DLS to individuals with DD to determine the most effective and efficient method. In one such study, Ulke-Kurkcuoglu (2015) examined the effectiveness and efficiency of least-to-most prompting versus VM to help three young children with ASD during play activities. The researcher indicated no difference between the two interventions regarding effects, maintenance, and generalization. However, leastto-most prompting was noted to be more efficient than VM for two of the three participants.

In another study, Cannella-Malone, Chan, and Jimenez (2017) compared the effects of self-directed VP with error correction to least-to-most prompting when teaching vocational skills (i.e., paper collating, folding, and photocopying) for two adults 
with ID. The researchers reported that both interventions were effective with nearly the same level of efficiency.

Together, the research by Ulke-Kurkcuoglu (2015) and Cannella-Malone et al. (2017) extended the literature by demonstrating that both types of VBI (i.e., VM and VP) were as effective as least-to-most prompting. Such findings provided instructional options for practitioners in the field (Cannella-Malone et al., 2017). However, there were limitations to both studies that warrant consideration. First, neither research team measured a control behavior during the baseline or comparison phases of the study. Moreover, a best treatment phase was not used in either study. The lack of both of these design features make it difficult to rule out the possibility of multiple treatment interference, a potential confounding variable when using the adapted alternating treatments design, which was used in both studies (Wolery, Gast, \& Ledford, 2014). Furthermore, Cannella-Malone et al. added a model as a potential discriminative stimulus prior to implementing least-to-most prompting. Thus, it is conceivable that this research team compared VP to live modeling (followed by least-to-most prompting to boost participant performance), which could make the comparison between VP and least-tomost prompting unclear.

There is a need to compare the effects of VP (implemented without additional prompts) to least-to-most prompting (implemented without additional instructional procedures) to understand if there is a difference in terms of effectiveness or efficiency between these two approaches. Such information can guide the educational practices of teachers and related services providers when designing instructional programs for adolescents with ASD and ID. 
Therefore, the purpose of this study was to compare the effectiveness and efficiency of VP alone to least-to-most prompting alone on teaching office-related tasks to adolescents with ASD and ID. An additional purpose was to examine the social validity of both interventions considering the perspectives of the student participants and their teachers.

\section{Method}

\section{Participants}

Three middle school-aged children with ASD and ID participated in this study. Participants were chosen according to the following criteria: (a) had a diagnosis of ASD; (b) had normal hearing, vision, and motor ability; (c) could attend to video clips for at least one minute; (d) followed simple one-step directions; and (e) demonstrated difficulty with DLS, including vocational skills. Note that all participant characteristic data were obtained from direct observations using Childhood Autism Rating Scale-Second Edition (CARS-2; Schopler, Reichler, \& Rochen-Renner, 1988) as well as conducting parent, teacher, and school administrator interviews and questionnaires.

Leo was a 13-year-old male with ASD, Down syndrome, and moderate ID. He had difficulty with DLS, and he required help from others to perform many of these skills independently. Leo was able to imitate gross and fine motor movements. He could follow a simple two-step direction, and he could speak using verbal approximations.

Academically, he could read some sight words, but he generally required prompting from others to complete learning tasks.

Nadia was a 12-year, 9-month old female. She experienced ASD, Down syndrome, and moderate ID. Nadia demonstrated difficulty with DLS, and she required 
assistance from others to complete these tasks. Nadia was able to imitate gross and fine motor movements. She could also follow two-step directions. She could communicate with others using vocal verbal behavior, but in incomplete sentences. Although she experienced difficulties in reading a sentence and counting numbers, she showed progress in these areas throughout the academic year. She demonstrated no behavior problems in the classroom.

Amanda was a 15-year-old female with ASD and moderate ID. She demonstrated low levels of DLS and vocational skills, and she needed assistance from others to perform many of these skills independently. Amanda could imitate multi-step behaviors, and she could follow simple multiple-step directions. She could speak in complete sentences and engage in a conversation of at least two exchanges. Amanda could read a short passage; however, she had difficulty maintaining on-task behavior while learning.

\section{Setting}

The study was conducted in a private, separate day school for students with DD in the southeast region of the United States. Sessions were conducted in an unoccupied classroom measuring $5 \times 6 \mathrm{~m}$. The room contained tables, chairs, cabinets, a sink, a fish tank, overhead projector, a dry erase board, posters, and various academic supplies. No student activities occurred in the classroom during sessions.

\section{Independent and Dependent Variables}

We compared the effects of VP alone and least-to-most prompting alone to teach three office-related tasks served as dependent variables in this study. These tasks included making a photocopy, making a label tag for a file folder, and sending a fax. A task analysis of these skills is presented in Table 3. 
Table 3

Task Analyses of Target Tasks and Video Clip (Duration in Seconds).

\begin{tabular}{|c|c|c|c|c|c|}
\hline Copying a paper & Duration & Labeling a file & Duration & Faxing a paper & Duration \\
\hline 1. Take the folder from the & 18 & 1. Take the folder from the & 20 & 1. Press "Fax" button & 11 \\
\hline basket and put it in front of & & basket & & 2. Take the folder from the & 16 \\
\hline you & & 2. Turn on the device & 15 & basket and put it in front of you & \\
\hline 2. Turn on the printer & 18 & 3. Press A & 12 & 3. Open the folder & 12 \\
\hline 3. Open the lid & 14 & 4. Press R & 12 & 4. Take and put the paper facing & 19 \\
\hline 4. Open the folder & 14 & 5. Press $\mathrm{T}$ & 13 & down in the feeder & \\
\hline 5. Take and put the original & 22 & 6. Press the Print button & 13 & 5. Enter the 1st three fax & 15 \\
\hline facing down on the glass & & 7. Press the Enter button & 16 & numbers (\#\#) & \\
\hline correctly aligned & & 8. Squeeze the cutter & 16 & 6. Enter the 2nd three fax & 16 \\
\hline 6. Close the lid & 15 & button on the side & & numbers (\#\#) & \\
\hline 7. Press the Black button & 22 & 9. Take the label & 14 & 7. Enter the final four fax & 15 \\
\hline 8. Put the copy in the folder & 18 & 10. Remove the paper & 29 & numbers (\#\#\#) & \\
\hline 9. Open the lid & 14 & backing from the label & & 8. Press the Start button & 16 \\
\hline $\begin{array}{l}\text { 10. Take the original and put it } \\
\text { in the folder }\end{array}$ & 19 & $\begin{array}{l}\text { 11. Put the label on the } \\
\text { folder }\end{array}$ & 15 & $\begin{array}{l}\text { 9. Take and put the paper in the } \\
\text { folder }\end{array}$ & 16 \\
\hline 11. Close the folder & 13 & 12. Throw away the paper & 17 & 10. Take and put the report in & 15 \\
\hline 12. Close the lid & 14 & backing in the trash & & the folder & \\
\hline \multirow[t]{3}{*}{ 13. Put the folder in the basket } & 16 & 13. Turn off the label & 14 & 11. Close the folder & 12 \\
\hline & & device & & 12. Put the folder in the basket & 14 \\
\hline & & $\begin{array}{l}\text { 14. Put the folder in the } \\
\text { basket }\end{array}$ & 17 & & \\
\hline Total Duration & $3: 37$ & & $3: 23$ & & $2: 57$ \\
\hline
\end{tabular}

\section{Materials}

Materials used during photocopying sessions were a Canon MG 3022 printer loaded with blank paper $(8.5 " \times 11$ "), an office basket $(20 \times 10 \mathrm{~cm})$, a file folder in the office basket, and an original paper $(8.5 " \times 11 ")$ to be copied located inside the file folder. Materials used during label making sessions were a Brother label device (PT-D-210 model) with white plastic labels, an office basket $(20 \times 10 \mathrm{~cm})$, a file folder in the office basket, and a paper tag showing the word, "ART" to be printed. Materials used during faxing sessions were a fax machine (Brother IntelliFAX High-Speed Laser), an office basket $(20 \times 10 \mathrm{~cm})$, a file folder in the office basket, an original paper $\left(8.5 " \times 11^{\prime \prime}\right)$ to be faxed located in the file folder, a fax report paper, and a white sticker above the keyboard of the fax machine showing a phone number to be used. An Apple 
iPad Air 2 (9.7" screen size) was used to present video clips during the VP condition of the study. A stopwatch, data collection forms, and reinforcers were used as needed throughout the experiment.

\section{Video Clip Development}

Using the VP intervention required developing video clips for each step in the task analysis. A female adult performing each step in a task analysis was filmed using an Apple iPad Air 2. Each task step was filmed from the adult model's perspective showing the model's hands and arms while performing the task step. Each video clip was filmed as follows: a verbal direction, Watch this video, was given; the model performed a task step while a voice-over direction was simultaneously presented (e.g., Press the print button); and the final verbal direction, Now, you do it, was delivered at the end of the video clip.

The photocopy task included 13 video clips with total duration of $3 \mathrm{~min}, 37 \mathrm{~s}$; individual video clips ranged from 13-22 s. The label making task included 14 video clips with total duration of $3 \mathrm{~min}, 23 \mathrm{~s}$; individual video clips ranged from 12-29 s. The faxing task included 12 video clips with a total duration of 2 min, $57 \mathrm{~s}$; individual video clips ranged from 11-19 s.

\section{Data Collection and Analysis}

By using an event recording system, we recorded the percent of task analysis steps completed correctly and independently by the participants (see Appendix C). A correct response was recorded when the participants (a) started performing the step within $5 \mathrm{~s}$ of receiving the direction provided on the video clip (when VP was used) or by the researcher (when least-to-most prompting was used), and (b) completed the step 
within $30 \mathrm{~s}$ of starting the task. An incorrect response was recorded when a participant did not meet these criteria or made a topographical error while attempting to complete a task step. Percent correct was calculated by dividing the number of steps correct by the total number of steps and multiplying by 100 (Ayres \& Ledford, 2014).

Duration of teaching time was also collected by the first author. That researcher started a stopwatch at the beginning of a session and stopped it at the end of the session. Total duration was calculated by adding together the duration for each session (Ayres \& Ledford, 2014).

For data analysis and determination of effectiveness, we conducted a visual analysis of the data including an evaluation of the level, trend, variability, immediacy of effect, and separation of data paths. Visual analysis of data is standard practice in behavior analytic studies (Gast \& Spriggs, 2014). Additionally, the means and ranges of participants responding across all conditions and phases were analyzed. Finally, we conducted a post hoc analysis of sessions-to-criterion, percent of errors, and total duration of teaching time to analyze the efficiency of the instructional procedures (Ayres \& Ledford, 2014). Note that the post hoc analysis was conducted only for the comparison phase data. The mastery criterion was determined as scoring $100 \%$ in three consecutive sessions or showing stabile data points (Wolery et al., 2014).

\section{Experimental Design}

We used the adapted alternating treatments design (AATD) to compare the effectiveness and efficiency of VP versus least-to-most prompting when teaching officerelated tasks to the participants (Sindelar, Rosenberg, \& Wilson, 1985). The design incorporated four phases including: (a) continuous baseline, (b) comparison phase with 
control probes, (c) best treatment phase, and (d) final treatment phase (the final treatment phase was applied for only one participant to teach the one skill she did not acquire and to demonstrate equivalency of task difficulty). The two interventions were applied to two tasks; a third task was continuously measured as a control during baseline and probed during the comparison phase to control multiple treatment interference effect. We counterbalanced VP, least-to-most prompting, and the control probed across participants and tasks (see Table 4).

Additionally, we implemented the order of the conditions randomly across participants, and we waited at least $1 \mathrm{hr}$ between sessions to mitigate the possibility of multiple treatment interference (Wolery et al., 2014). Lastly, we estimated the tasks to be of equal difficulty using a logical anal ysis (Wolery et al., 2014). Each task analysis contained nearly the same number of steps and consisted of gross and fine motor movements that were similar across tasks. Moreover, previous research has demonstrated that these skills are functionally independent but equivalent in difficulty (Bennett, Gutierrez, \& Loughrey, 2016; Bennett, Gutierrez, \& Honsberger, 2013).

Table 4

Counterbalance of Tasks and Interventions Across Participants.

\begin{tabular}{lccc}
\hline Participant & Video prompting & Least-to-most prompting & Control \\
\hline Leo & Fax & Label & Photocopy \\
Nadia & Label & Photocopy & Fax \\
Amanda & Photocopy & Fax & Label \\
\hline
\end{tabular}




\section{Experimental Procedures}

\section{Pre-baseline activities}

Before experimental sessions began, the first author observed the participants in their classrooms to mitigate reactivity (Gast \& Ledford, 2014). The first author also met with participants' teachers and parents to ascertain the participants' learning needs and potential reinforcers. Additionally, both authors conducted rehearsal sessions practicing data collection methods until at least $90 \%$ agreement was reached for three sessions. Lastly, the first author conducted a multiple stimulus without replacement preference assessment to identify potential reinforcers for each participant (DeLeon \& Iwata, 1996). Assessing preferences of participants before introducing interventions has rarely been conducted in the VBI literature (Bennett, Aljehany, \& Altaf, 2017).

During the assessment, the first author presented five items (e.g., food, objects, toys, and activities) in a straight line on the table and asked the participants to choose one item. When the participant chose an item, the assessor allowed him or her to engage with it (e.g., hold it or consume it) while removing other items from the table. In the next trial, the assessor presented the items again without the first chosen item. Identical procedures continued until the last item was selected. The assessor conducted five trials in this manner. For scoring, the first item chosen was given one point, the second item selected was given two points, the third item picked was given three points, the fourth item selected was given four points, and the last item taken was given five points (see Appendix D). The scores for each item were summed at the end of the five sessions, and items that received the lowest and second lowest scores were used as potential 
reinforcing stimuli for the participants (Cannella-Malone, Sabielny, Jimenez, \& Miller, 2013).

\section{General procedure}

During all phases and conditions, the following common procedures were applied across sessions. One-to-one teaching was conducted during all sessions to minimize incidental modeling effects (Wolery et al., 2014). The first author brought the participant from his or her classroom to the spare classroom where sessions were conducted. The participant sat down on a chair facing a table. The targeted device (i.e., printer, label maker, or fax machine) was placed on the table approximately $40 \mathrm{~cm}$ to the right of the participant. A folder with or without original paper (depending on the task) in a basket was placed on the table approximately $40 \mathrm{~cm}$ to the left of the participant. During VP sessions, the iPad was placed on the table approximately $40 \mathrm{~cm}$ in front of the participant. Each session was started by verbally introducing the target task and its materials to the participant.

\section{Baseline}

During baseline sessions, the researcher provided the initial direction to the participant to begin working on the task (e.g., Take the paper from the folder and make a copy). No prompting or any type of assistance was provided to the participants. If the participant responded within $5 \mathrm{~s}$, and performed the step independently and accurately within $30 \mathrm{~s}$, the researcher provided verbal praise (e.g., good job). If the participant did not respond within $5 \mathrm{~s}$, performed the step inaccurately, or took more than $30 \mathrm{~s}$ to complete the step, the researcher counted that as an incorrect response and ended the session. 
Participants could complete tasks steps out of order relative to the task analyses provided those steps were not required to be in a specific order. For instance, a participant could take the folder from that basket before turning on the copy machine; however, he or she had to open the lid to the copy machine before inserting the paper to be copied. This baseline procedure resembles the single opportunity to respond assessment method (Cooper, Heron, \& Heward, 2007). Baseline session continued until the data paths for each dependent variable were stable (Wolery et al., 2014).

\section{Comparison}

Video prompting condition. During VP sessions, the researcher provided the initial task direction to the participant (e.g., Take the paper from the folder and send a fax to [fax number]), and then the researcher played the video clip of the first step in the task analysis. All instructions thereafter were on the video recording. If the participant responded within $5 \mathrm{~s}$, and completed the step correctly within $30 \mathrm{~s}$, the researcher provided verbal praise, counted that as a correct response, and played the next video clip. However, if the participant did not respond within $5 \mathrm{~s}$, or did not complete the step correctly within $30 \mathrm{~s}$, the researcher counted that as an incorrect response. At this point, the researcher completed the task step while blocking the participant's view and played the next video clip (to control for the possibility of the participant observing a live model

and to set up the next task step before playing the following video clip). These procedures were repeated until all the steps of the task were attempted or completed. No additional instructions, prompting, or error correction procedures were provided. The reinforcing stimulus was given to a participant when he or she completed $90 \%$ of the task steps correctly. 
Least-to-most prompting condition. During least-to-most prompting sessions, the researcher provided the initial direction to the participant (e.g., Make a label that says, "ART" and put it on the folder). When the participant completed the task step independently, correctly, and within the aforementioned timeframe, the researcher verbally praised him or her. If, however, the participant did not respond after receiving the initial direction within $5 \mathrm{~s}$, or did not complete the task step correctly within $30 \mathrm{~s}$, the least-to-most prompting levels were applied using the same timeframes. First, the researcher provided a verbal prompt (e.g., Turn on the device). Second, if the correct response did not occur, the researcher provided a verbal and gestural prompt (e.g., Turn on the device while pointing to the button). Third, if the correct response did not occur, the researcher provided a verbal and model prompt (e.g., Turn on the device and then demonstrated the step). Fourth, if the correct response did not occur, the researcher provided a verbal and a partial physical prompt (e.g., Turn on the device and then lightly guided the participant's hand to turn on the device). Fifth, if the correct response did not occur, the researcher provided a verbal and full physical prompt (e.g., Turn on the device with hand-over-hand guidance). These procedures were repeated until all the steps of the task analysis were attempted or completed. The reinforcing stimulus was delivered to a participant when he or she completed the $90 \%$ of the task steps independently and correctly.

Control task probes. Control probes on the third task were conducted continuously during the baseline and intermittently during the comparison phase for each participant. The procedures were identical to those implemented during baseline. The 
control probe was conducted after every third session in the comparison phase or sooner if there was the possibility of an ascending trend in the data path (Wolery et al., 2014).

\section{Best Treatment}

After completing the comparison phase, the superior intervention relative to each participant, whether VP or least-to-most prompting, was used to teach the control task assessed during the baseline and comparison phases. The procedures were identical to those applied during the VP or least-to-most prompting intervention conditions.

\section{Final Treatment}

This phase was applied for one participant (Amanda) to teach her to send a fax, which she did not master using least-to-most prompting during the comparison phase. During the final treatment phase, we applied VP, the superior treatment for Amanda. These procedures were identical to those applied during the VP condition.

\section{Interobserver Agreement and Treatment Fidelity}

The first and second authors collected interobserver agreement (IOA) data using the item-by-item method, whereby an item was scored as an agreement when the researchers recorded the same code on a task step (see Appendix E). The percent of IOA was calculated by dividing the total number of agreements by agreements plus disagreements and multiplying by 100 (Cooper et al., 2007). Overall, IOA data were collected across $36 \%$ (range 25-50\%) of all sessions (across all participants, tasks, and conditions). The average IOA equaled 99\% (range 92-100\%).

The second author collected treatment fidelity (TF) data across 36\% (range 25-50\%) of all sessions (across all participants, tasks, and conditions; see Appendix F). The TF equaled $97 \%$ (range $83-100 \%$ ). The percent of TF was calculated by dividing the 
total number of procedures performed correctly by the total number of planned procedures and multiplying by 100 (Ayres \& Ledford, 2014).

\section{Social validity}

At the end of the study, all participants and two of the participants' teachers completed social validity questionnaires. These questionnaires measured opinions regarding the appropriateness of the target behaviors, acceptability of the intervention procedures, and satisfaction with the outcomes of the study (Wolf, 1978). There were seven questions with four answer choices in the participant questionnaire (Yes; Yes, but not much; No; and I do not know). The first author helped the participants as needed (e.g., reading a question). The teacher questionnaire contained six statements with a 5-point Likert-type scale ranging from strongly agree to strongly disagree. Teachers were given the questionnaire individually. Responses of participants and teachers were analyzed qualitatively (see Appendix G).

\section{Results}

Figure 3 displays percent of correct responses across all participants, phases, and conditions of the study. Percent correct is presented on the y-axis and sessions are displayed on the $\mathrm{x}$-axis. Baseline data indicated that each participant emitted few steps of the tasks analyses correctly. During the comparison phase, each participant demonstrated learning gains using either VP or least-to-most prompting; however, one strategy emerged as the better intervention for each participant. During the best treatment phase, the participants mastered the skill using the superior intervention. Finally, during the final treatment phase, Amanda demonstrated mastery of the skill within three sessions (see Figure 3). 

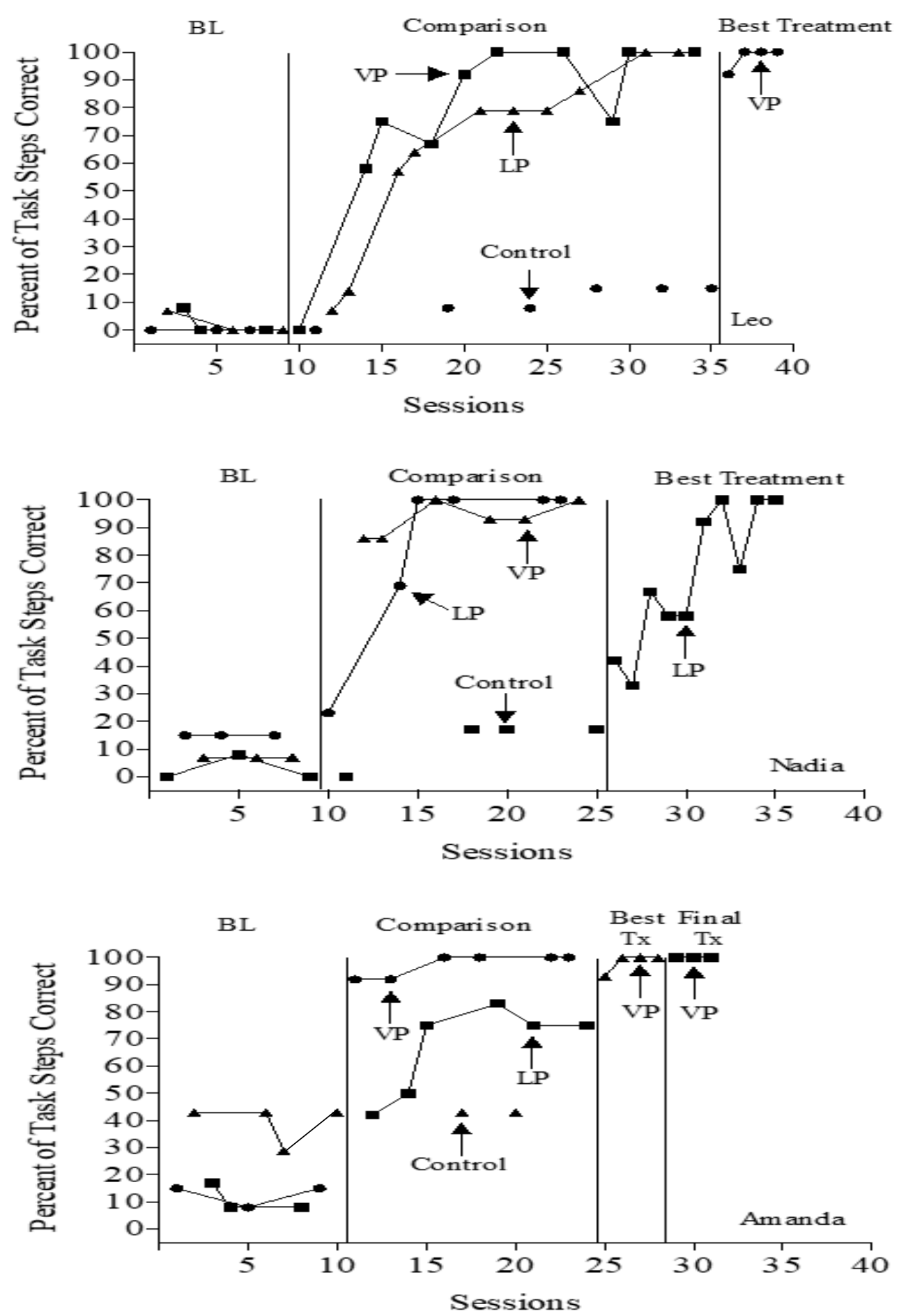

Figure 3. Percent of task steps completed correctly. $\mathrm{BL}=$ baseline; circles = photocopy; $\mathrm{LP}=$ least-to-most prompting; squares $=$ faxing; triangles $=$ labeling; $\mathrm{Tx}=$ treatment; $\mathrm{VP}=$ video prompting. 


\section{Effectiveness of Interventions}

Leo. During the baseline phase, Leo performed the task steps of faxing with an average of $3 \%$ correct (range $0-8 \%$ ) and label making with an average of $2 \%$ correct (range $0-7 \%$ ). He did not complete any steps for photocopying during this phase. Each data path showed low performance with no positive trends.

During the comparison phase, Leo performed the task steps of faxing (using VP) with an average of $77 \%$ correct (range $0-100 \%$ ), label making (using least-to-most prompting) with an average of $66.5 \%$ correct (range $7-100 \%$ ), and photocopying (control probe) with an average of $10 \%$ correct (range $0-15 \%$ ). Both interventions' data paths demonstrated high performances with stable levels and accelerating trends, indicating the effectiveness of both interventions. The control probes showed low stable performance with a zero celerating trend in the last three sessions. There was minimal overlap between the intervention data paths, with the most overlap occurring during the first session and the final sessions once the tasks were mastered. Moreover, there was marginal overlap between the intervention data paths and the control probes during the first two sessions.

VP was selected as the best treatment for Leo given his higher levels of responding using that intervention and the speed with which that intervention led to mastery of the task. during the best treatment phase, Leo correctly performed the photocopy task steps (using VP) with an average of 98\% correct (range 92-100\%). These data were high in level, had a zero celerating trend, demonstrated stability, and revealed an immediate level shift compared to the control probes, indicating the effectiveness of VP for improving Leo’s performance. 
Nadia. During the baseline phase, Nadia performed the task steps of label making with an average of 7\% correct (range 7-7\%), photocopy with an average of 15\% correct (range 15-15\%), and faxing with an average of 3\% correct (range 0-8\%). Her data in each task showed low performance, stable levels of responding, and zero celerating trends. During the comparison phase, Nadia performed the task steps of label making (using VP) with an average of 93\% correct (range 86-100\%), photocopy (using least-to-most prompting) with an average of $82 \%$ correct (range 23-100\%), and faxing (control probe) with an average of $13 \%$ correct (range $0-17 \%$ ). Both intervention data paths had immediate accelerating trends that stabilized after the first several sessions; there was little variability, indicating the effectiveness of both interventions. Additionally, the control probes during this phase showed low performance with a stable level and a zero celerating trend in the final three probe sessions. The intervention data paths showed substantial overlap; however, there was no overlap of the intervention data paths with the control probes.

Note that least-to-most prompting was selected as the best treatment because Nadia reached the mastery criterion using that intervention (she had 100\% accuracy for four consecutive sessions). This was not the case when VP was used. Nadia correctly performed faxing (using least-to-most prompting) with an average of $72.5 \%$ correct (range 42-100\%) during the best treatment phase. The intervention data path showed no immediate level shift. Additionally, the first six sessions showed high variability. However, these data stabilized with $100 \%$ responding for three of the four final sessions, indicating the effectiveness of the intervention. 
Amanda. During the baseline phase, Amanda performed the task steps of photocopy with an average of $13 \%$ correct (range 8-15\%), faxing with an average of $11 \%$ correct (range 8-17\%), and making a label with an average of 38\% correct (range 2943\%). These data paths demonstrated low, but stable levels of responding with no positive trend directions.

In the comparison phase, Amanda performed the task steps of photocopy (using VP) an average of 97\% correct (range 92-100\%), faxing (using least-to-most prompting) an average of $67 \%$ correct (range $42-83 \%$ ), and making a label (control probe) an average of $43 \%$ correct (range 43-43\%). The VP data path showed an immediate level shift. These data were high in level, stable, and had a zero celerating trend during the final sessions of the phase. The least-to-most prompting data path revealed a modest level shift with low stable responding during the last four sessions of the phase. There was no overlap between the intervention data paths, with only one data point overlapping between the control probes and the least-to-most prompting data path.

VP was the superior intervention for Amanda. Therefore, during the best treatment phase, this intervention was applied to the control task. Amanda correctly performed the task steps of making a label (using VP) with an average of $98 \%$ correct (range 93-100\%). During this phase, the data demonstrated an immediate level shift, high levels of responding, and stability with a zero celerating trend during the final three sessions of the phase.

During final treatment phase, Amanda achieved 100\% correct responding during the three sessions of this phase. Similar to her pattern of responding in previous 
intervention phases, these data demonstrated an immediate level shift with stable responding as indicated by the zero celerating trend.

\section{Efficiency of Interventions}

Efficiency data of VP and least-to-most prompting for each participant during the comparison phase are presented in Table 5. We examined sessions-to-criterion, percent of errors, and total duration of teaching time (Ayres \& Ledford, 2014). The analysis of sessions-to-criterion suggested that VP was more efficient than least-to-most prompting for Leo and Amanda; however, both interventions were equally efficient for Nadia. When evaluating the percent of errors, VP was more efficient than least-to-most prompting for all participants. However, when assessing total duration of teaching time, least-to-most prompting was marginally more efficient than VP for Leo and Amanda. Least-to-most prompting was substantially more efficient for Nadia (see Table 5).

Table 5

Efficiency Data of Video Prompting and Least-to-Most Prompting.

Video Prompting (Least-to-Most Prompting)

\begin{tabular}{cccc}
\hline Participant & $\begin{array}{c}\text { Sessions-to- } \\
\text { criterion }\end{array}$ & $\begin{array}{c}\text { Percent of } \\
\text { errors }\end{array}$ & $\begin{array}{c}\text { Total duration of teaching time } \\
(\mathrm{min}: \mathrm{sec})\end{array}$ \\
Leo & 7 (not met) & $23(33.5)$ & $55: 30(52: 25)$ \\
Nadia & $5(5)$ & $7(18)$ & $28: 12(17: 48)$ \\
Amanda & 3 (not met) & $3(33)$ & $24: 36(21: 23)$ \\
\hline
\end{tabular}
Note: In parenthesis $=$ least-to-most prompting data; Min $=$ minutes; No parenthesis $=$ video prompting data; $\mathrm{Sec}=$ seconds. 


\section{Social Validity of Interventions}

The three students and two classroom teachers participated in interviews to assess the social validity of this study. The results indicated that all participants appreciated learning the targeted tasks, enjoyed watching videos via an iPad, and found that receiving prompts from the instructor as acceptable. Also, they thought VP and least-to-most prompting helped them in completing the tasks. Two participants liked VP more than least-to-most prompting. Furthermore, two participants indicated that VP was more helpful than least-to-most promoting. Both teachers strongly agreed that the targeted tasks were appropriate and important for their students, VP and least-to-most prompting were effective interventions, the study helped their students to learn new office-related skills, and that both interventions were likely to be used in the future. One of the teachers preferred the use of least-to-most prompting over VP, while another teacher preferred both interventions.

\section{Discussion}

This study examined the effectiveness, efficiency, and social validity of VP alone compared to least-to-most prompting alone across three office-related tasks among adolescents with ASD and moderate ID. Both interventions appeared to be effective in teaching the tasks to two participants. However, VP was substantially more effective than least-to-most prompting for improving the performance of the third participant. These findings suggest that VP and least-to-most prompting can be used to improve the acquisition of chained tasks, such as office-related skills, among students with ASD and ID. Similar results were provided by Cannella-Malone et al. (2017), which supported the effectiveness of self-directed VP with error correction to improve job-related skills for 
two adults with DD. Also, the present results were consistent with those reported in the Cannella-Malone et al. (2017) and Ulke-Kurkcuoglu (2015) studies supporting the effectiveness of least-to-most prompting for all participants with DD when learning the targeted skills.

This study contributes to the current literature in showing the effectiveness of both interventions in isolation by comparing least-to-most prompting alone to VP without additional response prompting and error correction procedures. Additionally, the present study addressed some internal validity limitations reported in the Cannella-Malone et al. (2017) and Ulke-Kurkcuoglu (2015) studies by analyzing a control behavior and implementing a best treatment phase, which increased the validity of the results in supporting the effectiveness of both interventions.

Each participant learned the skills with fewer errors when using VP. Additionally, when using VP, two of the three participants had fewer sessions-to-criterion compared to using least-to-most prompting. For the remaining participant, Nadia, the sessions-tocriterion data were equal. Therefore, the overall data indicated that VP can be considered more efficient than least-to-most prompting regarding these two analyses of efficiency. This result differs from those reported by Ulke-Kurkcuoglu (2015) who found that leastto-most prompting helped two of three children with ASD to learn multiple-step pretend play skills with fewer sessions, trials, and errors compared to VM. Note that some procedural differences between both studies exist that might explain the different results between these studies. In the current study, we targeted office-related skills, applied VP, and implemented five levels of prompting when implementing the least-to-most prompting strategy. In contrast, Ulke-Kurkcuoglu targeted pretend play skills, applied 
VM, and used two levels of prompting during the least-to-most prompting procedure. Thus, there is a need for more investigation regarding the efficiency of VP and least-tomost prompting when teaching skills to individuals with ASD.

An additional finding related to efficiency was that participants took more instructional time to complete the tasks across VP sessions compared to the instructional time of least-to-most prompting. This outcome suggests that when the students use leastto-most prompting to complete, or attempt, all steps in the task analyses, they seem to require fewer minutes of instruction compared to using VP. Similar findings were reported in the Cannella-Malone et al. (2017) study. The reason for the differences in duration between both interventions could be that participants were required to observe the entire video clip of each step in the task analysis, which may increase the instructional time during VP sessions. Thus, the value of duration of instruction as an efficiency measure is unclear given the time constraints inherent to VP and other VBI strategies.

Finally, positive perspectives were provided by participants and their teachers regarding both interventions and the targeted skills. This finding extends the literature base by supporting the importance of learning office-related skills for secondary students with ASD and ID and the effectiveness of VP and least-to-most prompting based on social viewpoints (Horner et al., 2005). Positive perspectives similar to those in this study were reported by other researchers, as well (e.g., Ulke-Kurkcuoglu, 2015).

\section{Implications}

The findings from this study have important implications for professionals. The time and effort required to develop instructional materials may concern classroom teachers. Some teachers may have many other teaching duties that take most of their 
time. Teachers should know that developing, saving, and presenting videos require technological skills and planning time. Such planning time is reduced in the case of using least-to-most prompting. For example, using VP for teaching a task, the teacher must develop a task analysis, prepare all required technology devices, film each task step, edit the video clips, save the video material, and present the videos using an appropriate application. However, issues of ease of planning might be mitigated since the videos can be re-used by students learning the tasks, and the videos can be used in future academic years with other students. Moreover, once students learn the generalized skill of learning from videos, they can learn new skills without the teacher's presence (Cannella-Malone et al., 2017).

Moreover, the implementation of VP or least-to-most promoting to improve DLS depends on the learning needs of the students. Attending skills, imitation, and motor abilities, as well as the verbal/non-verbal communication skills of the students should be considered before teachers decide to use VP or least-to-most prompting. Differing student learning preferences might indicate using one strategy over the other. For instance, students that struggle learning from a model might be better served using least-to-most prompting. Similarly, students that experience tactile defensiveness might not benefit from the physical prompts used when implementing least-to-most prompting. Teachers' understanding of students' learning characteristics could allow the teacher to select the instructional strategy most likely to promote skill acquisition.

\section{Limitations and Future Research}

This study included limitations that should be considered. First, maintenance and generalization data were not collected. Thus, we could not determine the effectiveness of 
both interventions over time and under different conditions (Cooper et al., 2007). Future research may extend the results of this study by examining maintenance and generalization when comparing VP and least-to-most prompting. Second, the external validity of the findings is limited because of the small sample size of participants. Future researchers are encouraged to replicate this study to increase its external validity across the population of students with ASD and ID. Third, the researcher removed the participants from their real-life classrooms and conducted study sessions in an unoccupied classroom. Thus, the effects of the interventions in authentic environments are unknown. It is possible that the effectiveness or efficiency of one or both interventions could change as a function of stimuli presented in authentic settings (e.g., more people, noise, and equipment). Therefore, we suggest future research in such settings to examine these variables. Fourth, the IOA data were not collected for the duration of the teaching time. This limitation might be mitigated given the other efficiency measures reported. Nevertheless, this is a limit that others should consider when analyzing these findings. Finally, we used a single-opportunity method during the baseline; thus, there was the possibility that participants' baseline responses could have been suppressed. However, this baseline assessment method has been documented in the peer-reviewed literature when researchers examined behavior chains where order of the steps were important for overall task completion (e.g., Bennett et al., 2016; CanellaMalone et al., 2006).

\section{Conclusion}

The results from this study provide teachers, related service providers, and caregivers additional options when teaching skills to adolescents with ASD and ID. The 
major findings from this study show that while the interventions were effective and efficient, participant characteristics or preference should be considered when professionals are planning instruction for students. Although additional research is needed to understand difference between these, and other strategies, the current results add to the literature based demonstrating that video prompting and least-to-most prompting can be used when teaching secondary students with ASD and ID learning office-related vocational tasks.

\section{References (Chapter III)}

Ayres, K. M., \& Ledford, J. R. (2014). Dependent Measures and Measurement Systems. In D. L. Gast and J. R. Ledford (Eds.). Single case research methodology: Applications in special education and behavioral sciences (2nd Ed.) (pp. 124153). New York, NY: Routledge.

Banda, D. R., Dogoe, M. S., \& Matuszny, R. (2011). Review of video prompting studies with persons with developmental disabilities. Education and Training in Autism and Developmental Disabilities, 46, 514-527.

Bellini, S., \& Akullian, J. (2007). A meta-analysis of video modeling and video selfmodeling interventions for children and adolescents with autism spectrum disorders. Exceptional children, 73(3), 264-287.

Bennett, K. D., Aljehany, M. S., \& Altaf, E. M. (2017). Systematic Review of VideoBased Instruction Component and Parametric Analyses. Journal of Special Education Technology, 32(2), 80-90.

Bennett, K. D., Gutierrez, A., \& Honsberger, T. (2013). A comparison of video prompting with and without voice-over narration on the clerical skills of adolescents with autism. Research in Autism Spectrum Disorders, 7, 1273-1281. doi: 10.1016/j.rasd.2013.07.013

Bennett, K. D., Gutierrez, A., \& Loughery, T. O. (2016) Comparison of screen sizes when using video prompting to teach adolescents with autism. Education and Training in Autism and Developmental Disabilities, 51(4), 379-390. 
Cannella-Malone, H. I., Chan, J. M., \& Jimenez, E. D. (2017). Comparing self-directed video prompting to least-to-most prompting in post-secondary students with moderate intellectual disabilities. International Journal of Developmental Disabilities, 63(4), 211-220

Cannella-Malone, H. I., Sabielny, L. M., Jimenez, E. D., \& Miller, M. M. (2013). Pick one! Conducting preference assessments with students with significant disabilities. TEACHING Exceptional Children, 45(6), 16-23.

Cannella-Malone, H., Miller, O., Schaefer, J. M., Jimenez, E. D., Page, E. J., \& Sabielny, L. M. (2016). Using video prompting to teach leisure skills to students with significant disabilities. Exceptional Children, 82(4), 463-478. doi: $10.1177 / 0014402915598778$

Cooper, J. O., Heron, T. E. and Heward, W. L. 2007. Applied behavior analysis. 2nd ed. Upper Saddle River, NJ: Pearson.

DeLeon, I. G., \& Iwata, B. A. (1996). Evaluation of a multiple-stimulus presentation format for assessing reinforcer preferences. Journal of Applied Behavior Analysis, $29,519-533$.

Domire, S. C., \& Wolfe, P. (2014). Effects of video prompting techniques on teaching daily living skills to children with autism spectrum disorders: A review. Research and Practice for Persons with Severe Disabilities, 39(3), 211-226. doi: $10.1177 / 1540796914555578$

Gardner, S. J., \& Wolfe, P. S. (2015). Teaching students with developmental disabilities daily living skills using point-of-view modeling plus video prompting with error correction. Focus on Autism and Other Developmental Disabilities, 30(4), 195 207. doi: $10.1177 / 1088357614547810$

Gast D. L., \& Spriggs A. D. (2014). Visual Analysis of Graphic Data. In D. L. Gast and J. R. Ledford (Eds.). Single case research methodology: Applications in special education and behavioral sciences (2nd Ed.) (pp. 176-211). New York, NY: Routledge.

Hayden, M. F. (1997). Class-action, civil rights litigation for institutionalized persons with mental retardation and other developmental disabilities: A review. Mental \& Physical Disability Law Reporter, 21, 411-423

Hendricks, D. (2010). Employment and adults with autism spectrum disorders: challenges and strategies for success. Journal of Vocational Rehabilitation, 32, $125-134$. 
Horner, R. H., Carr, E. G., Halle, J., McGee, G., Odom, S., \& Wolery, M. (2005). The use of single-subject research to identify evidence-based practice in special education. Exceptional children, 71(2), 165-179.

Kraijer, D. (2000). Review of adaptive behavior studies in mentally retarded persons with autism/pervasive developmental disorder. Journal of Autism and Developmental Disorders, 30, 39-47.

MacDuff, G. S., Krantz, P. J., \& McClannahan, L. E. (1993). Teaching children with autism to use photographic activity schedules: Maintenance and generalization of complex response chains. Journal of Applied Behavioral Analysis, 26, 89-97.

Schopler, E., Reichler, R. J., Rochen-Renner, B. (1988). The childhood autism rating scale (CARS). Los Angeles, CA: Western Psychological Services.

Sindelar, P. T., Rosenberg, M. S., \& Wilson, R. J. (1985). An adapted alternating treatments design for instructional research. Education and Treatment of Children, 8, 67-76.

Ulke-Kurkcuoglu, B. (2015). A comparison of least-to-most prompting and video modeling for teaching pretend play skills to children with autism spectrum disorder. Educational Sciences: Theory \& Practice, 15(2), 499-517.

Van Laarhoven, T., Johnson, J., Van Laarhoven-Myers, T., Grider, K., \& Grider, K. (2009). The effectiveness of using a video iPod as a prompting device in employment settings. Journal of Behavioral Education, 18(2), 119-141.

Wolery, M., Ault, M. J., \& Dyle, P. M. (1992). Teaching students with moderate and severe disabilities: Use of response prompting strategies. White Plains, NY: Longman.

Wolery, M., Gast, D. L., \& Ledford, J. R. (2014). Comparison designs. In D. L. Gast \& J. R. Ledford (Eds.), Single case research methodology: Applications in special education and behavioral sciences (pp. 377-396). New York, NY: Routledge.

Wolf, M. M. (1978). Social validity: The case for subjective measurement or how applied behavior analysis is finding its heart. Journal of applied behavior analysis, 11(2), 203-214.

Wong, C., Odom, S. L., Hume, K. Cox, A. W., Fettig, A., Kucharczyk, S., ... Schultz, T. R. (2015). Evidence-based practices for children, youth, and young adults with autism spectrum disorder: A comprehensive review. Journal of Autism and Developmental Disorders, 45(7), 1951-1966. 


\section{CHAPTER IV \\ CONCLUSIONS}

This chapter includes the summary of both papers, extended discussions related to the findings of Paper One, extended discussions related to the findings of Paper Two, an overarching finding obtained from both papers, overall practical implications, and overarching future directions driven from both papers.

\section{Summary of Papers}

Autism Spectrum Disorder (ASD) is a lifelong developmental disability (DD) described by significant limitations in social communication and behavioral skills, as well as stereotyped characteristics of interests such as repeated behaviors (American

Psychiatric Association, 2013). Impairments in these areas of development have negative results on the daily living skills (DLS) of a child or an adult with ASD (Park, Yelland, Taffe, \& Gray, 2012). Deficits in DLS among individuals with ASD are documented in the literature base (Liss et al., 2001). Because of these deficits, limited DLS lead to poor independent life skills and job-related skills (Cannella-Malone et al. 2011). Therefore, it is important to identify the most effective intervention practices to teach DLS to enhance the social living and future careers of individuals with ASD (Gray et al., 2014).

Many interventions have been used to teach DLS to individuals with DD and ASD, and one of these is video prompting (VP; Banda, Dogoe, \& Matuszny, 2011). During the use of VP, the learner observes a short video clip of one step in the task analysis, attempts that step, and repeats the process until completing all the steps in the task sequence (Sigafoos et al., 2007). In fact, implementing effective practices when teaching students with DD and other students with disabilities is required by legislation, 
such as the Individuals with Disabilities Education Improvement Act of 2004 (Horner et al., 2005). Regarding this matter, some published review articles have provided valuable insight relevant to VP for improving a variety of behaviors of individuals with DD, including ASD (Banda et al., 2011; Domire \& Wolfe, 2014; Gardner \& Wolfe, 2013; Hong et al., 2016). Collectively, these reviews supported the effectiveness of VP to teach DLS for individuals of all ages with DD and ASD. Moreover, comparing the effects of VP to response prompting interventions, such as least-to-most prompting, on teaching DLS to children with ASD have been established and supported the effectiveness of VP (Cannella-Malone, Chan, \& Jimenez, 2017; Ulke-Kurkcuoglu, 2015). Indeed, conducting literature reviews on VP and comparing the effects of VP to other effective interventions can help provide further information related to some features, components, efficiency, and effects of VP treatment packages for teaching DLS to students with DD and ASD.

However, to date, the literature related to the use of VP in isolation for improving DLS of individuals with ASD has not been statistically evaluated across single-case research design (SCRD) studies. Additionally, there is a need to extend the literature relevant to VP by comparing the effects of VP to least-to-most prompting without combining other teaching strategies when teaching DLS to adolescents with ASD and intellectual disability (ID). Thus, the overarching aim of this dissertation was to address these gaps by examining the evidence of the effectiveness of VP by conducting a metaanalytic review within SCRD studies in Paper One and comparing VP to least-to-most prompting on DLS of adolescents with ASD and ID in Paper Two.

In Paper One, a 6-step process was conducted to evaluate the effects of VP interventions statistically. In the first step, a comprehensive literature search that involved 
reviewing online databases, peer-reviewed journals, and reference sections of included studies was conducted to identify relevant studies to be included in the meta-analysis, resulting in 955 studies. In the second step, the applications of the inclusion criteria and What Works Clearinghouse (WWC) standards on those studies resulted in 17 studies. In the third step, the descriptive data of each study were extracted considering participants, settings, independent variables, dependent variables, SCRD used, and A-B phase contrasts. During the fourth step of the meta-analytic review, the data points of studies' graphs were extracted using the rank-order method (Parker, Vannest, \& Davis, 2011). Also, each A-B phase contrast was classified across three moderators (VP type, age, and disability). In the fifth step, individual effect sizes (ESs), overall ES, and ESs of each moderator variable were calculated using the web-based Tau- $U$ calculator and WinPEPI meta-analytic software. In the final step, the calculation results were analyzed based on the overall Tau- $U$ value, its $S E$, CI hypothesis testing, and the Kruskal-Wallis test to determine significant differences across moderators' variables.

In Paper Two, a comparative SCRD was applied to compare the effects and efficiency of VP and least-to-most prompting among three secondary-aged participants with ASD and ID when completing office-related skills. Participants' performances were assessed before introducing interventions during the baseline phase. Both interventions were introduced alternatively for evaluating the performances of participants to complete target skills during the comparison phase. Then, the most effective intervention was used with each participant to complete the control task during the best treatment phase. For one participant, a final treatment phase was applied to help her master a skill using VP. 
Several procedures were applied to increase the internal validity of study two, including measuring a control behavior during baseline and comparison phases, controlling for multiple treatment interference effects, counterbalancing interventions among tasks across participants, randomizing sessions, conducting a best treatment phase, and collecting interobserver agreement (IOA) and treatment fidelity (TF) data. Effectiveness, efficiency, and social validity data were collected for the comparison. During the VP intervention procedures, the participant used VP instruction without receiving additional response prompting or error correction. During the least-to-most prompting procedures, the participant received five levels of prompting until completing the skill independently.

\section{Paper One Extended Discussion}

The purpose of Paper One was to determine the magnitude of change of DLS for individuals with ASD across multiple SCRD studies in response to the effects of VP interventions, and to examine the ESs of VP across the VP intervention type, participant age, and participant disability moderators.

The first examination in Paper One was related to the overall effects of VP for teaching DLS to individuals with ASD. The results from this study revealed a highmoderate to strong ES. The omnibus Tau- $U$ ES was $0.92(S E=.03, \mathrm{CI} 95=[0.86,0.99])$. Such finding indicates that $92 \%$ of data points of A and B phases across all included studies did not overlap, which is a significant indicator for the effectiveness of VP for teaching DLS (Parker \& Vannest, 2009). This finding provides further evidence regarding the effectiveness of VP with and without additional procedures for teaching DLS to individuals with ASD. A similar finding was reported in existing literature 
reviews (Banda et al., 2011; Domire \& Wolfe, 2014; Gardner \& Wolfe, 2013). For instance, Banda et al. (2011) reported that the majority of participants with DD across 12 studies showed high-performance improvements when learning a variety of behaviors and skills using VP with and without other strategies.

The second examination was related to the ES of VP for improving DLS for individuals with ASD, considering VP intervention types. Many current studies have combined the VP with response prompting and error correction procedures. This combination may limit our understanding regarding whether the behavioral change is a result of using VP alone or VP with additional procedures. In Paper One, no statistical effect differences on improving DLS for individuals with ASD were found in response to VP alone and VP with response prompting and error correction. In fact, the Tau- $U$ ESs of VP alone and VP with response prompting and error correction were almost identical. This finding suggests that VP alone or VP with response prompting and error correction appear to have similar effects when teaching DLS to individuals with ASD.

The third examination was related to the ES of VP for improving DLS to individuals with ASD considering the two participant disability variables. Video prompting was equally effective for teaching DLS to individuals with ASD with and without a secondary diagnosis of ID. However, the VP ES value for individuals with ASD was slightly larger than the VP ES value for individuals with ASD plus ID. It is possible that learning characteristic differences among individuals with ASD and individuals with ASD and ID may affect their responses differentially when using VP. Individuals with ASD demonstrate high focus on, and attention to, visual stimuli while learning, and this characteristic is supported when using VP (Ayres \& Langone, 2005). 
Similarly, Hong et al. (2016) found no significant differences between participants with ASD, participants with ASD plus ID, and participants with high-functioning autism in response to VM and VP interventions when learning DLS.

The findings related to the VP ESs regarding the VP type and participant disability moderators suggest that students with ASD and ID might need additional response prompting or error correction to complete the skills when using VP. Existing research studies have proposed that VP combined with additional response prompting and error correction systems can enhance participants' performances. For example, Cannella-Malone, Wheaton, Wu, Tullis, and Park (2012) compared the effects of VP with and without error correction among three individuals with severe DD to teach washing tables and sweeping skills. They found that VP with error correction was more effective than VP without error correction for two individuals, while neither intervention was effective for one individual. In another example, a treatment package combining VP, live modeling, least-to-most prompting, and error correction was used to improve leisure skills of nine adolescents and adults with significant disabilities (Cannella-Malone et al., 2016). The study found that the treatment package showed positive outcomes for five participants, mixed outcomes for three participants, and no effect on one participant. Importantly, the study also reported that all participants rarely responded correctly when the videos were presented alone.

For practical applications, teachers should consider the use of additional response prompts or error correction strategies when VP instruction does not help the student learn the skill. Depending on the disability characteristics and difficulty of the task, teachers may decide whether to use VP alone or a VP treatment package when teaching DLS. 
Note that teachers must have a plan to fade these additional prompting and error corrections so that students can complete the task independently (Banda et al., 2011). For future research, studies should examine the impact of these additional procedures when combined with VP on skill acquisition.

Another finding was related to the ES of VP for improving DLS to individuals with ASD considering the age of participants. The results showed that VP is similarly effective in early childhood, elementary, secondary, and adult-aged participants. Video prompting ESs across age groups were within the range of high-moderate to strong. Specifically, VP is an effective intervention when used with secondary-aged and adult students, and this is supported by data in the peer-reviewed literature. For example, three secondary-aged students with ASD could complete office-related tasks using VP alone presented on a large screen while two of them learned these tasks on a small screen (Bennett, Gutierrez, \& Loughrey, 2016). Thus, educators might use this strategy with confidence when teaching DLS to this populations of students.

Unfortunately, at this time, there is not enough data to suggest the use of VP to teach DLS to young children with ASD. Data related to early childhood and elementaryaged students were minimal, which limited our conclusions regarding the effectiveness of VP for this specific population. Similar results were indicated by Banda et al. (2011), whereby there were limited studies using VP with these populations. For future research, more studies are needed among the early childhood and elementary-aged students before researchers can make a conclusion related to the effectiveness of VP when teaching DLS to these populations. 
Another contribution that was added to the literature and knowledge was identifying studies on VP that showed high-quality of SCRD. Comprehensive SCRD criteria were applied on included studies to evaluate design quality. Regarding the implication of WWC guidelines, 15 studies were excluded from further analyses in Paper One because they did not meet the SCRD Standards of WWC with or without reservations. The most frequent reasons for studies to be excluded was applying designs that did not (a) provide at least three different occurrences of intervention effects and (b) include at least three data points, especially when examining data under the additional sub-standards for multiple-probe designs (MPD).

Such findings indicate that researchers should provide strong evidence of a causal relation between the intervention and the target behavior by presenting a minimum of three demonstrations of intervention effects and establishing stable data points, especially in the baseline phase. Importantly, when the MPD is used, researchers should provide data probes that demonstrate consistency with the trend and level of prior baseline data points. Also, at least one probe, and ideally three probes, should be conducted before introducing the intervention. For empirical research studies, applying the SCRD standards of the WWC can help to improve the design quality, increase the reliability and validity of the data collected, and provide evidence for a casual relation between the independent and dependent variables (Kratochwill et al., 2013).

Kratochwill et al. (2013) suggested that an intervention can be considered an evidence-based practice when the following conditions have been met: (a) studies have been conducted across three different research teams without duplication of authorship, (b) there are at least five high-quality SCRD on the topic showing positive effects, and 
(c) the studies included at least 20 cases/participants. In Paper One, four different research teams conducted 12 high-quality SCRD studies, indicating the effectiveness of VP alone across 43 participants with ASD (see Table 6). Thus, VP alone met each of the Kratochwill et al. criteria to be an evidence-based practice for teaching DLS to individuals with ASD. This finding is supported by Wong et al. (2015) in which they consider video-based modeling as an evidence-based practice for teaching a variety of skills to individuals with ASD.

Table 6

Video Prompting as an Evidence-based Practice.

$\begin{array}{ccc}\text { The research team } & \text { Number of high- } & \text { Number of } \\ \text { quality SCRD studies } & \text { participants }\end{array}$

Mechling, Ayres, Foster, \& Bryant, 2013; Mechling \& 2 10

Gustafson, 2008.

Cannella-Malone et al., 2012; Cannella-Malone et al., 5

2011; Cannella-Malone, O’Reilly, Edrisinha, Sigafoos,

\& Lancioni, 2006; Sigafoos et al., 2005; Sigafoos et al., 2007.

Yanardag, Akmanoglu, \& Yilmaz, 2013. 1

Bennett, Crocco, Loughrey, \& McDowell, 2017; 4 13

Bennett, Gutierrez, \& Loughrey, 2016; Bennett,

Gutierrez, \& Honsberger, 2013; Gutierrez, Bennett, McDowell, Cramer, \& Crocco, 2016. 


\section{Paper Two Extended Discussion}

The purpose of Paper Two was to assess the effectiveness of VP and least-to-most prompting using an adapted alternating-treatments design (AATD) for completing three office-related tasks for three secondary students with ASD and ID. Paper Two concluded that VP and least-to-most prompting showed positive outcomes for all participants with ASD and ID when teaching office-related skills. However, VP was slightly more effective and efficient than least-to-most prompting for two participants. These results extend the literature on instructional practices for individuals with disabilities by supporting the effectiveness of VP and least-to-most prompting for teaching DLS to individuals with DD. This extension is consistent with currently published studies relevant to Paper Two (Cannella-Malone et al., 2017; Ulke-Kurkcuoglu, 2015). In terms of practical implications, educators may effectively teach office-related skills that include chained behaviors for secondary-aged students by using VP or least-to-most prompting. However, they should take into consideration the level of disability, the task's requirements, and the student's preference.

In addition to the discussion presented in Chapter III regarding the results of Paper Two, the following sections include some additional discussion points. It is important to mention that the findings of Paper Two add further evidence regarding the effectiveness of some parameters of VP interventions. First, the effectiveness of presenting video clips via a handheld device (iPad) was supported in this study. Existing studies have documented benefits of introducing videos via handheld devices for teaching individuals with DD (e.g., Burke et al., 2013). Second, there are mixed results in the literature regarding the effects of VP on small and large screens among individuals with 
DD (Bennett, Gutierrez, \& Loughrey, 2016; Mechling \& Ayres, 2012; Mechling \& Youhouse, 2012; Miltenberger \& Charlop, 2015). This study provided additional support for studies that showed the effectiveness of VP presented on large screens (e.g., Mechling \& Ayres, 2012). Finally, custom-made video clips were used in this experiment, whereby the researcher filmed, edited, and organized the presented videos. Applying customized videos has demonstrated positive outcomes in this study and others (e.g., Mechling et al., 2013).

There are two proposed reasons for the effectiveness of VP for all participants in Paper Two. First, individuals with ASD are often strong visual learners, so they tend to gain more benefits from visually-oriented interventions such as VP (McCoy \& Hermansen, 2007; Quill, 1995). Second, motivation is a core factor in the modeling process (Bandura, 1977), and students with DD show lack of motivation to complete learning tasks (Domire \& Wolfe, 2014). Video clips via technology devices, such as iPads and iPods, could be external motivators to increase students' engagements while learning (Charlop-Christy \& Freeman, 2000).

Amanda was the only participant who could not master a skill in Paper Two. Least-to-most prompting was ineffective to improve her performance to complete the faxing task. However, VP helped her to complete the same task successfully. It is possible that if we conducted more least-to-most prompting sessions, she would have mastered the faxing task. Also, it is possible that the faxing task was particularly complex for her, and least-to-most prompting was not the appropriate intervention for that task.

In another explanation related to this matter, VP was used as a form of antecedent-based learning in this study, that involved presenting the skill and then 
allowing the learner an opportunity to react. In contrast, least-to-most prompting was used as a form of consequence learning, which refers to giving the participant an opportunity to perform the skill firstly, and then providing a prompt if an incorrect response occurs. Some students with ASD and ID have difficulties in memorizing the skill requirement, recalling complex information, and performing multi-step tasks (Boutot \& Myles, 2011). Video prompting, as a form of antecedent learning, may be more appropriate and supportive for such students, as illustrated by Amanda.

Although one participant could not complete a task successfully using least-tomost prompting, this intervention can be an alternative teaching practice for students who have problems attending and viewing videos. The use of modeling approaches, including VP with some students with DD who have significant behavioral challenges, attention deficits, and poor imitational skills may be not the best teaching strategy option for teachers (Bandura 1977; MacDonald, Dickson, Martineau, \& Ahearn, 2015). There are some advantages of using least-to-most prompting in classrooms that may include: (a) easy to operate for teachers, (b) easy to use for students, (c) adaptable prompting levels, (d) cost-effective, and (e) efficient when combined with other interventions (Demchak, 1990; Seaver \& Bourret, 2014; Taber-Doughty, 2005). In addition, a selffading procedure is one of the features of using least-to-most prompting. When the learner's performance increases, the number of prompts gradually fades, thus enhancing independent learning (Sabielny \& Cannella-Malone, 2014).

\section{Overarching Finding of Collected Papers}

Even though Paper One and Paper Two have different purposes, they have a major shared finding. Both papers supported the effectiveness of VP alone when teaching 
DLS to secondary-aged children with ASD and ID. In Paper One, the Tau- $U$ values across the VP alone sub-moderator, secondary-aged participant sub-moderator, and participant with ASD plus ID sub-moderator were within the range of high-moderate to strong ESs. Similarly, in Paper Two, the overall Tau- $U$ value for A-B phase contrasts of VP across all the three participants showed a strong ES (Tau- $U=0.97, E S=0.2$, CI95 = $[0.58,1])$. Thus, both papers demonstrate that VP is an effective intervention for teaching office-related skills, as a domain of DLS to secondary-aged children with ASD and ID. Indeed, this overarching finding is compatible with some published studies (e.g., Cannella-Malone et al., 2011).

\section{Overall Practical Implications of Collected Papers}

Besides the previously discussed implications, there are two overall practical implications driven by both papers. First, VP is a highly effective and efficient teaching strategy for improving daily living and vocational skills of individuals with ASD, especially secondary-aged children and adults in the classroom. Teachers can teach these skills by developing task analyses that are appropriate for the learners' abilities, presenting each task step via a video clip, and giving learners the opportunities to watch and complete these steps. Note that teachers should consider the complexity of the task when applying VP (Banda et al., 2011).

Moreover, some students with ASD may learn DLS better using VP with and without response prompting, or least-to-most prompting based on their individual abilities. It is essential that teachers evaluate each student individually to choose the most effective and efficient strategy when teaching DLS to their students. For example, some students may not need additional prompting or feedback when using VP, while others 
may need these procedures to master the skill. Other students might not benefit from the use of VP at all. Other teaching practice options, such as least-to-most prompting, may be helpful for these students. Educators should consider (a) whether the student can attend and model the task presented on the videos, and (b) the student's preferences regarding the intervention and its procedures before applying the teaching strategy.

\section{Overarching Future Directions}

There are two essential future research directions generated by the two papers. While DLS can be taught effectively using VP practices, sustainable skills are only shown when the effects of VP are continued over time and generalized beyond the experiment's training and settings. Individuals with ASD have demonstrated significant limitations to maintain and generalize learned skills (MacDuff, Kratnz, \& McClannhan, 1993). Both papers suggest that there is a need to examine the effects of VP on individuals with DD and ASD to maintain learned skills over time and use these skills across different situations and environments. Such information will enhance the literature and knowledge on VP, and provide valuable implications for practices.

Another area of future research is to compare VP interventions to other response prompting and error correction systems. There are several response prompting and error correction practices, such as graduated guidance, time delay, and most-to-least prompting. Indeed, each practice has unique features and procedures. Comparing the effects of VP to these features and procedures will extend the literature base and knowledge regarding the efficiency and some components of VP interventions. For example, comparing the effects of VP to a time delay system to improve a DLS to 
children with ASD may indicate which intervention increases skill acquisition more efficiently.

In conclusion, the current collected papers dissertation presents evidence of the positive outcomes obtained when using VP interventions. Additionally, this collected papers series is among the first examination of VP ESs on DLS for individuals with ASD within SCRD. It is also one of the first comparison studies on the effects of VP without additional prompting strategies to least-to-most prompting on the skill acquisition among secondary-aged students with ASD and ID. The current findings extend the literature base related to the use of VP and least-to-most prompting, and these findings provide practical implications for teachers and other caregivers when teaching DLS to students with ASD.

\section{References (Chapter IV)}

American Psychiatric Association. (2013). Diagnostic and statistical manual of mental disorders (5th ed.). Arlington, VA: Author.

Ayres, K. M., \& Langone, J. (2005). Intervention and instruction with video for students with autism: A review of the literature. Education and Training in Developmental Disabilities, 40, 183-196.

Banda, D. R., Dogoe, M. S., \& Matuszny, R. (2011). Review of video prompting studies with persons with developmental disabilities. Education and Training in Autism and Developmental Disabilities, 46, 514-527.

Bandura, A. (1977). Social learning theory. Englewood Cliffs, NJ: Prentice Hall.

Bennett, K. D., Crocco, C., Loughrey, T. O., \& McDowell, L. S. (2017). Effects of video prompting without voice-over narration among students with autism spectrum disorder. Behavioral Development Bulletin, 22(1), 147-158. doi: 10.1037/bdb0000058. 
Bennett, K. D., Gutierrez, A., \& Honsberger, T. (2013). A comparison of video prompting with and without voice-over narration on the clerical skills of adolescents with autism. Research in Autism Spectrum Disorders, 7(10), 12731281. doi: 10.1016/j.rasd.2013.07.013.

Bennett, K. D., Gutierrez Jr, A., \& Loughrey, T. O. (2016). Comparison of screen sizes when using video prompting to teach adolescents with autism. Education and Training in Autism and Developmental Disabilities, 51(4), 379.

Boutot, E., \& Myles, B. (2011). Autism spectrum disorders: Foundations, characteristics, and effective strategies (Fourth ed.). Boston, New Jersy: Pearson.

Burke, R. V., Allen, K. D., Howard, M. R., Downey, D., Matz, M. G., \& Bowen, S. L. (2013). Tablet-based video modeling and prompting in the workplace for individuals with autism. Journal of Vocational Rehabilitation, 38(1), 1-14.

Cannella-Malone, H. I., Chan, J. M., \& Jimenez, E. D. (2017). Comparing self-directed video prompting to least-to-most prompting in post-secondary students with moderate intellectual disabilities. International Journal of Developmental Disabilities, 63(4), 211-220.

Cannella-Malone, H. I., Fleming, C., Chung, Y., Wheeler, G. M., Basbagill, A. R., \& Singh, A. H. (2011). Teaching daily living skills to seven individuals with severe intellectual disabilities: A comparison of video prompting to video modeling. Journal of Positive Behavior Interventions, 13, 144-153. doi: 10.1177/1098300710366593.

Cannella-Malone, H. I, Miller, O., Schaefer, J. M., Jimenez, E. D., Page, E. J., \& Sabielny, L. M. (2016). Using video prompting to teach leisure skills to students with significant disabilities. Exceptional Children, 82(4), 463-478. doi: $10.1177 / 0014402915598778$.

Cannella-Malone, H. I., Wheaton, J. E., Wu, P., Tullis, C. A., \& Park, J. H. (2012). Comparing the effects of video prompting with and without error correction on skill acquisition for students with intellectual disability. Education and Training in Autism and Developmental Disabilities, 47(3), 332-344.

Cannella-Malone, H., O’Reilly, M., Edrisinha, C., Sigafoos, J., \& Lancioni, G. E. (2006). Comparing video prompting to video modeling for teaching daily living skills to six adults with developmental disabilities. Education and Training in Developmental Disabilities, 41, 344-356.

Charlop-Christy, M., Le, L., \& Freeman, K. (2000). A comparison of video modeling with in vivo modeling for teaching children with autism. Journal of Autism and Developmental Disorders, 30, 537-552. 
Demchak, M. (1990). Response prompting and fading methods: a review. American Journal of Mental Retardation, 94, 603-615.

Domire, S. C., \& Wolfe, P. (2014). Effects of video prompting techniques on teaching daily living skills to children with autism spectrum disorders: A review. Research and Practice for Persons with Severe Disabilities, 39(3), 211-226. doi: $10.1177 / 1540796914555578$.

Gardner, S., \& Wolfe, P. (2013). Use of video modeling and video prompting interventions for teaching daily living skills to individuals with autism spectrum disorders: A review. Research and Practice for Persons with Severe Disabilities, 38(2), 73-87.

Gray, K. M., Keating, C. M., Taffe, J. R., Brereton, A. V., Einfeld, S. L., Reardon, T. C., \& Tonge, B. J. (2014). Adult outcomes in autism: Community inclusion and living skills. Journal of autism and developmental disorders, 44(12), 3006-3015. doi:10.1007/s10803-014-2159-x.

Gutierrez, A., Bennett, K. D., McDowell, L. S., Cramer, E. D., \& Crocco, C. (2016). Comparison of video prompting with and without voice-over narration: A replication with young children with autism. Behavioral Interventions, 31(4), 377389. doi: 10.1002/bin.1456.

Hong, E. R., Ganz, J. B., Mason, R., Morin, K., Davis, J. L., Ninci, J., ... \& Gilliland, W. D. (2016). The effects of video modeling in teaching functional living skills to persons with ASD: A meta-analysis of single-case studies. Research in Developmental Disabilities, 57, 158-169. doi: 10.1016/j.ridd.2016.07.001.

Horner, R. H., Carr, E. G., Halle, J., McGee, G., Odom, S., \& Wolery, M. (2005). The use of single-subject research to identify evidence-based practice in special education. Exceptional children, 71(2), 165-179.

Kratochwill, T. R., Hitchcock, J. H., Horner, R. H., Levin, J. R., Odom, S. L., Rindskopf, D. M., \& Shadish, W. R. (2013). Single-case intervention research design standards. Remedial and Special Education, 34, 26-38. doi:10.1177/0741932512452794.

Liss, M., Harel, B., Fein, D., Allen, D., Dunn, M., Feinstein, C., et al. (2001). Predictors and correlates of adaptive functioning in children with developmental disorders. Journal of Autism and Developmental Disorders, 31, 219-230.

MacDonald, R. P., Dickson, C. A., Martineau, M., \& Ahearn, W. H. (2015). Prerequisite skills that support learning through video modeling. Education and Treatment of Children, 38(1), 33-47. 
MacDuff, G. S., Kratnz, P. J., \& McClannhan, L. E. (1993). Teaching children with autism to use photographic activity schedules: maintenance and generalization of complex response chains. Journal of Applied Behavior Analysis, 26, 89-97.

McCoy, K., \& Hermansen, E. (2007). Video modeling for individuals with autism: A review of model types and effects. Education and Treatment of Children, 18(3), 21-34.

Mechling, L. C., \& Ayres, K. M. (2012). A comparative study: Completion of fine motor office related tasks by high school students with autism using video models on large and small screen sizes. Journal of Autism and Developmental Disorders, 42, 2364-2373. doi: 10.1007/s10803-012-1484-1.

Mechling, L. C., Ayres, K. M., Foster, A. L., \& Bryant, K. J. (2013). Comparing the effects of commercially available and custom-made video prompting for teaching cooking skills to high school students with autism. Remedial \& Special Education, 34(6), 371-383. doi: 10.1177/0741932513494856.

Mechling, L. C., \& Gustafson, M. R. (2008). Comparison of static picture and video prompting on the performance of cooking-related tasks by students with autism. Journal of Special Education Technology, 23(3), 31-45.

Mechling, L. C., \& Youhouse, I. R. (2012). Comparison of task performance by students with autism and moderate intellectual disabilities when presenting video models on large and small screen sizes. Journal of Special Education Technology, 27(1), $1-14$.

Miltenberger, C. A., \& Charlop, M. H. (2015). The comparative effectiveness of portable video modeling vs. traditional video modeling interventions with children with autism spectrum disorders. Journal of Developmental and Physical disabilities, 27(3), 341-358. doi: 10.1007/s10882-014-9416-y.

Park, C. J., Yelland, G. W., Taffe, J. R., \& Gray, K. M. (2012). Brief report: the relationship between language skills, adaptive behavior, and emotional and behavior problems in preschoolers with autism. Journal of Autism and Developmental Disorders, 42, 2761-2766. doi:10.1007/s10803-012-1534-8.

Parker, R. I., Vannest, K. J., \& Davis, J. L. (2011). Effect size in single case research: A review of nine nonoverlap techniques. Behavior Modification, 35, 303-322. doi: $10.1177 / 0145445511399147$.

Parker, R. I., \& Vannest, K. (2009). An improved effect size for single-case research: Nonoverlap of all pairs. Behavior Therapy, 40(4), 357-367. 
Quill, K. A. (1995). Visually cued instruction for children with autism and pervasive developmental disorders. Focus on Autistic Behavior, 10, 10-20.

Sabielny, L. M., \& Cannella-Malone, H. I. (2014). Comparison of prompting strategies on the acquisition of daily living skills. Education and Training in Autism and Developmental Disabilities, 145-152.

Seaver, J. L., \& Bourret, J. C. (2014). An evaluation of response prompts for teaching behavior chains. Journal of Applied Behavior Analysis, 47(4), 777-792.

Sigafoos, J., O’Reilly, M., Cannella, H., Edrisinha, C., de la Cruz, B., Upadhyaya, M....Young, D. (2007). Evaluation of a video prompting and fading procedure for teaching dish washing skills to adults with developmental disabilities. Journal of Behavioral Education, 16(2), 93-109. doi: 10.1007/S10864-006-9004-z.

Sigafoos, J., O'Reilly, M., Cannella, H., Upadhyaya, M., Edrisinha, C., Lancioni, G. E.,...Y Young, D. (2005). Computer-presented video prompting for teaching microwave oven use to three adults with developmental disabilities. Journal of Behavioral Education, 14, 189-201. doi: 10.1007/s10864-005-6297-2.

Taber-Doughty, T. (2005). Considering student choice when selecting instructional strategies: A comparison of three prompting systems. Research in Developmental Disabilities, 26(5), 411-432.

Ulke-Kurkcuoglu, B. (2015). A comparison of least-to-most prompting and video modeling for teaching pretend play skills to children with autism spectrum disorder. Educational Sciences: Theory \& Practice, 15(2), 499-517.

Wong, C., Odom, S. L., Hume, K. A., Cox, A. W., Fettig, A., Kucharczy k, S., . . \& Schultz, T. R. (2015). Evidence-based practices for children, youth, and young adults with autism spectrum disorder: a comprehensive review. Journal of Autism and Developmental Disorders, 45, 1951-1966.

Yanardag, M., Akmanoglu, N., \& Yilmaz, I. (2013). The effectiveness of video prompting on teaching aquatic play skills for children with autism. Disability and Rehabilitation, 35(1), 47-56. doi: 10.3109/09638288.2012.687030. 
APPENDICES 


\section{Appendix A}

\section{The Inclusion Criteria Data Form, Paper One}

\section{Reviewer:}

Direction: Mark $(\sqrt{ })$ if the study meets the criterion.

Keys: SCN: Study code number; IC1: The article must be published in a peer-previewed journal between 1991-2017 and written in English; IC2: The article must include at least one participant diagnosed with ASD; IC3: The article must use VP alone or VP plus a response prompting system; IC4: The article must target any functional living skills; IC5: The article must use a SCRD.

\begin{tabular}{|l|l|l|l|l|l|l|l|}
\hline SCN & Article Citation & IC1 & IC2 & IC3 & IC4 & IC5 & Decision \\
\hline S01 & & & & & & & \\
\hline S02 & & & & & & & \\
\hline S03 & & & & & & & \\
\hline S04 & & & & & & & \\
\hline S05 & & & & & & & \\
\hline
\end{tabular}




\section{Appendix B}

The WWC Standards Evaluation Form, Paper One

\section{Article Citation}

\begin{tabular}{|c|ll|}
\hline Overall & $\circ$ & Meets Design Standards without Reservations \\
Classification & $\circ$ & Meets Design Standards with Reservations \\
& $\circ$ & Does Not Meet Design Standards \\
\hline
\end{tabular}

\begin{tabular}{|c|c|}
\hline WWC Design Standards & Status \\
\hline $\begin{array}{l}\text { 1. An appropriate design was selected considering the dependent } \\
\text { variable. }\end{array}$ & $\begin{array}{ll} & \mathrm{MS} \\
\circ & \mathrm{NO} / \mathrm{S}\end{array}$ \\
\hline $\begin{array}{l}\text { 2. The researcher must systematically control the intervention variables } \\
\text { by identifying when and how conditions change. }\end{array}$ & $\begin{array}{ll}\circ & \mathrm{MS} \\
\circ & \mathrm{NO} / \mathrm{S}\end{array}$ \\
\hline $\begin{array}{l}\text { 3-a. The IOA data must be collected systematically by at least two } \\
\text { examiners for each participant/case on each functional/daily living task } \\
\text { during each condition. }\end{array}$ & $\begin{array}{ll}\circ & \mathrm{MS} \\
\circ & \mathrm{NO} / \mathrm{S}\end{array}$ \\
\hline $\begin{array}{l}\text { 3-b. The IOA must be collected on a minimum of } 20 \% \text { of all sessions in } \\
\text { a condition/phase (e.g., baseline phase: } 20 \% \text {; intervention phase: } 20 \% \text { ). }\end{array}$ & $\begin{array}{ll}\circ & \mathrm{MS} \\
\circ & \mathrm{NO} / \mathrm{S}\end{array}$ \\
\hline $\begin{array}{l}3 \text {-c. The overall (across all conditions/phases) IOA value must be above } \\
80 \% \text { using percentage agreement or } 60 \% \text { using Cohen's Kappa } \\
\text { measures. }\end{array}$ & $\begin{array}{ll}\circ & \mathrm{MS} \\
\circ & \mathrm{NO} / \mathrm{S}\end{array}$ \\
\hline 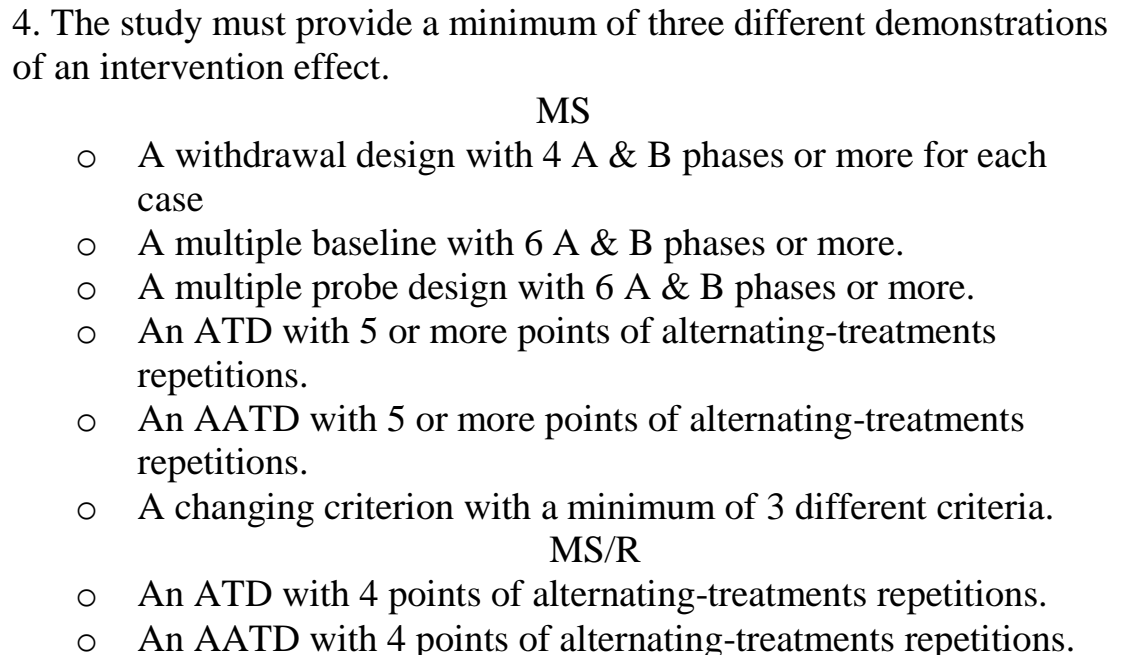 & $\begin{array}{ll}\circ & \mathrm{MS} \\
\circ & \mathrm{MS} / \mathrm{R} \\
\circ & \mathrm{NO} / \mathrm{S}\end{array}$ \\
\hline 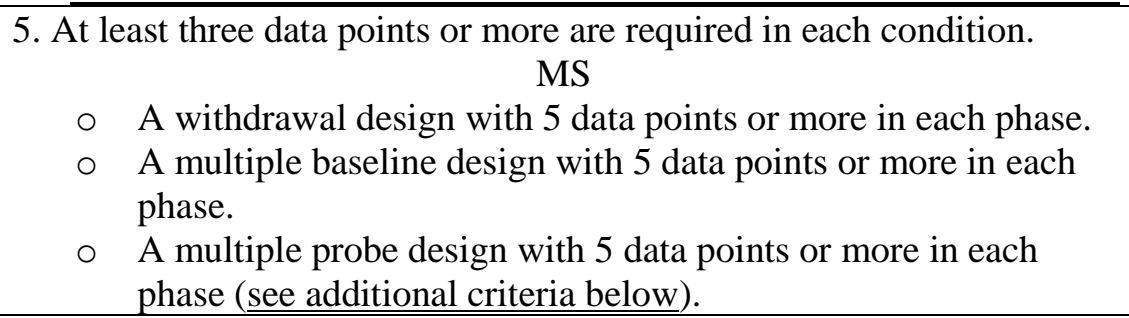 & $\begin{array}{ll} & \mathrm{MS} \\
\circ & \mathrm{MS} / \mathrm{R} \\
\circ & \mathrm{NO} / \mathrm{S}\end{array}$ \\
\hline
\end{tabular}


$\circ$ An ATD with 5 or more data points of comparison among the treatment conditions and at most 2 data points per phase; plus, if the design includes a baseline or best treatment phase, it must have at least 5 data points.

- An AATD with at least 5 data points of comparison among the treatment conditions and at most 2 data points per phase; plus at least 5 data points in the baseline phase

\section{$\mathrm{MS} / \mathrm{R}$}

- A withdrawal with 3 or 4 data points in a phase.

- A multiple baseline with 3 or 4 data points in a phase.

- A multiple probe design with 3 or 4 data points in a phase (see additional criteria below).

- An ATD with at least 4 data points of comparison among the treatment conditions and at most 2 data points per phase; plus, if the design includes a baseline or best treatment phase, it must have 3 or 4 data points.

- An AATD with at least 4 data points of comparison among the treatment conditions and at most 2 data points per phase plus at least 3 or 4 data points in the baseline phase.

\section{Additional criteria for multiple probe designs}

\section{MS}

- During the first three sessions, 3 consecutive probe points for each case are provided.

- During the three sessions, 3 consecutive probe points must be included before introducing the intervention in each case.

- Each case not receiving the intervention must have a probe point in a session where another case either first receives the intervention or reaches the criterion mastery (overlapping not necessary). This point must be consistent in level and trend with the case's previous baseline points.

\section{$\mathrm{MS} / \mathrm{R}$}

○ During the first three sessions, 2 or 1 probe point for each case is provided.

- During the three sessions, 2 or 1 probe points must be available before introducing the VP intervention in each case.

MS: meet standard without reservations; MS/R: meet standard with reservations; NO/S: does not meet standard; ATD: alternating treatment design; AATD: adapted alternating treatment design. 


\section{Appendix C}

The Data Collection Form, Paper Two

Participant ID:

Task:

Observer: .......

Session \#:

Setting:

Date:

Start time:

Stop time:

Intervention: ( ) VP or ( ) LP

Condition: Baseline ( ), Comparison ( ), Best Intervention ( ), Maintenance ( ), Control ( )

Data Summary

Number of correct responses:

Number of incorrect responses:

Percentage of correct responses:

Percentage of incorrect responses:

IOA percentage:

TF percentage:

Total teaching time:

Directions

$(+)=$ initiate within $5 \mathrm{~s}$, complete within 30 s, correct independent performance.

$(-)=$ not initiate within $5 \mathrm{~s}$, not completing within $30 \mathrm{~s}$, incorrect performance, not independent performance. $\mathrm{V}=$ Verbal prompt, $\mathrm{G}$ = verbal and gestural prompt, $\mathrm{M}=$ verbal and model prompt, $\mathrm{PP}=$ verbal and partial physical prompt, and $\mathrm{FP}=$ verbal and full physical prompt, $\mathrm{BL}=$ baseline phase, $\mathrm{C}=$ control phase, $\mathrm{M}=$ main phase

Out of order is ok in some steps.

\begin{tabular}{|c|c|c|c|}
\hline \multirow{2}{*}{ Task analysis steps } & \multicolumn{3}{|c|}{ Participant's response } \\
\hline & $\mathrm{BL} / \mathrm{C} / \mathrm{M}$ & $\mathrm{VP}$ & LP \\
\hline \multicolumn{4}{|c|}{ Making a Copy: take the paper from the folder and make a copy } \\
\hline $\begin{array}{l}\text { 1. Take the folder from the basket and } \\
\text { put it in front of you }\end{array}$ & & & $\begin{array}{r}(\mathrm{V})(\mathrm{G})(\mathrm{M})(\mathrm{PP}) \\
(\mathrm{FP})\end{array}$ \\
\hline 2. Turn on the printer & & & $\begin{array}{r}(\mathrm{V})(\mathrm{G})(\mathrm{M})(\mathrm{PP}) \\
(\mathrm{FP})\end{array}$ \\
\hline 3. Open the lid & & & $\begin{array}{r}(\mathrm{V})(\mathrm{G})(\mathrm{M})(\mathrm{PP}) \\
(\mathrm{FP})\end{array}$ \\
\hline 4. Open the folder & & & $(\mathrm{V})(\mathrm{G})(\mathrm{M})(\mathrm{PP})(\mathrm{FP})$ \\
\hline $\begin{array}{l}\text { 5. Take and put the original facing down } \\
\text { on the glass correctly aligned }\end{array}$ & & & $(\mathrm{V})(\mathrm{G})(\mathrm{M})(\mathrm{PP})(\mathrm{FP})$ \\
\hline 6. Close the lid & & & $(\mathrm{V})(\mathrm{G})(\mathrm{M})(\mathrm{PP})(\mathrm{FP})$ \\
\hline 7. Press the Black button & & & $(\mathrm{V})(\mathrm{G})(\mathrm{M})(\mathrm{PP})(\mathrm{FP})$ \\
\hline 8. Put the copy in the folder & & & $(\mathrm{V})(\mathrm{G})(\mathrm{M})(\mathrm{PP})(\mathrm{FP})$ \\
\hline 9. Open the lid & & & (V) (G) (M) (PP) (FP) \\
\hline
\end{tabular}




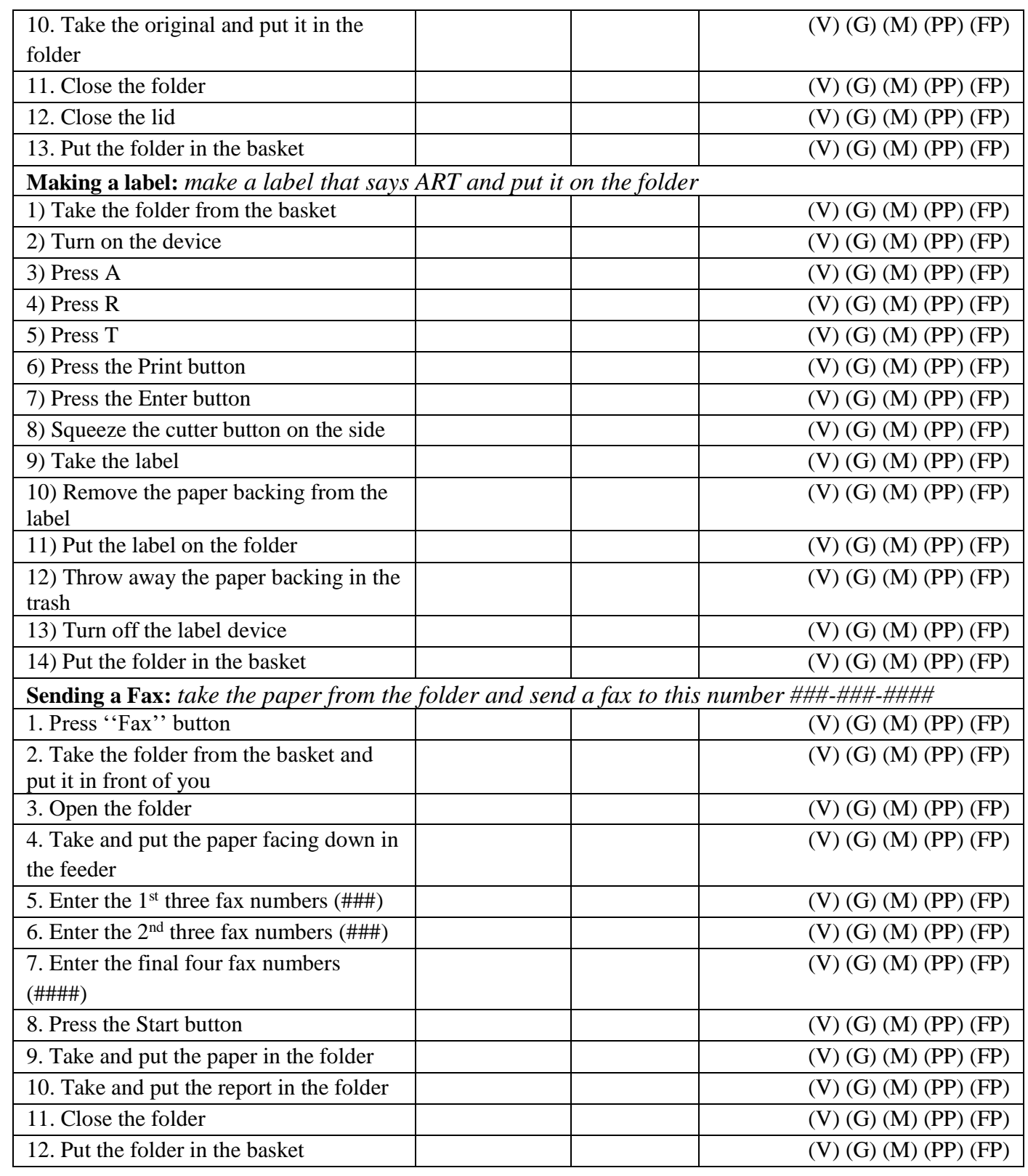




\section{Appendix D}

Multiple Stimulus Without Replacement Preference Assessment Data Form

\begin{tabular}{|l|l|l|l|l|l|l|}
\hline Items & Session 1 & Session 2 & Session 3 & Session 4 & Session 5 & Total \\
\hline & & & & & & \\
\hline & & & & & & \\
\hline & & & & & & \\
\hline & & & & & & \\
\hline
\end{tabular}

Rank items from the lowest total to the highest total to obtain a preference hierarchy, where the lower number indicates a higher preference.

1.

2.

3.

4.

5 .

Notes: 


\section{Appendix E}

The Interobserver Agreement Data Form, Paper Two

Participant ID

Task:

Observer: .......

Session \#:

Setting:

Date:

Start time:

Stop time:

Intervention: ( ) VP or ( ) LP

Condition: Baseline ( ), Comparison ( ), Best Intervention ( ), Maintenance ( ), Control ( )

\section{Data Summary}

Number of correct responses:

Number of incorrect responses:

Percentage of correct responses:

Percentage of incorrect responses:

IOA percentage:

TF percentage:

Total teaching time:

\begin{tabular}{|l|l|l|l|}
\hline \multicolumn{1}{|c|}{ Task analysis steps } & Researcher & $2^{\text {nd }}$ observer & Agree/Disagree? \\
\hline $\begin{array}{l}\text { 1. Take the folder from the basket and put it in a Copy } \\
\text { front of you }\end{array}$ & & & \\
\hline 2. Turn on the printer & & & \\
\hline 3. Open the lid & & & \\
\hline 4. Open the folder & & & \\
\hline $\begin{array}{l}\text { 5. Put the original facing down on the glass } \\
\text { correctly aligned }\end{array}$ & & & \\
\hline 6. Close the lid & & & \\
\hline 7. Press the Black button & & & \\
\hline 8. Put the copy in the folder & & & \\
\hline 9. Open the lid & & & \\
\hline 10. Take the original and put it in the folder & & & \\
\hline 11. Close the folder & & & \\
\hline 12. Close the lid & & & \\
\hline 13. Put the folder in the basket & & & \\
\hline Total & & & \\
\hline \multicolumn{2}{|c|}{ Making a label } & & \\
\hline 1) Take the folder from the basket & & & \\
\hline 2) Turn on the device & & & \\
\hline 3) Press A & & & \\
\hline 4) Press R & & & \\
\hline 5) Press T & & & \\
\hline 6) Press the Print button & & & \\
\hline 7) Press the Enter button & & & \\
\hline 8) Squeeze the cutter button on the side & & \\
\hline 9) Take the label & & & \\
\hline
\end{tabular}




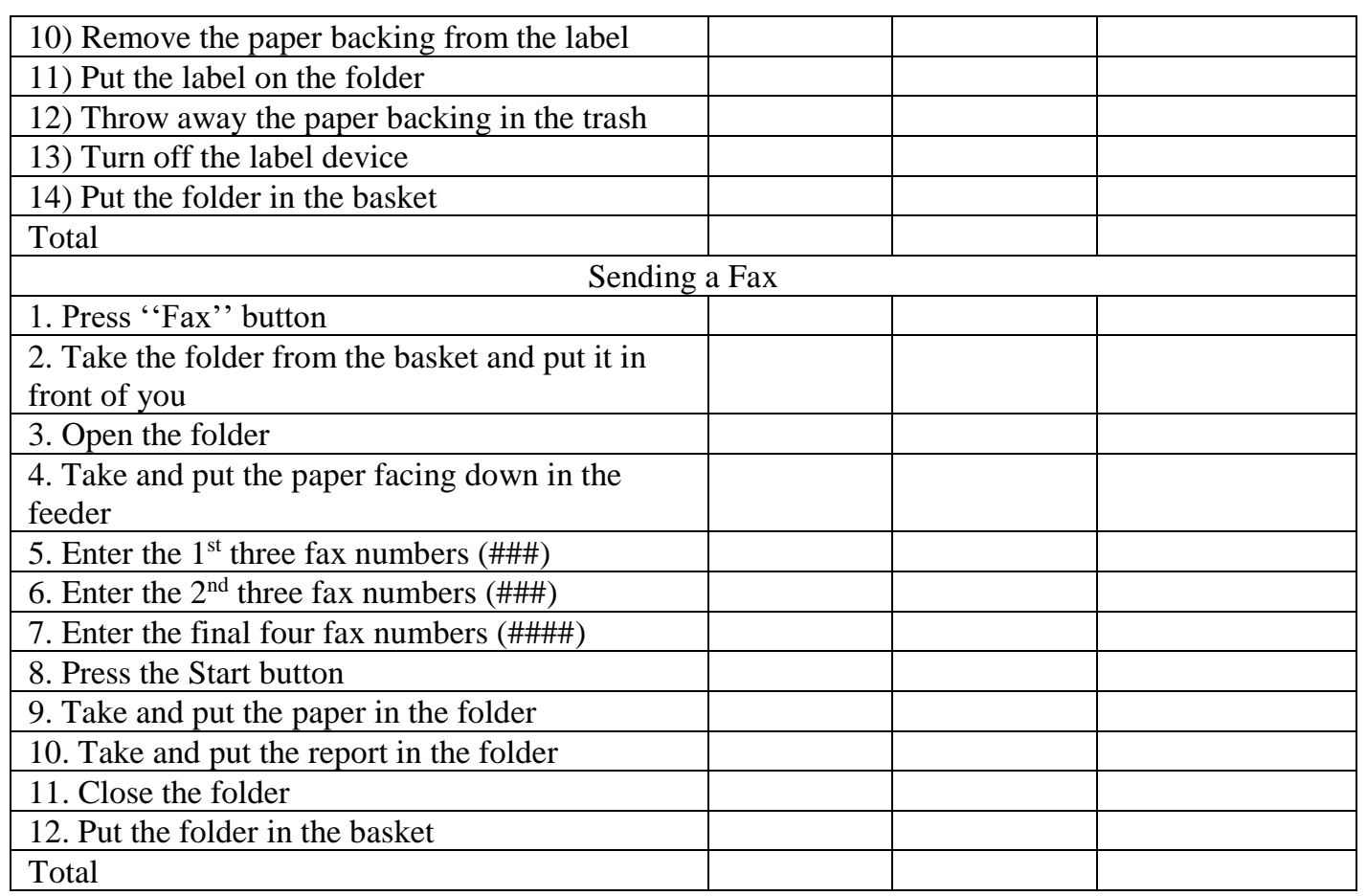




\section{Appendix F}

\section{Procedural Fidelity Data Form, Paper Two}

Participant ID

Date:

Observer:

Session \#:

Task:

Setting:

Start time:

Stop time:

Total time:

Condition: ( ) Baseline ( ) Comparison ( ) Best Intervention ( ) Control $\mathrm{N}$ of correct implementation: $\quad \mathrm{N}$ of incorrect implementation: $\quad \%$ of PF:

\begin{tabular}{|c|c|}
\hline Procedures & Mark + or -- \\
\hline \multicolumn{2}{|l|}{ Baseline/Control } \\
\hline $\begin{array}{l}\text { 1. The instructor prepares required materials before starting the } \\
\text { session. }\end{array}$ & \\
\hline $\begin{array}{l}\text { 2. provides the general task direction: "take the paper from the } \\
\text { folder and make a copy; make a label that says ART on the folder; } \\
\text { take the paper from the folder and send a fax to this number } 305- \\
348-2086 \text { ". }\end{array}$ & \\
\hline $\begin{array}{l}\text { 3. ends the session when the participant makes the first error, does } \\
\text { not respond during } 5 \mathrm{~s} \text {, or takes more than } 30 \text { s to complete the step. }\end{array}$ & \\
\hline 4. verbally praises the participant for correct responses. & \\
\hline 5. thanks the participant at the end of the session. & \\
\hline 6. provides no assistance, such as prompting or feedback. & \\
\hline \multicolumn{2}{|l|}{ Video prompting } \\
\hline $\begin{array}{l}\text { 1. The implementer prepares required materials before starting the } \\
\text { session. }\end{array}$ & \\
\hline 2. places the iPad in the front of the participant. & \\
\hline 3. plays the correct video clip to the participant. & \\
\hline $\begin{array}{l}\text { 4. follows the planned time frames: } 5 \mathrm{~s} \text { for initial responding and } \\
\text { 30s for completing the step. }\end{array}$ & \\
\hline 5. verbally praises the participant for correct responses. & \\
\hline $\begin{array}{l}\text { 6. completes the step with blocking the participant's view when } \\
\text { incorrect responses provided }\end{array}$ & \\
\hline
\end{tabular}


7. thanks and reinforces the participant at the end of the session when providing at least $90 \%$ correct response.

8. Provides no assistance, such as prompting or feedback.

\section{Least-to-most prompting}

1. The instructor prepares required materials before starting the session.

2. provides required step directions

3. follows the planned time frames: $5 \mathrm{~s}$ for initial responding and 30s for completing the step.

4. provides prompting hierarchies correctly and gradually when the participant provides typographical, duration, or latency errors. 5 . verbally praises the participant for correct responses.

6. completes the step with blocking the participant's view when he/she provides incorrect responses after all prompts given.

7. thanks and reinforces the participant at the end of the session when providing at least $90 \%$ correct response. 


\section{Appendix G}

Participant Social Validity Questionnaire, Paper Two

Participant ID:

Date:

Instruction: Mark the choice that represents your thought.

\begin{tabular}{|l|l|l|l|l|}
\hline \multicolumn{1}{|c|}{ Question } & Yes & No & \multicolumn{1}{|c|}{$\begin{array}{c}\text { Yes, but } \\
\text { not much }\end{array}$} & $\begin{array}{c}\text { I don't } \\
\text { know }\end{array}$ \\
\hline $\begin{array}{l}\text { 1. Did you like learning how to make } \\
\text { photocopying, labeling, and faxing? }\end{array}$ & & & & \\
\hline $\begin{array}{l}\text { 2. Did you enjoy using iPad and } \\
\text { watching videos? }\end{array}$ & & & & \\
\hline $\begin{array}{l}\text { 3. Were the iPad and videos helpful to } \\
\text { do the task? }\end{array}$ & & & & \\
\hline $\begin{array}{l}\text { 4. Did you enjoy when I prompted you } \\
\text { to do the task? }\end{array}$ & & & & \\
\hline $\begin{array}{l}\text { 5. Were my prompts helpful to do the } \\
\text { task? }\end{array}$ & $\begin{array}{l}\text { A) iPad and Videos } \\
\text { 6. Which intervention did you like } \\
\text { more? }\end{array}$ & \begin{tabular}{l} 
B) Teacher's prompting/helping \\
\hline $\begin{array}{l}\text { 7. Which intervention was more helpful and Videos } \\
\text { to complete the task? }\end{array}$
\end{tabular} & & \\
\hline
\end{tabular}

Thank you for participating in this survey 


\section{Instructor Social Validity Questionnaire}

Teacher ID:

Date:

Instruction: Mark the choice that represents your thought.

\begin{tabular}{|l|l|l|l|l|l|}
\hline \multicolumn{1}{|c|}{ Statement } & $\begin{array}{l}\text { Strongly } \\
\text { Disagree }\end{array}$ & Disagree & $\begin{array}{c}\text { Neither } \\
\text { Agree nor } \\
\text { Disagree }\end{array}$ & Agree & $\begin{array}{c}\text { Strongly } \\
\text { Agree }\end{array}$ \\
\hline $\begin{array}{l}\text { 1. Making a photocopy, } \\
\text { labeling a folder, and } \\
\text { sending a fax tasks are } \\
\text { appropriate and important } \\
\text { for the student to learn. }\end{array}$ & & & & \\
\hline $\begin{array}{l}\text { 2. Video prompting can be } \\
\text { an effective intervention for } \\
\text { teaching the tasks to the } \\
\text { student. }\end{array}$ & & & & & \\
\hline $\begin{array}{l}\text { 3. I would like to use video } \\
\text { prompting in the future. }\end{array}$ & & & & & \\
\hline $\begin{array}{l}\text { 4. Least-to-most prompting } \\
\text { can be an effective } \\
\text { intervention for teaching the } \\
\text { tasks to the student. }\end{array}$ & & & & & \\
\hline $\begin{array}{l}\text { 5. I would like to use least- } \\
\text { to-most prompting in the } \\
\text { future }\end{array}$ & & & & & \\
\hline $\begin{array}{l}\text { 6. This experiment helps my } \\
\text { student to learn new office- } \\
\text { related tasks }\end{array}$ & & & & & \\
\hline $\begin{array}{l}\text { 7. Which intervention do } \\
\text { you prefer when teaching a } \\
\text { daily living skill and why? }\end{array}$ & $\begin{array}{l}\text { B) None of them } \\
\text { D) They are equals }\end{array}$ & & & \\
\hline
\end{tabular}

Thank you for participating in this survey 


\section{Appendix H}

Intuitional Review Board Approval, Paper Two

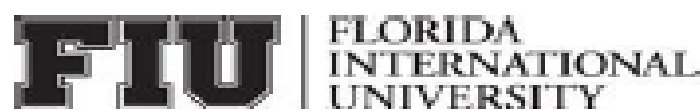

Office of Research Integrity UNIVERSITY

\section{MEMIORANDUM}

To:

$\mathrm{CC}$ :

From:

Date:

Protocol Title:
Dr. Kyle Bennett

File

Maria Melendez-Vargas, MIBA, IRB Coordinator

November 28, 2017

-A Comparison of Video Prompting to Least-to-Most Prompting for

Teaching Functional Living Skills to Individuals with Autism Spectrum

Disorder"

The Social and Behavioral Institutional Review Board of Florida International University has approved your study for the use of human subjects via the Expedited Review process. Your study was found to be in compliance with this institution's Federal Wide Assurance $(00000060)$.

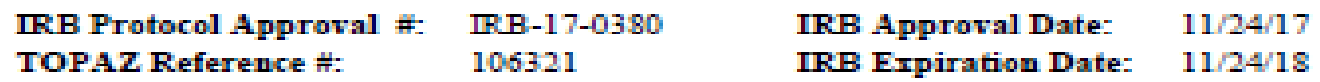

As a requirement of IRB Approval you are required to:

1) Submit an IRB Amendment Form for all proposed additions or changes in the procedures involving human subjects. All additions and changes must be reviewed and approved by the IRB prior to implementation.

2) Promptly submit an IRB Event Report Form for every serious or unusual or unanticipated adverse event, problems with the rights or welfare of the human subjects, and/or deviations from the approved protocol.

3) Utilize copies of the date stamped consent document(s) for obtaining consent from subjects (umless waived by the IRB). Signed consent documents must be retained for at least three years after the completion of the study.

4) Receive annual review and re-approval of your study prior to your IRB erpiration date. Submit the IRB Renewal Form at least 30 days in advance of the study's expiration date.

5) Submit an IRB Project Completion Report Form when the study is finished or discontinued.

Special Condirions: N/A.

For further information, you may visit the IRB website at http//iresearch.fiuedu/irb.

MIV/em 


\title{
Appendix I
}

\author{
Parental Consent and Child Assent Forms, Paper Two
}

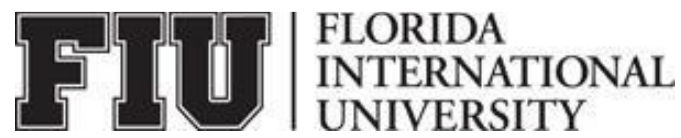

PARENTAL CONSENT TO PARTICIPATE IN A RESEARCH STUDY

A Comparison of Video Prompting to Least-to-most Prompting for Teaching Functional Living

Skills to Individuals with Autism Spectrum Disorder

\section{PURPOSE OF THE STUDY}

You are being asked to give your permission for your child , to be in a research study. The purpose of this study is to compare the effect of video prompting (watching video clips before completing a task) and the effect of least-to-most prompting (using verbal, gestural, model, and physical prompts) for teaching daily living skills to students with autism. The researchers for this study are Mashal Aljehany, a doctoral candidate at Florida International University and Dr. Kyle D. Bennett, an Associate Professor at Florida International University.

\section{NUMBER OF STUDY PARTICIPANTS}

If you agree to allow your child to participate in this study, he/she will be one of four participants in this research study.

\section{DURATION OF THE STUDY}

Your child's participation will require up to 45 minutes on the days that we work with your child. We plan to work with your child for three to four days a week, for about 15 weeks.

\section{PROCEDURES}

If your child participates in this study, we will do the following things:

1. We will ask you or your child's teacher about your child's behaviors using the Childhood Autism Ration Scale-2 to determine the characteristics or features of your child related to his or her diagnosis of autism spectrum disorder. We will also observe your child in his or her classroom to complete this assessment. We will ask you or your child's teacher about their vision, hearing, ability to follow simple instructions, their ability to imitate others, and their ability to view videos.

2. We will ask you and your child's teacher about items that are rewarding that can be used to teach your child skills. Then, we will implement a preference assessment to determine what items your child prefers and might serve as rewards while learning skills. During this assessment, five items (for example, food, objects, toys, and activities) will be presented on a table to your child. We will ask your child to choose one of the presented items. When your child chooses an item, we will allow him/her to engage with it (for example, consume food or play with toys) while removing other items from the table. In 
the next trial, we will re-present the items again without the first one that was chosen. This will continue until the last item is selected and this process will repeat several times.

1. Next, we will watch your child complete the three daily living skills selected for teaching. During this time, we will not help your child complete the tasks. We will collect data on their abilities to perform the skills. At times, we will reward your child when he/she is correct.

2. Then, we will attempt to teach two of the three skills. One skill will be taught using video prompting and one skill will be taught using least-to-most prompting. The final skill will not be taught at this time but we will periodically ask your child to attempt the skill while we observe them doing so. Video prompting involves your child watching a video clip of someone performing one step of the skill. After the video clip plays, we will ask your child to imitate what they viewed. They will be given 5-seconds to initiate the step and 30-seconds to complete the step. If they are correct, we will reward them. If they are not correct, we will distract them and complete that step for them. Next, we will show the next step of the skill in the video. This procedure repeats until the task is completed. Using least-to-most prompting, we will ask your child to complete one of the tasks. Your child will be given 5-seconds to start each step and 30-seconds to complete each step before we being to help them. If they are correct on a step, we will reward them. If they are not correct, we will assist them by prompting them. The first prompt given will be a verbal prompt where we repeat the direction. The second prompt, if needed, will be a gestural prompt (for example, pointing to the materials). The third prompt, if needed, will be us modeling how to complete the step. The fourth type of prompt, if needed, is partial hand-over-hand assistance. The final type of prompt, if needed, is full hand-over-hand assistance.

3. After we attempt to teach the first two tasks, we will teach the third task using the procedure (either video prompting or least-to-most prompting) that worked the best in teaching the other skills.

4. After we attempt to teach the third skill, we will observe your child completing all three skills once a week for four weeks. We will only collect data at this time and not provide assistance. We do this to see if the skills maintain over time.

5. At the end of the study we will ask your child questions about his/her participation (for example, did they like video prompting, did they like least-to-most prompting, did they like one procedure more than the other). We will also ask his/her teacher about their opinions of the study.

\section{RISKS AND/OR DISCOMFORTS}

There are minimal risks involved in this study. It is possible that your child may not like the physical prompting procedure because it requires an adult to partially or fully guide his/her hand 
while completing a step. If your child does not like this, we will stop that type of prompting. Also, your child might not learn one or more of the skills being taught.

\section{BENEFITS}

It is expected that this study will benefit your child by daily living skills and identifying an effective intervention practice that meets his/her learning style for teaching these types of skills. For educators, the result of this study might provide information about determining effective teaching methods when teaching daily living skills to students with autism. For the community, improving daily living skills of students with autism might reflect positively on their independence, interactions with others, and future post-secondary education and career.

\section{ALTERNATIVES}

There are other teaching strategies that can be used to help improve your child's daily living skills. Some strategies include the using picture prompts and other types of adult prompting systems. These strategies, however, are not part of this study. Any significant new findings developed during the course of the research which may relate to your child's willingness to continue participation will be provided to you.

\section{CONFIDENTIALITY}

The records of this study will be kept private and will be protected to the fullest extent provided by law. In any sort of report we might publish or present, we will not include any information that will make it possible to identify your child as a subject. Research records will be stored securely and only the researcher team will have access to the records. However, your child's records may be reviewed for audit purposes by authorized University or other agents who will be bound by the same provisions of confidentiality.

If we learn about serious harm to you or someone else, we will take steps to protect the person endangered even if it requires telling the authorities without your permission. If we have reason to believe that your child is being abused, we will report this to the Florida Abuse hotline. In these instances, we would only disclose information to the extent necessary to prevent harm.

\section{COMPENSATION \& COSTS}

You and your child will not be compensated for participation nor will you or they be responsible for any costs in order to participate in this study.

\section{RIGHT TO DECLINE OR WITHDRAW}

Your child's participation in this study is voluntary. Your child is free to participate in the study or withdraw his/her consent at any time during the study. Your child's withdrawal or lack of participation will not affect any benefits to which he/she is otherwise entitled. The investigator 
reserves the right to remove your child from the study without your consent at such time that they feel it is in the best interest.

\section{RESEARCHER CONTACT INFORMATION}

If you have any questions about the purpose, procedures, or any other issues relating to this research study you may contact Mashal Aljehany at (305) 3671143 or email at malje0042fiu.edu. You may also contact Dr. Kyle D. Bennett at 305-348-3641 or email at kyle.bennett@fiu.edu.

\section{IRB CONTACT INFORMATION}

If you would like to talk with someone about your child's rights of being a subject in this research study or about ethical issues with this research study, you may contact the FIU Office of Research Integrity by phone at 305-348-2494 or by email at ori@ fiu.edu.

\section{PARTICIPANT AGREEMENT}

I have read the information in this consent form and agree to allow my child to participate in this study. I have had a chance to ask any questions I have about this study, and they have been answered for me. I understand that I will be given a copy of this form for my records.

Printed Name of Parent/ Guardian

Printed Name of Child Participant

Signature of Person Obtaining Consent

Date 


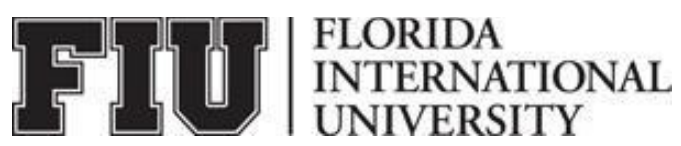

CHILD ASSENT TO PARTICIPATE IN A RESEARCH STUDY

A Comparison of Video Prompting to Least-to-Most Prompting for Teaching Office-Related Skills to Children with ASD and ID

\section{WHY ARE YOU DOING THIS STUDY?}

We would like for you to be in a research study we are doing. A research study is a way to learn information about something. We would like to find out more about using video prompting and leastto-most prompting to help students with autism do daily living tasks.

\section{HOW MANY OTHERS WILL BE IN THIS STUDY?}

If you agree to participate in this study, you will be one of four students in this research study.

\section{HOW LONG WILL THE STUDY LAST?}

Your participation will require up to 45 minutes each day that we work with you. We will work with you three to four days a week, for about 15 weeks.

\section{WHAT WILL HAPPEN IN THIS STUDY?}

If you would participate in this study, we will ask you to do the following things:

1. We will ask your parents and teachers questions about you.

2. Then, you will be asked to identify the most likable rewards to you. During this assessment, five items (for example, foods, objects, toys, and activities) will be presented on a table. We will ask you to choose one of the items. You can eat any food items you chose or play with any toys or games you chose for a few seconds. Next, we will re-present the items again without the first one that was chosen. This will continue until the last item is selected. We will repeat this process a few times.

3. Next, we will observe you completing tasks.

4. Then you will be taught three different daily living skills. We will choose these skills based on your needs.

5. Sometimes you will watch small video clips that show how to do a skill. Then, you will copy what you watched.

6. Sometimes, we will help you to do a skill by providing verbal prompts, gestural prompts, live modeling, and hand-over-hand prompts.

7. Then, we will watch you complete the tasks for a few more weeks. During this time, we will only watch you do the tasks and we will not help you.

8. At the end of the study, we will ask you questions about your time being in the study. 


\section{CAN ANYTHING GOOD HAPPEN TO ME?}

This study may help you learn a few new daily living skills.

\section{DO I HAVE OTHER CHOICES?}

There are other things to help you learn new daily living skills such as looking at pictures or following other adult prompts, but these are not part of this study.

\section{WILL ANYONE KNOW I AM IN THE STUDY?}

The records of this study will be kept private and will be protected by the researchers. Your real name will not be used on any information that we will collect for the study. In any kind of report we might publish or present, we will not use your real name.

\section{WILL I BE GIVEN ANYTHING FOR PARTICIPATING?}

You will not need to pay for anything to participate in this study, and you will not receive anything for participating in this study.

\section{WHAT IF I DO NOT WANT TO DO THIS?}

You do not have to be in this study if you don't want to and you can quit the study at any time. If you don't like a question, you don't have to answer it and, if you ask, your answers will not be used in the study. No one will get mad at you if you decide you don't want to participate.

\section{WHO CAN I TALK TO ABOUT THE STUDY?}

If you have any questions about the research study you may contact Mashal Aljehany at (305) 3671143 or email at malje004@ fiu.edu. You may also contact Dr. Kyle Bennett at 305-348-3641 or email at kyle.bennett@fiu.edu. If you would like to talk with someone about your rights of being a participant in this research study, you may contact the FIU Office of Research Integrity by phone at 305-348-2494 or by email at ori@fiu.edu.

\section{PARTICIPANT AGREEMENT}

This research study has been explained to me and I agree to be in this study.

Signature of Child Participant

Printed Name of Child Participant
Date

$$
\text { Date }
$$




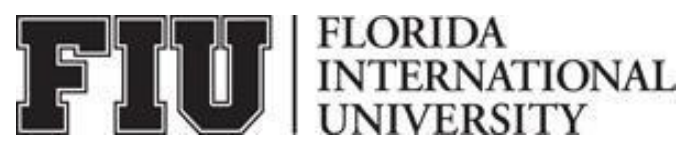

CHILD VERBAL ASSENT TO PARTICIPATE IN A RESEARCH STUDY

A Comparison of Video Prompting to Least-to-Most Prompting for Teaching Office-Related Skills to Children with ASD and ID

Hello, my name is Mashal Aljeheny. You have been chosen to be in a research study about helping kids do daily living skills at home, school, and community. The purpose of this study is to teach you some skills by watching video clips and prompting. If you decide to be in this study, you will be one of four children in this research study. Participation in this study will take about 45 minute on days that we work with you. We will work with you 3-4 days per week, for about 15 weeks. If you agree to be in the study, we will ask you to do the following things:

1. Let us talk to your parents and teacher and ask them questions about you.

2. Let us identify the rewards that you like.

3. Let us ask you to follow some directions and watch you complete tasks, such as preparing a lunch or folding clothes.

4. Let us teach you to do some daily living skills, such as preparing a lunch or folding clothes by watching videos and my prompting.

5. Sometimes you will watch small video clips that show you how to do a skill. Then, you will copy what you watched.

6. Sometimes, we will help you do a skill by providing verbal prompts, gestural prompts, live modeling, and hand-over-hand prompts.

7. Then, we will watch you complete the tasks for a few more weeks. During this time, we will only watch you do the tasks and we will not help you.

8. At the end of the study, we will ask you some questions about being in the study.

Nothing bad will happen to you while you participate in this study. However, if you do not like it when we help you, you can ask us to stop and we will. Also, you might not learn one or more the skills being taught.

You don't have to pay anything to be in this study, and you will not be paid to be in this study. If you have questions during this study, please stop us and ask.

If we publish a report on this study or present this study to other people, we will not use your name or give any information that will make it easy for people to figure out it is you. We will keep all research papers locked on a computer, and only the research team will have access to it.

If you have questions, you can have your parents call me at (305) 367-1143 or email me at malje004@fiu.edu. They may also contact Dr. Kyle Bennett at 305-348-3641 or email him at kyle.bennett@fiu.edu. If you would like to talk with someone about being in this study, you can have your parents call the FIU Office of Research Integrity at 305-348-2494 or email ori@ fiu.edu.

Your participation in this research is your choice, and nothing bad will happen to you if you decide you want to stop. Do you consent to participate in this project? 


\section{CURRICULUM VITAE}

\section{MASHAL SALMAN ALJEHANY}

2008

Bachelor of Education, Special Education

King Abdulaziz University (KAU)

Jeddah, Saudi Arabia

2013

Master of Education, Special Education

University of North Carolina at Greensboro

Greensboro, North Carolina, USA

2018

Doctor of Education, Exceptional Student Education

Florida International University

Miami, Florida, USA

$2009-2012$

Teaching Assistant

Special Education Department, KAU

Jeddah, Saudi Arabia

2013 - present

College Instructor

Special Education Department, University of Jeddah

Jeddah, Saudi Arabia

\section{PUBLICATIONS AND PRESENTATIONS}

Aljehany, M. S., \& Bennett, K. D. (2018). Meta-Analysis of Video Prompting to Teach Daily Living Skills to Individuals with Autism Spectrum Disorder. Journal of Special Education Technology, 0162643418780495.

Bennett, K.D., Aljehany, M.S., \& Altaf, E.M. (2017). Systematic Review of VideoBased Instruction Component and Parametric Analyses. Journal of Special Education Technology, 32(2), 80-90.

Bennett, K.D., Aljehany, M.S., \& Altaf, E. M. (January 2017). Systematic review of video-based instruction component analyses. Poster presented at the $18^{\text {th }}$ International Conference on Autism, Intellectual Disabilities, \& Developmental Disabilities: Council for Exceptional Children Division on Autism and Developmental Disabilities. Clearwater Beach, FL. (REFEREED)

Aljehany, M.S., \& Bennett, K.D. (Manuscript in preparation). A Comparison of Video Prompting and Least-to-most Prompting for Teaching Office-Related Tasks to Children with Autism and Intellectual Disability. 